UNIVERSIDADE DE SÃO PAULO

INSTITUTO DE QUÍMICA DE SÃO CARLOS

ANTONIO CARLOS ROVEDA JÚNIOR

\title{
Ancoramento de nitrosilo complexo de rutênio em dendrímeros PAMAM e estudo de suas propriedades químicas e biológicas
}




\title{
Ancoramento de nitrosilo complexo de rutênio em dendrímeros PAMAM e estudo de suas propriedades químicas e biológicas
}

\author{
Dissertação apresentada ao Instituto de Química \\ de São Carlos, Universidade de São Paulo, \\ como um dos requisitos para a obtenção do \\ título de Mestre em Ciências \\ Área de concentração: Química Analítica
}

Orientador: Prof. Dr. Douglas Wagner Franco 
Dedico este trabalho aos meus pais, Antonio e Maria, que sempre me deram força e incentivo pra seguir em frente e nunca desistir dos sonhos. E a todos os familiares pelo amor, apoio, e compreensão pela distância nos últimos anos. Agradeço por sempre terem acreditado em mim. Sem vocês eu não seria nada! 
"A ciência se compõe de erros que, por sua vez, são os passos até a verdade" Julio Verne

"A gente não pode viver no artifício do brilho e do sucesso.

Tem que ter uma passagem útil nessa vida"

\author{
Ney Matogrosso
}

"A ciência e a religião são as alavancas da inteligência humana" 


\section{Agradecimentos}

A Deus por ter me dado esta oportunidade e saúde para alcançar os objetivos.

Ao professor Douglas Wagner Franco pela oportunidade, pela orientação, amizade e por todos os ensinamentos transmitidos.

Aos profs. Drs., Antonio Burtoloso, Júlio César Borges e Hidetake, pela valiosa ajuda nas discussões científicas

Aos profs. Drs. Daniel Rodrigues e Benedito dos Santos Lima Neto pela amizade e pelas discussões científicas.

Ao Diego, Renata e aos profs. Drs. João Santa e Fernando Cunha pelo auxílio nos ensaios biológicos.

Aos amigos do nosso grupo de pesquisa, em especial à Daniela (que me iniciou nos trabalhos de síntese), Gustavo, Maykon e Clayston pelo incentivo, apoio e pelas valiosas discussões durante todo o trabalho.

Ao Thiago Abrahão pela amizade, auxílio nos experimentos, pelas valiosas discussões e por sempre questionar o meu trabalho de forma muito construtiva.

Aos amigos do Laboratório de Química Inorgânica e Analítica e do Laboratório da Química da Aguardente por fazerem parte da minha família aqui em São Carlos e por terem me aturado sempre com bom humor e companheirismo nessa longa jornada, tornando o laboratório a minha casa.

Ao prof. Dr. Antonio Gilberto Ferreira e ao doutorando e amigo Eduardo Sanches (Balinha) pelo auxílio nos experimentos de Ressonância Magnética Nuclear.

Aos técnicos Sylvana, Carlinhos, Paulo e Marcio pela amizade e pela ajuda nos experimentos.

À Veroneide, Gislei, Cláudia e Ana pela amizade e por sempre estarem dispostas a ajudar em tudo.

À Ivonete e à Silmara pela amizade e pela conversa sempre amiga.

Aos funcionários da seção de pós-graduação, biblioteca, oficina mecânica, eletrônica, informática, vidraria, aos motoristas e aos seguranças pela amizade e pelos serviços prestados.

À Daniely Nakayama pelo carinho, amizade e compreensão enquanto estivemos juntos.

A todos os amigos e companheiros de república em São Carlos e em Rio Preto durante a graduação.

À Larissa, pela amizade e por ter me mostrado novamente o caminho da religião.

Ao Barbie e ao Rodrigo por serem a minha família aqui em São Carlos e me aturarem nos momentos de "acidez".

À FAPESP pelo auxílio financeiro. 


\section{RESUMO}

$\mathrm{O}$ ancoramento do complexo trans-[ $\mathrm{Ru}^{\mathrm{III}}\left(\mathrm{NH}_{3}\right)_{4}\left(\mathrm{SO}_{4}\right)$ ina $] \mathrm{Cl}$ em dendrímeros PAMAM de geração 0 e 2 (G0 e G2) foi realizada por meio de uma ligação peptídica, e esses produtos foram submetidos à reação com $\mathrm{NO}_{(\mathrm{g})}$ gerando os respectivos nitrosilo complexos G0/RuNO e G2/RuNO. A caracterização desses compostos por infravermelho, UV-vis, voltametria cíclica, $\mathrm{RMN}$ de ${ }^{1} \mathrm{H}$ e ${ }^{13} \mathrm{C}$, e análise elementar indica que os nitrosilo complexos foram imobilizados na superfície dos PAMAM G0 e G2. Os espectros de infravermelho para G0/RuNO e G2/RuNO apresentaram apenas um estiramento vNO ${ }^{+}$, respectivamente em 1933 e $1937 \mathrm{~cm}^{-1}$, e para o produto RuNO (não ligado ao dendrímero) em $1933 \mathrm{~cm}^{-1}$. O espectro eletrônico para esses três compostos apresentou bandas nas regiões de 230, 270 e $330 \mathrm{~nm}$, e por meio de voltametria cíclica observou-se o processo eletroquímico relativo a $\mathrm{NO}^{+} / \mathrm{NO}^{0}$ com $\mathrm{E}_{\mathrm{NO}}^{+} /{ }_{\mathrm{NO}}^{0}$ vs ECS igual a $-0,173 \mathrm{~V}$ para G0/RuNO, $-0,178 \mathrm{~V}$ G2/RuNO e $-0,175 \mathrm{~V}$ para RuNO. O espectro de ${ }^{1} \mathrm{H}$ RMN do complexo RuNO apresentou dois dubletos com deslocamentos químicos centrados em 8,73 e 8,35 ppm, referentes aos hidrogênios aromáticos respectivamente nas posições orto e meta do ligante ina coordenado ao metal. Para G0/RuNO e G2/RuNO esses sinais foram observados em 8,73 e 8,36 ppm, e os sinais referentes aos dendrímeros nesses produtos foram verificados entre 2,7 e 4,0 ppm. O espectro de $\mathrm{RMN}{ }^{13} \mathrm{C}$ para o complexo RuNO apresentou quatro sinais, e para G0/RuNO e G2/RuNO, respectivamente, dez e doze sinais, conforme esperado para esses compostos. Apesar dos resultados supracitados indicarem que o ancoramento ocorreu de forma satisfatória, os dados de análise elementar apresentaram desvios significativos entre o valor teórico e o experimental, principalmente para G2/RuNO. Em adição, foram realizados ensaios em células do baço de camundongos para verificar a toxicidade dos nitrosilo complexos às células saudáveis, e os resultados indicaram baixa citotoxicidade ( $<15 \%)$ para RuNO, G0/RuNO e G2/RuNO. Também foram realizados experimentos sobre a atividade in vitro desses compostos contra os parasitos Trypanosoma cruzi e Leishmania major. Os melhores resultados, ainda que preliminares, foram obtidos com a maior concentração, $200 \mu \mathrm{M}$ (em relação à $\mathrm{Ru}$ ), em que observou-se atividade tripanocida (média) em torno de $88 \%$ para G2/RuNO, $82 \%$ para G0/RuNO e 72\% para RuNO, enquanto que para o Bz (referência) esse valor foi de $96 \%$. Já a atividade leishmanicida (concentração de $200 \mu \mathrm{M}$ ) desses compostos ficou entre 60 a 70\% (65\% para G2RuNO, 69\% para G0/RuNO e 60\% para RuNO). 


\begin{abstract}
The anchoring of the complex trans-[ $\mathrm{Ru}^{\mathrm{III}}\left(\mathrm{NH}_{3}\right)_{4}\left(\mathrm{SO}_{4}\right)$ ina $] \mathrm{Cl}$ on PAMAM dendrimers of generation 0 and 2 ( $\mathrm{G} 0$ and $\mathrm{G} 2$ ) was performed by a peptide bond, and the products were submitted to reaction with $\mathrm{NO}(\mathrm{g})$ generating the related nitrosyl complexes G0/RuNO and G2/RuNO. The characterization of these compounds by IR, UV-vis, cyclic voltammetry, ${ }^{1} \mathrm{H}$ and ${ }^{13} \mathrm{C} \mathrm{NMR}$, and elemental analysis indicated that the nitrosyl complexes were immobilized on the surface of PAMAM G0 and G2. Infrared spectra for G0/RuNO and G2/RuNO showed only one $v \mathrm{NO}^{+}$band in 1933 and $1937 \mathrm{~cm}^{-1}$ respectively, and for RuNO (complex not bounded to the dendrimer) at $1933 \mathrm{~cm}^{-1}$. Electronic spectra for these three compounds showed bands in the regions of 230, 270 and $330 \mathrm{~nm}$, and by cyclic voltammetry it was possible to observe the electrochemical process relative to $\mathrm{NO}^{+} / \mathrm{NO}^{0}$ with $\mathrm{E}_{\mathrm{NO}}{ }^{+} / \mathrm{NO}{ }^{0}$ equal to $-0.173 \mathrm{~V}$ vs SCE for G0/RuNO , $-0.178 \mathrm{~V}$ for G2/RuNO and $-0.175 \mathrm{~V}$ for RuNO. The ${ }^{1} \mathrm{H}$ NMR spectra for RuNO complex showed two doublets with chemical shifts centered at 8.73 and $8.35 \mathrm{ppm}$, respectively referring to the aromatic hydrogens in the ortho and meta positions of the ina ligand coordinated to the metal. The same signals obtained for G0/RuNO and G2/RuNO were observed in 8.73 and $8.36 \mathrm{ppm}$, and signals related to dendrimers between 2.7 and 4.0 ppm. The ${ }^{13} \mathrm{C}$ NMR spectrum for RuNO exhibited four signals, and for G0/RuNO and G2/RuNO, respectively, ten and twelve signals, as expected for these compounds. Despite the results above, which indicate that anchoring occurred satisfactorily, the elemental analysis showed significant deviations between the theoretical and experimental values, especially for G2/RuNO. In adition, in vitro assays were performed on mice spleen cells to determine the toxicity of the nitrosyl complex to healthy cells, and the results showed low cytotoxicity $(<15 \%)$ for RuNO, G0/RuNO and G2/RuNO. In vitro experiments were also carried out to determine the activity of these compounds against the parasite Trypanosoma cruzi and Leishmania major. The best results (preliminary) were obtained with the highest concentration $200 \mu \mathrm{M}$ (relative to $\mathrm{Ru}$ ), which was observed trypanocidal activity (average) around $88 \%$ for G2/RuNO, $82 \%$ for G0/RuNO and $72 \%$ for RuNO, while for Bz (reference) it was around $96 \%$. The leishmanicidal activity (concentration of $200 \mu \mathrm{M}$ ) of these compounds was in the range of 60 to $70 \%$ ( $65 \%$ for G2RuNO, $69 \%$ for G0/RuNO and $60 \%$ for RuNO).
\end{abstract}




\section{LISTA DE ABREVIATURAS}

\begin{tabular}{|c|c|c|}
\hline isn & - & isonicotinamida \\
\hline ina & - & ácido isonicotínico \\
\hline pic & - & picolina \\
\hline nic & - & nicotinamida \\
\hline $\mathrm{P}(\mathrm{OEt})_{3}$ & - & trieltilfosfito \\
\hline pirazina & - & nicotinamida \\
\hline L-Hist & - & L-histidina \\
\hline $\mathrm{NO}$ & - & óxido nítrico \\
\hline $\mathrm{NO}^{+}$ & - & cátion nitrosil \\
\hline NOS & - & óxido nítrico sintase \\
\hline ECS & - & eletrodo de calomelano saturado \\
\hline$\delta$ & - & deslocamento químico \\
\hline$\lambda$ & - & comprimento de onda \\
\hline$\varepsilon$ & - & absortividade molar \\
\hline $\mathrm{E}_{1 / 2}$ & - & potencial de meia onda \\
\hline $\mathrm{IC}_{50}$ & - & concentração correspondente a $50 \%$ de inibição \\
\hline PAMAM & - & poliamidoamina \\
\hline G0 & - & PAMAM de geração 0 \\
\hline $\mathrm{G} 2$ & - & PAMAM de geração 2 \\
\hline DCC & - & dicicloexilcarbodiimida \\
\hline G0/RuSO4 & - & $\mathrm{G} 0 /$ trans- $\left[\mathrm{Ru}^{\mathrm{III}}\left(\mathrm{NH}_{3}\right)_{4}\left(\mathrm{SO}_{4}\right) \mathrm{ina}\right] \mathrm{Cl}$ \\
\hline G2/RuSO4 & - & $\mathrm{G} 2 /$ trans- $\left[\mathrm{Ru}^{\mathrm{III}}\left(\mathrm{NH}_{3}\right)_{4}\left(\mathrm{SO}_{4}\right) \mathrm{ina}\right] \mathrm{Cl}$ \\
\hline RuNO & - & trans- $\left[\mathrm{Ru}^{\mathrm{II}}\left(\mathrm{NO}^{+}\right)\left(\mathrm{NH}_{3}\right)_{4} \mathrm{ina}\right]\left(\mathrm{BF}_{4}\right)_{3}$ \\
\hline G0/RuNO & - & $\mathrm{G} 0 /$ trans- $\left[\mathrm{Ru}^{\mathrm{II}}\left(\mathrm{NO}^{+}\right)\left(\mathrm{NH}_{3}\right)_{4} \mathrm{ina}\right]\left(\mathrm{BF}_{4}\right)_{3}$ \\
\hline G2/RuNO & - & $\mathrm{G} 2 /$ trans- $\left[\mathrm{Ru}^{\mathrm{II}}\left(\mathrm{NO}^{+}\right)\left(\mathrm{NH}_{3}\right)_{4} \mathrm{ina}\right]\left(\mathrm{BF}_{4}\right)_{3}$ \\
\hline $\mathrm{Bz}$ & - & Benznidazol \\
\hline
\end{tabular}




\section{LISTA DE FIGURAS}

Figura 1 - Estrutura dos compostos comumente utilizados no tratamento da doença de Chagas

Figura 2 - Estrutura dos compostos de antimônio utilizados para o tratamento de leishmaniose.

Figura 3 - Estrutura do composto utilizado como alternativa aos compostos de antimônio para o tratamento da leishmaniose. 19

Figura 4 - Compostos de Platina com atividade anti-T. cruzi 20

Figura 5 - Compostos de rutênio com ação anti-T.cruzi

Figura 6 - Estruturas químicas dos compostos Bz e RuBz.

Figura 7 - Produção de NO via oxidação de L-arginina a L-citrulina [57-58]. 23

Figura 8 - Estrutura geral para as tetraaminas de $\mathrm{Ru}(\mathrm{II})$. 25

Figura 9 - Esquema do ciclo catalítico para a conversão de nitrito a óxido nítrico promovido pelos complexos de rutênio[49,89].

Figura 10 - Estrutura do dendrímero PAMAM com grupos terminais amina - os círculos representam as gerações 0,1 e 2 do dendrímero[104]...... .28

Figura 11 - Fórmulas estruturais do ácido isonicotínico e isonicotinamida. .29

Figura 12 - Rota de síntese do complexo trans- $\left[\mathrm{Ru}^{\mathrm{II}}\left(\mathrm{NH}_{3}\right)_{4}\left(\mathrm{SO}_{2}\right) \mathrm{Cl}\right] \mathrm{Cl}$................................ 34

Figura 13 - Reações envolvidas na síntese do complexo trans-[ $\mathrm{Ru}^{\mathrm{III}}\left(\mathrm{NH}_{3}\right)_{4}\left(\mathrm{SO}_{4}\right)$ ina $] \mathrm{Cl}$........ 35

Figura 14 - Reações envolvidas na síntese do complexo trans- $\left[\mathrm{Ru}^{\mathrm{II}}\left(\mathrm{NO}^{+}\right)\left(\mathrm{NH}_{3}\right)_{4}\right.$ ina $]\left(\mathrm{BF}_{4}\right)_{3} .36$

Figura 15 - Conjunto de reação para formação de ligação peptídica [114].....

Figura 16 - Rota de síntese do complexo GX/trans-[Ru ${ }^{\mathrm{II}}\left(\mathrm{NO}^{+}\right)\left(\mathrm{NH}_{3}\right)_{4}$ ina $]\left(\mathrm{BF}_{4}\right)_{3}$ em que X representa a geração do dendrímero (0 ou 2). 37

Figura 17 - Fórmula estrutural proposta para o complexo trans-[ $\mathrm{Ru}^{\mathrm{III}}\left(\mathrm{NH}_{3}\right)_{4}\left(\mathrm{SO}_{4}\right)$ ina $] \mathrm{Cl} . . . .42$ 
Figura 18 - Espectro na região de infravermelho do sólido trans-[Ru ${ }^{\mathrm{III}}\left(\mathrm{NH}_{3}\right)_{4}\left(\mathrm{SO}_{4}\right)$ ina $] \mathrm{Cl}$ em pastilha de $\mathrm{KBr}$.

Figura 19 - Voltamograma cíclico para o íon trans-[Ru ${ }^{\mathrm{III}}(\mathrm{NH} 3) 4(\mathrm{SO} 4)$ ina $]^{+}$em solução aquosa. Eletrólito $\mu=0,10 \mathrm{~mol} \mathrm{~L}-1\left(\mathrm{CF}_{3} \mathrm{COOH} / \mathrm{CF}_{3} \mathrm{COONa}\right), \mathrm{pH} 2,0$, temperatura de $25^{\circ} \mathrm{C}, \mathrm{v}=200 \mathrm{mV} \mathrm{s}^{-1}$ 45

Figura 20 - Espectro eletrônico do íon trans- $\left[\mathrm{Ru}^{\mathrm{III}}\left(\mathrm{NH}_{3}\right)_{4}\left(\mathrm{SO}_{4}\right) \text { ina }\right]^{+}$em solução aquosa, $\mathrm{pH}$ 2,0 e $\mu=0,10 \mathrm{~mol} \mathrm{~L}{ }^{-1}\left(\mathrm{CF}_{3} \mathrm{COOH} / \mathrm{CF}_{3} \mathrm{COONa}\right)$, temperatura de $25^{\circ} \mathrm{C}, \mathrm{C}_{\mathrm{Ru}}=$ $1,75.10^{-4} \mathrm{molL}^{-1}$ 46

Figura 21 - Estrutura proposta para o complexo trans-[Ru $\left.{ }^{\mathrm{II}}\left(\mathrm{NO}^{+}\right)\left(\mathrm{NH}_{3}\right)_{4} \mathrm{ina}\right]\left(\mathrm{BF}_{4}\right)_{3}$

Figura $22-$ Espectro na região do infravermelho para o complexo trans- $\left[\mathrm{Ru}^{\mathrm{II}}\left(\mathrm{NO}^{+}\right)(\mathrm{NH} 3)_{4}\right.$ ina $]\left(\mathrm{BF}_{4}\right)_{3} \cdot 2 \mathrm{H}_{2} \mathrm{O}$ em pastilhas de $\mathrm{KBr}$. 48

Figura 23 - Voltamogramas cíclicos do íon complexo trans- $\left[\mathrm{Ru}^{\mathrm{II}}\left(\mathrm{NO}^{+}\right)\left(\mathrm{NH}_{3}\right)_{4} \mathrm{ina}\right]^{3+}$ em solução aquosa, eletrólito $\mathrm{pH} 2,0$ e $\mu=0,10 \mathrm{~mol} \mathrm{~L}-1\left(\mathrm{CF}_{3} \mathrm{COOH} / \mathrm{CF}_{3} \mathrm{COONa}\right)$, temperatura de $25^{\circ} \mathrm{C}, \mathrm{v}=100 \mathrm{mV} \mathrm{s}^{-1}$ 50

Figura 24 - Espectro eletrônico do íon trans-[Ru ${ }^{\mathrm{II}}\left(\mathrm{NO}^{+}\right)\left(\mathrm{NH}_{3}\right)_{4}$ ina $]^{3+}$ em solução aquosa, pH 2,0 e $\mu=0,10 \mathrm{~mol} \mathrm{~L}^{-1} \mathrm{CF}_{3} \mathrm{COOH} / \mathrm{CF}_{3} \mathrm{COONa}$, temperatura de $25^{\circ} \mathrm{C}$. 51

Figura 25 - Espectro de ${ }^{1} \mathrm{H}$ RMN do complexo trans- $\left[\mathrm{Ru}^{\mathrm{II}}\left(\mathrm{NO}^{+}\right)\left(\mathrm{NH}_{3}\right)_{4} \mathrm{ina}_{4}\left(\mathrm{BF}_{4}\right)_{3}\right.$ em $\mathrm{D}_{2} \mathrm{O}$, (1M CF $\left.\mathrm{CF}_{3} \mathrm{COOD}\right) . \mathrm{O}$ espectro menor é uma ampliação do espectro na faixa de $8,0 \mathrm{a}$ $9,0 \mathrm{ppm}$. 52

Figura 26 - Espectro de ${ }^{1} \mathrm{H}$ RMN do ácido isonicotínico (ina) em $\mathrm{D}_{2} \mathrm{O}$. O espectro menor é uma ampliação do espectro na faixa de 8,0 a 8,8 ppm. 53

Figura 27 - Espectro de ${ }^{13} \mathrm{C}$ RMN do complexo trans-[Ru ${ }^{\mathrm{II}}\left(\mathrm{NO}^{+}\right)\left(\mathrm{NH}_{3}\right)_{4}$ ina $]\left(\mathrm{BF}_{4}\right)_{3}$ em $\mathrm{D}_{2} \mathrm{O}$, (solução $1 \mathrm{M} \mathrm{CF}_{3} \mathrm{COOD}$ ). Os números 1, 2, 3, 4 correspondem aos carbonos na estrutura do complexo e os respectivos sinais no espectro. 54 
Figura 28 - Espectros de infravermelho do dendrímero PAMAM G0 (-) e dos complexos trans-[Ru ${ }^{\mathrm{III}}\left(\mathrm{NH}_{3}\right)_{4}\left(\mathrm{SO}_{4}\right)$ ina $] \mathrm{Cl}(-)$ e G0/RuSO4 (-), em pastilha de $\mathrm{KBr}$. 55

Figura 29 - Espectros de infravermelho do dendrímero PAMAM G2 (-), do complexo trans- $\left[\mathrm{Ru}^{\mathrm{III}}\left(\mathrm{NH}_{3}\right)_{4}\left(\mathrm{SO}_{4}\right)\right.$ ina $] \mathrm{Cl}$ (-) e do composto $\mathrm{G0} / \mathrm{RuSO} 4$ e (-), em pastilha de $\mathrm{KBr}$. 57

Figura 30 - Voltamograma cíclico do complexo G0/RuSO4 em solução aquosa, pH 2,0 e $\mu=$ $0,10 \mathrm{~mol} \mathrm{~L}^{-1} \mathrm{CF}_{3} \mathrm{COOH} / \mathrm{CF}_{3} \mathrm{COONa}$, temperatura de $25^{\circ} \mathrm{C}, \mathrm{v}=200 \mathrm{mV} \mathrm{s}{ }^{-1} \ldots . .58$ Figura 31 - Voltamograma cíclico do complexo G0/RuSO4 em solução aquosa, pH 2,0 e $\mu=$ 0,10 $\mathrm{mol} \mathrm{L}^{-1} \mathrm{CF}_{3} \mathrm{COOH} / \mathrm{CF}_{3} \mathrm{COONa}$, temperatura de $25^{\circ} \mathrm{C}, \mathrm{v}=200 \mathrm{mV} \mathrm{s}^{-1} \ldots . .59$

Figura 32 - Fórmula estrutural proposta para o complexo G0/RuNO ...................................60

Figura 33 - Fórmula Estrutural do dendrímero PAMAM geração 2 .....................................61

Figura 34 - Espectro eletrônico para o complexo G0/RuNO em solução aquosa, pH 2,0 e $\mu=$ $0,10 \mathrm{~mol} \mathrm{~L}-1\left(\mathrm{CF}_{3} \mathrm{COOH} / \mathrm{CF}_{3} \mathrm{COONa}\right)$, temperatura de $25^{\circ} \mathrm{C}$. 63

Figura 35 - Espectro eletrônico para o complexo G2/RuNO em solução aquosa, pH 2,0 e $\mu=$ $0,10 \mathrm{~mol} \mathrm{~L}^{-1}\left(\mathrm{CF}_{3} \mathrm{COOH} / \mathrm{CF}_{3} \mathrm{COONa}\right)$, temperatura de $25^{\circ} \mathrm{C}$ 64

Figura 36 - Voltamograma cíclico dos compostos (I) G0/RuNO e (II) G2/RuNO em solução aquosa, $\mathrm{pH} 2,0$ e $\mu=0,10 \mathrm{~mol} \mathrm{~L}-1 \mathrm{CF}_{3} \mathrm{COOH} / \mathrm{CF}_{3} \mathrm{COONa}$, temperatura de $25^{\circ} \mathrm{C}$, $\mathrm{v}=100 \mathrm{mVs}^{-1}$ 66

Figura 37 - Espectro de infravermelho dos complexos trans- $\left[\mathrm{Ru}^{\mathrm{II}}\left(\mathrm{NO}^{+}\right)\left(\mathrm{NH}_{3}\right)_{4}\right.$ ina $]\left(\mathrm{BF}_{4}\right)_{3}(-)$, G0/RuNO (-) e PAMAM G0 (-) em pastilha de KBr. 68

Figura 38 - Espectros de infravermelho dos complexos trans-[Ru ${ }^{\mathrm{II}}\left(\mathrm{NO}^{+}\right)\left(\mathrm{NH}_{3}\right)_{4}$ ina $]\left(\mathrm{BF}_{4}\right)_{3}(-)$, G2/RuNO (-) e PAMAM G2 (-) em pastilha de $\mathrm{KBr}$. .69

Figura 39 - Estrutura e ${ }^{1} \mathrm{H}$ RMN do dendrímero PAMAM de geração 0 em $\mathrm{D}_{2} \mathrm{O}$. O espectro menor é uma ampliação na região entre 2,4 2 3,4 ppm. As letras A, B, C, D e E 
correspondem ao tipo de hidrogênio na estrutura do G0 e o respectivo sinal no espectro de RMN.

Figura 40 - Espectro de RMN ${ }^{1} \mathrm{H}$ do dendrímero PAMAM de geração 2 em $\mathrm{D}_{2} \mathrm{O}$. O espectro menor é uma ampliação na região entre 2,3 a 3,5 ppm. 72

Figura 41 - Espectro de RMN ${ }^{1} \mathrm{H}$ do complexo (A) G0/RuNO em $\mathrm{D}_{2} \mathrm{O}$ (1M CF 3 COOD). O espectro (B) é uma ampliação do espectro (A) na faixa de 2,6 a 4,1 ppm. 73

Figura 42 - Espectro de $\mathrm{RMN}{ }^{1} \mathrm{H}$ do complexo (A) G2/RuNO em $\mathrm{D}_{2} \mathrm{O}$ (1M CF $3 \mathrm{COOD}$ ). O espectro (B) é uma ampliação do espectro (A) na faixa de 1,1 a 4,0 ppm. 74

Figura 43 - Espectro de RMN ${ }^{13} \mathrm{C}$ : (I) G0, (II) trans-[Ru ${ }^{\mathrm{II}}\left(\mathrm{NO}^{+}\right)\left(\mathrm{NH}_{3}\right)_{4}$ ina $]\left(\mathrm{BF}_{4}\right)_{3}$ e (III) G0/RuNO. Em (III), a letra R representa a estrutura do dendrímero. .76

Figura 44 - Espectro de RMN de ${ }^{13} \mathrm{C}$ : (I) G2, (II) trans-[Ru ${ }^{\mathrm{II}}\left(\mathrm{NO}^{+}\right)\left(\mathrm{NH}_{3}\right)_{4}$ ina $]\left(\mathrm{BF}_{4}\right)_{3}$ (solução $1 \mathrm{M} \mathrm{CF} \mathrm{CF}_{3} \mathrm{COOD}$ ) e (III) G2/RuNO (solução $1 \mathrm{M} \mathrm{CF}$ COOD). Em (III), a letra $\mathrm{R}$ representa a estrutura do dendrímero. 78

Figura 45 - Representação da ligação entre o complexo de rutênio e o dendrímero 79

Figura 46 - Estrutura dos compostos (a) trans- $\left[\mathrm{Ru}^{\mathrm{II}}\left(\mathrm{NO}^{+}\right)\left(\mathrm{NH}_{3}\right)_{4} \mathrm{isn}\right]\left(\mathrm{BF}_{4}\right)_{3}$ e (b) GX/RuNO (em que $\mathrm{X}=0$ e 2 ) e que $\mathrm{R}$ representa a estrutura do dendrímero. 79

Figura 47 - RMN de ${ }^{13} \mathrm{C}$ do complexo trans-[Ru ${ }^{\mathrm{II}}\left(\mathrm{NO}^{+}\right)\left(\mathrm{NH}_{3}\right)_{4}$ ina $]\left(\mathrm{BF}_{4}\right)_{3}$ (solução $1 \mathrm{M}$ $\left.\mathrm{CF}_{3} \mathrm{COOD}\right)$ 80

Figura 48 - Citotoxicidade dos compostos de rutênio sobre células saudáveis. Tween (controle positivo), Bz (referência). 81

Figura 49 - Atividade tripanocida para os nitrosilo complexos de rutênio e para Bz (controle positivo) sobre as formas tripomastigotas do $T$. cruzi após $24 \mathrm{~h}$ de incubação. As concentrações dos nitrosilo complexos utilizadas nos testes foram normalizadas em relação à quantidade de rutênio. 
Figura 50 - Atividade leishmanicida para os nitrosilo complexos de rutênio sobre as formas promastigotas de L. major após $24 \mathrm{~h}$ de incubação. As concentrações dos nitrosilo complexos utilizadas nos testes foram normalizadas em relação à quantidade de rutênio. 


\section{LISTA DE TABELAS}

Tabela 1 - Dados de análise elementar do complexo trans- $\left[\mathrm{Ru}^{\mathrm{III}}\left(\mathrm{NH}_{3}\right)_{4}\left(\mathrm{SO}_{4}\right)\right.$ ina $] \mathrm{Cl} 2 \mathrm{H}_{2} \mathrm{O}$

Tabela 2 - Principais frequências vibracionais e respectivas atribuições propostas para o complexo

$$
\text { trans }-\left[\mathrm{Ru}^{\text {III }}\left(\mathrm{NH}_{3}\right)_{4}\left(\mathrm{SO}_{4}\right) \text { ina }\right] \mathrm{Cl}^{2} 2 \mathrm{H}_{2} \mathrm{O} \text {. }
$$

Tabela 3 - Dados de análise elementar para o complexo trans-[Ru $\left(\mathrm{NO}^{+}\right)\left(\mathrm{NH}_{3}\right)_{4}$ ina $]\left(\mathrm{BF}_{4}\right)_{3} 2 \mathrm{H}_{2} \mathrm{O} . .47$

Tabela 4 - Principais frequências vibracionais e respectivas atribuições para o complexo trans- $\left[\mathrm{Ru}^{\mathrm{II}}\left(\mathrm{NO}^{+}\right)\left(\mathrm{NH}_{3}\right)_{4} \mathrm{ina}\right]\left(\mathrm{BF}_{4}\right)_{3} 2 \mathrm{H}_{2} \mathrm{O}$.

Tabela 5 - Dados de análise elementar de C, H, N e Ru para o complexo G0/RuNO

Tabela 6 - Dados de análise elementar de C, H, N e Ru para o complexo G2/RuNO 61

Tabela 7 - Resultados de espectroscopia eletrônica obtidos para os nitrosilo complexos livre e ancorado ao dendrímero G0. (Solução aquosa, pH 2,0 e $\mu=0,10 \mathrm{~mol} \mathrm{~L}^{-1}$ $\left(\mathrm{CF}_{3} \mathrm{COOH} / \mathrm{CF}_{3} \mathrm{COONa}\right)$, temperatura de $\left.25^{\circ} \mathrm{C}\right)$

Tabela 8 - Resultados de espectroscopia eletrônica para os nitrosilo complexos livre e ancorado ao dendrímero G2. (Solução aquosa, pH 2,0 e $\mu=0,10 \mathrm{~mol} \mathrm{~L}^{-1}\left(\mathrm{CF}_{3} \mathrm{COOH} \mathrm{CF}_{3} \mathrm{COONa}\right.$ ), temperatura de $25^{\circ} \mathrm{C}$ ) .65

Tabela 9 - Valores de $\left(\mathrm{E}_{1 / 2}\right)$ obtidos por voltametria cíclica para soluções contendo os nitrosilo complexos livre e ancorado ao dendrímero G0 (Solução aquosa, pH 2,0 e $\mu=0,10 \mathrm{~mol}$ $\mathrm{L}^{-1}\left(\mathrm{CF}_{3} \mathrm{COOH} / \mathrm{CF}_{3} \mathrm{COONa}\right)$, temperatura de $\left.25^{\circ} \mathrm{C}, \mathrm{v}=100 \mathrm{mV} \mathrm{s}^{-1}\right)$. 


\section{SUMÁRIO}

I - INTRODUÇÃO.

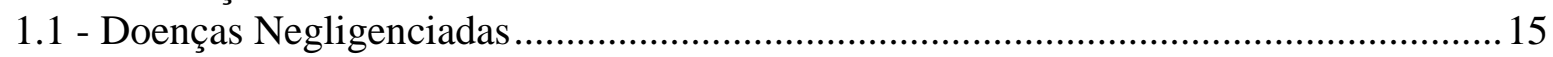

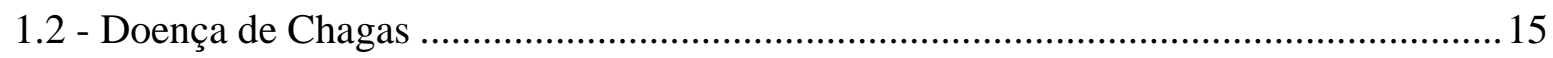

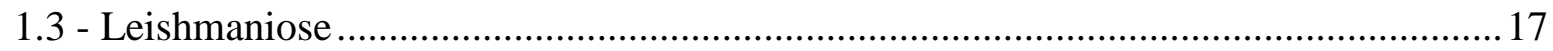

1.4 - Compostos metálicos utilizados como agentes quimioterápicos contra os parasitos

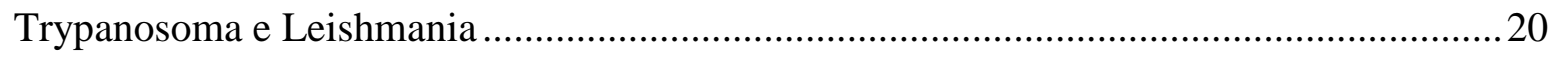

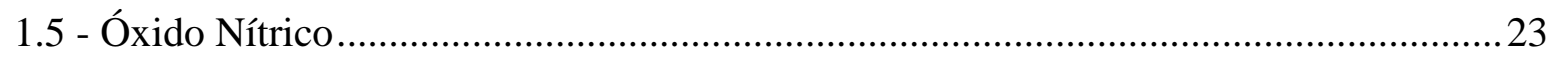

1.6 - Complexos transportadores de NO - Tetraaminas de Rutênio.......................................24

1.7 - Imobilização de complexos: a utilização dos dendrímeros ............................................27

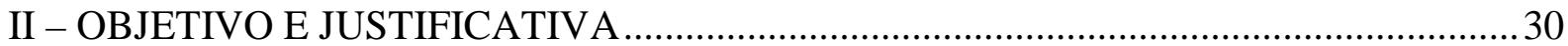

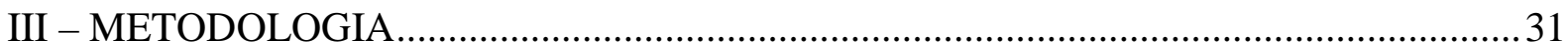

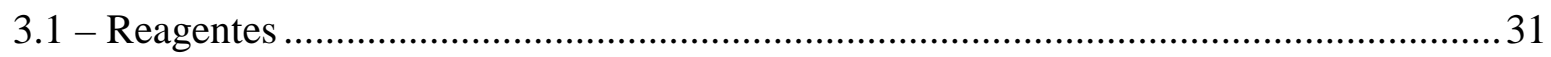

3.2 - Instrumentação e Técnicas Experimentais...............................................................32

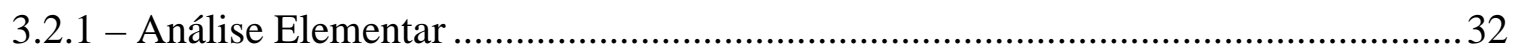

3.2.2 - Determinação de Rutênio ...................................................................................

3.2.3 - Espectroscopia vibracional................................................................................ 32

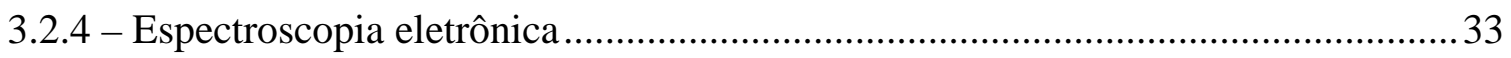

3.2.5 - Espectroscopia de ressonância magnética nuclear (RMN) …………………….....33

3.2.6 - Medidas de espectroscopia de ressonância de elétrons (RPE) .................................33

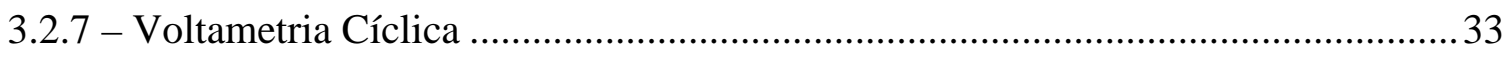

3.3 - Sínteses .......................................................................................................

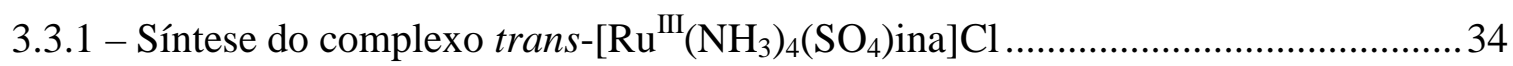

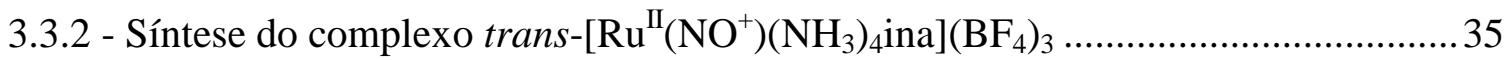

3.3.3 - Ancoramento dos complexos de rutênio nos dendrímeros poliamidoamina

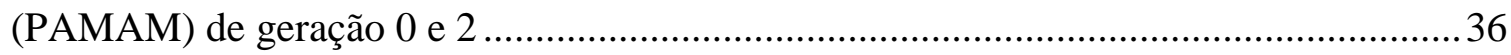

3.4 - Ensaios Biológicos............................................................................................. 40

3.4.1 - Citotoxicidade dos compostos in vitro ……………………………..................... 40

3.4.2 - Avaliação da atividade tripanocida in vitro sobre as formas tripomastigotas........40

3.4.3 - Determinação da atividade leishmanicida dos compostos ........................................41

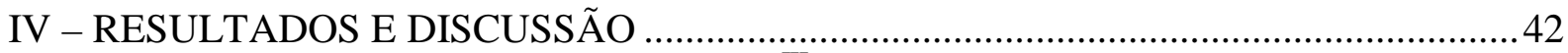

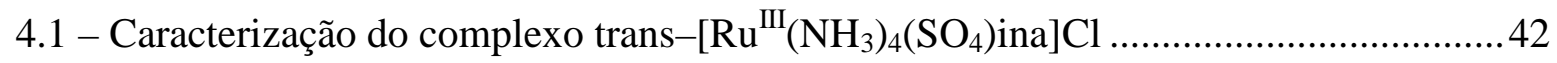

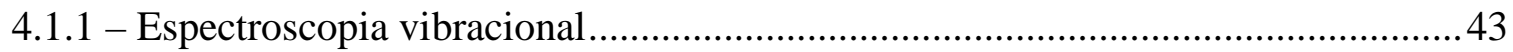

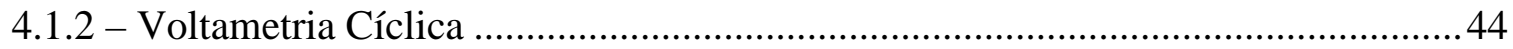

4.1.3 - Espectroscopia Eletrônica .................................................................................46 


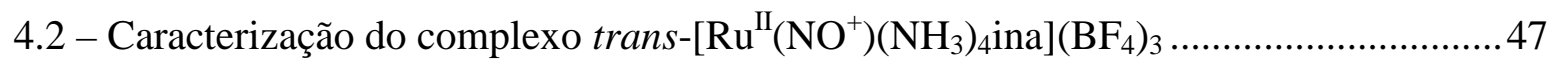

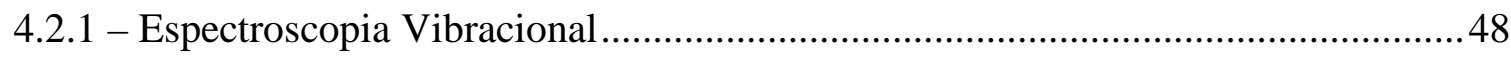

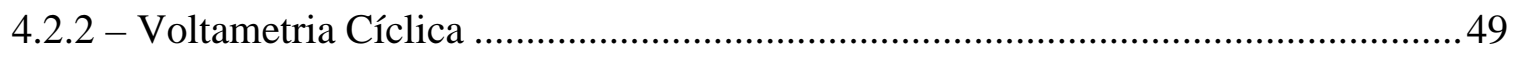

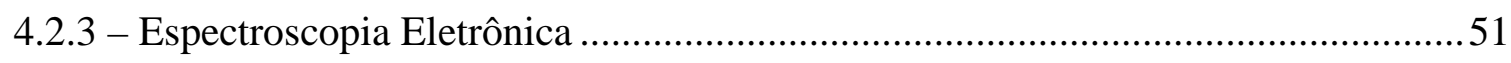

4.3 - Ancoramento dos complexos de rutênio nos dendrímeros PAMAM G0 e G2 ...........54

4.3.2 - Reação entre trans-[ $\mathrm{Ru}^{\mathrm{III}}\left(\mathrm{NH}_{3}\right)_{4}\left(\mathrm{SO}_{4}\right)$ ina]Cl e pamam $\mathrm{G} 0$ e $\mathrm{G} 2$...........................55

4.4 - Caracterização dos compostos G0/trans- $\left[\mathrm{Ru}^{\mathrm{II}}\left(\mathrm{NO}^{+}\right)\left(\mathrm{NH}_{3}\right)_{4}\right.$ ina $]\left(\mathrm{BF}_{4}\right)_{3} \mathrm{e}$

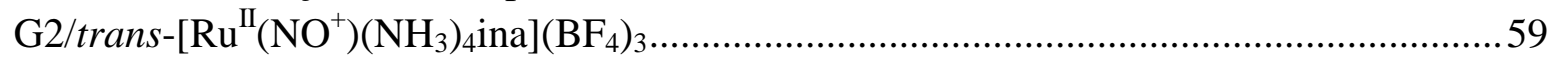

4.4.1 - Análise Elementar de C, H, N e Ru.....................................................................59

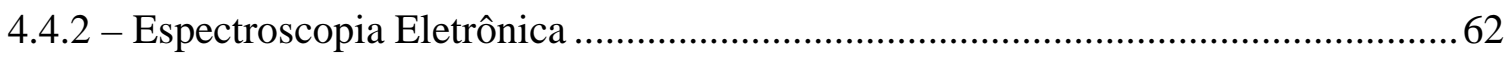

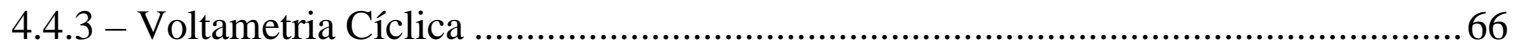

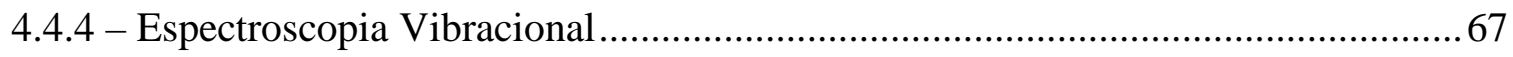

4.4.5 - Ressonância Magnética Nuclear de ${ }^{1} \mathrm{H}^{13} \mathrm{C}$.................................................... 71

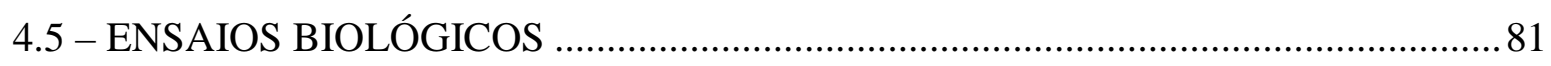

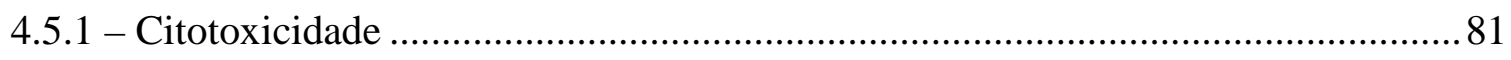

4.5.2 - Resultados preliminares da atividade tripanocida in vitro sobre as formas



4.5.3 - Resultados preliminares de atividade leishmanicida in vitro sobre as formas

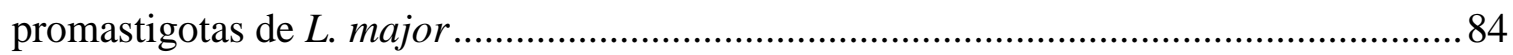

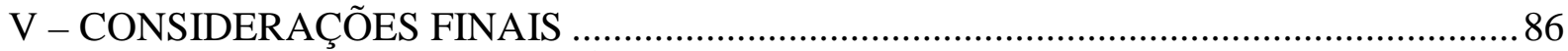

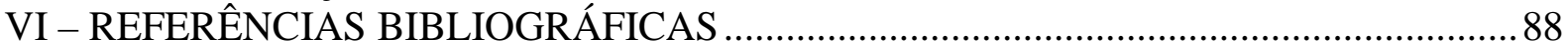




\section{I - INTRODUÇÃO}

\section{1 - Doenças Negligenciadas}

As doenças negligenciadas são um grupo de doenças endêmicas associadas à situação de pobreza e às condições precárias de vida da população. Essas doenças também são referidas na literatura como 'doenças de pobres', 'doenças órfãs' ou 'doenças tropicais' [1] devido ao fato de não disporem de tratamento adequado ou por não receberem a atenção devida pelos desenvolvedores de medicamentos, governos e dos programas de saúde pública. As doenças negligenciadas são causadas por vírus, parasitos ou bactérias, como por exemplo, dengue, tuberculose, malária, tripanossomíases, schistossomíase e leishmaniose [2]. Estima-se que existem no mundo 1 bilhão de pessoas infectadas por uma ou mais dessas doenças [3] e dados da Organização Mundial de Saúde (OMS) indicam que das 14 milhões de pessoas que morrem por ano devido às doenças negligenciadas, mais de 90\% vivem em países em desenvolvimento[2,4]. Este fato torna-se ainda mais relevante uma vez que as estatísticas sobre a produção de fármacos demonstram que as grandes empresas, além de estarem localizadas em países desenvolvidos, basicamente produzem fármacos que atendam à demanda desses países [5]. Além disso, as indústrias farmacêuticas direcionam os investimentos para a produção de medicamentos que ofereçam maior segurança de retorno financeiro [2] e pouco investem no desenvolvimento de medicamentos para o tratamento das doenças negligenciadas. Dessa forma, a busca por novas alternativas terapêuticas para essas doenças se faz necessária, bem como maiores investimentos em pesquisa e desenvolvimento (P\&D) de novas drogas, que são ainda insuficientes [1-2].

\section{2 - Doença de Chagas}

Descoberta em 1909 pelo médico brasileiro Carlos Chagas [6-7], a doença de Chagas é uma doença crônica, sistêmica [8-9] que foi reconhecida pela OMS como uma das 13 doenças 
tropicais mais negligenciadas do mundo [8]. O protozoário flagelado Trypanosoma cruzi, pertencente à ordem Kinetoplastida, família Trypanosomatidae e gênero Trypanosoma [6], é o agente causador dessa doença. Seu ciclo biológico é complexo, podendo infectar mamíferos, triatomíneos (insetos hematófagos) e seres humanos [10]. O parasito pode apresentar três formas distintas, sendo duas multiplicativas, epimastigota (presente no vetor e em cultura axênica) e amastigota (forma de replicação intracelular), e uma forma infectante, tripomastigota (forma sanguínea circulante e infectante)[6,11]. Entre mais de 100 espécies de triatomíneos com potencial para transmitir a doença de Chagas, as mais importantes são Triatoma infestans, Rhodnius prolixus e Triatoma dimidiata [9]. Os triatomíneos contraem o parasito T. cruzi ao alimentarem-se do sangue de um animal ou ser humano contaminado e transmitem a doença ao defecarem durante uma nova ingestão de sangue, depositando os parasitos no novo hospedeiro. Outras formas de se contrair a doença são por meio da ingestão de comidas ou bebidas contaminadas com o parasito [10] e por transfusão de sangue contaminado [12-13].

A infecção chagásica pode ser dividida em dois estágios, agudo e crônico, sendo que o primeiro dura em média 2 meses e o segundo geralmente perdura por toda a vida do hospedeiro[6]. Em muitos casos, a fase aguda da doença pode ser assintomática ou apresentar manifestações discretas (oligossintomática)[6,12], caracterizadas por mal-estar, febre e inchaço nos olhos [12-13]. Na fase crônica da doença, os pacientes podem desenvolver complicações no sistema gastrointestinal e/ou cardíaco [6,13]. Estima-se que existam entre 16 e 18 milhões de pessoas na fase crônica e que esta causa por ano aproximadamente 50 mil mortes [13].

Os principais compostos utilizados no tratamento da doença de Chagas são o benznidazol [14-17], Bz (Rochagan®, Radanil@), $N$-benzyl-2-nitroimidazol acetamida e o 
nifurtimox [14-15,18], Lampit®, 3-metil-4-(5'-nitrofurfurilidenoamino)tetrahidro-4H-1,4tiazina-1,1-dióxido, os quais têm a estrutura elucidada na Figura 1.

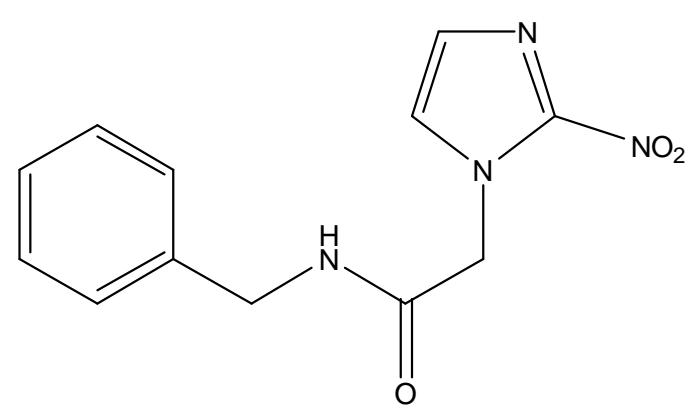

Benznidazol

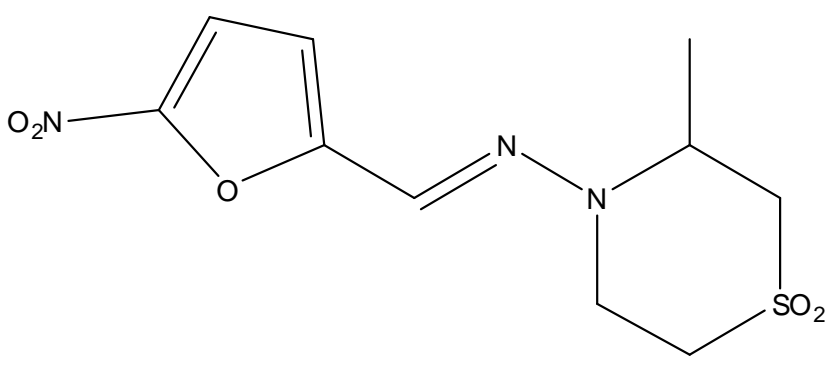

nifurtimox

Figura 1 - Estrutura dos compostos comumente utilizados no tratamento da doença de Chagas

O mecanismo de ação desses compostos ocorre por meio da geração de radicais e/ou metabólitos eletrofílicos [6,19-20]. Esses intermediários, por não serem específicos somente ao parasito devido à alta reatividade, também podem atuar negativamente em outros sistemas (hospedeiro humano)[6] e isso pode explicar os efeitos tóxicos observados nos pacientes tratados com essas drogas. Os efeitos adversos mais comuns para os fármacos em uso contra a doença de Chagas são sonolência, perda de peso, náuseas e vômitos [21] quando o tratamento é feito com nifurtimox, e febre, dermatites [21], dores musculares e dermatopatia alérgica para o tratamento com benznidazol [16,20-21].

\section{3 - Leishmaniose}

A leishmaniose é uma doença causada por um parasito flagelado membro do gênero Leishmania, ordem Kinetoplastida, o qual é um protozoário intracelular obrigatório [22-23]. O parasito apresenta duas formas (ou estágios), amastigota (aflagelado) e promastigota (flagelado), sendo que a primeira é encontrada nos tecidos dos vertebrados e a segunda no tubo digestivo do inseto transmissor e em meio de cultura axênicos [22]. Comum nas regiões 
dos trópicos, no sul da Europa, América e Ásia [22], estima-se que a leishmaniose está presente em 88 países e que afeta por volta de 12 milhões de pessoas no mundo [23].

Dependendo da espécie do parasito, a leishmaniose pode ser cutânea, mucocutânea ou visceral [23-24], sendo esta última, a forma mais severa da doença, a qual pode ser causada pelas espécies Leishmania donovani, Leishmania infantum e Leishmania chagasi [23]. A transmissão da leishmaniose geralmente ocorre por meio da picada de insetos do gênero Lutzomyia e Phlebotomus [22-23,25-27], os quais contraem o parasito ao alimentarem-se com o sangue de um hospedeiro previamente infectado. Outras formas de se transmitir a doença são por meio de transfusão de sangue [22], acidentes laboratoriais[28] ou de forma congênita [22]. A leishmaniose, dependendo da espécie do parasito e do hospedeiro, pode causar diversas manifestações clínicas tais como lesões cutâneas (na região infectada e/ou lesões difusas) [29], lesões linfáticas e úlceras nas mucosas [22,26,28].

A primeira forma de tratamento contra a leishmaniose baseia-se na utilização de compostos de antimônio pentavalente como estibogluconato de sódio (Pentostam®) e antimoniato de N-metil-glucamina (Glucantime®) (FIGURA 2), entretanto, o mecanismo de ação desses compostos ainda não está completamente elucidado [30]. Um problema decorrente da utilização desses medicamentos é a resistência adquirida pelo parasito [30-31], resultando na necessidade de aumento nas doses para que o tratamento seja eficiente. Outro problema decorrente do uso dessas drogas diz respeito aos efeitos colaterais, dentre os quais náuseas, fraqueza, hepato e cardiotoxicidade [30,32]. 

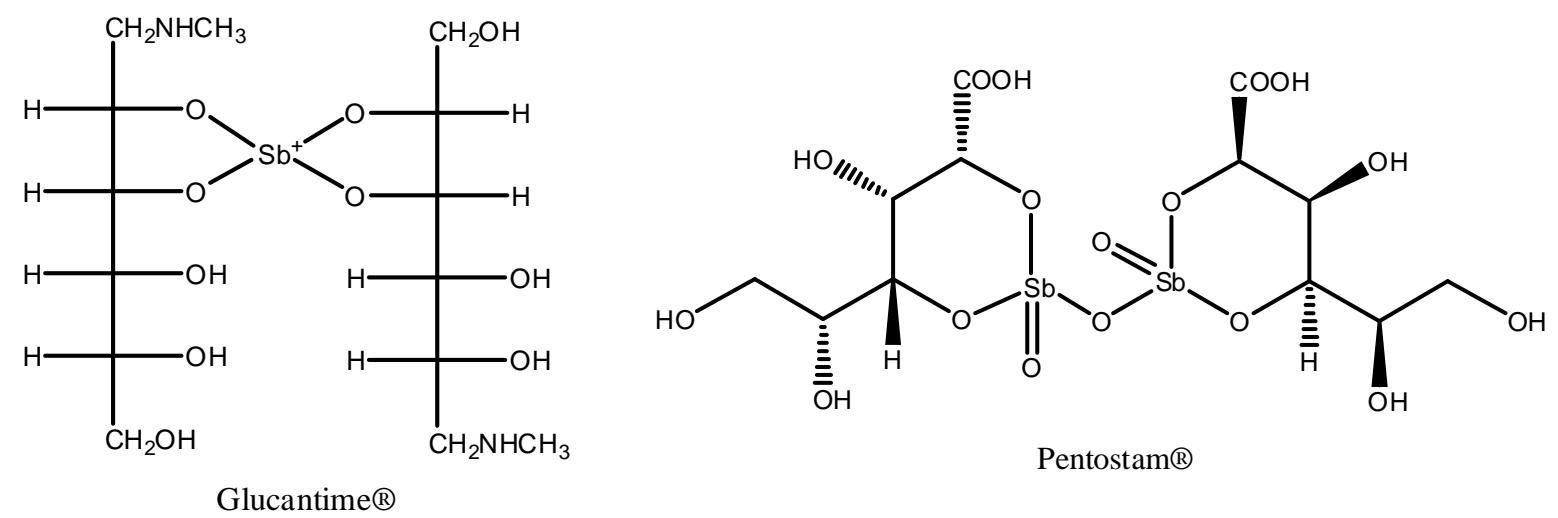

Figura 2 - Estrutura dos compostos de antimônio utilizados para o tratamento de leishmaniose.

A segunda escolha no tratamento da leishmaniose é a Anfotericina B (Fungizone®) [33] (FIGURA 3), que apresenta grande afinidade pelo ergosterol, um esterol predominante em Leishmania [31]. Esta droga também ocasiona diversos efeitos colaterais como náuseas, dores abdominais, vômitos, febre, cardiotoxicidade, insuficiência renal e anemia [33-34].

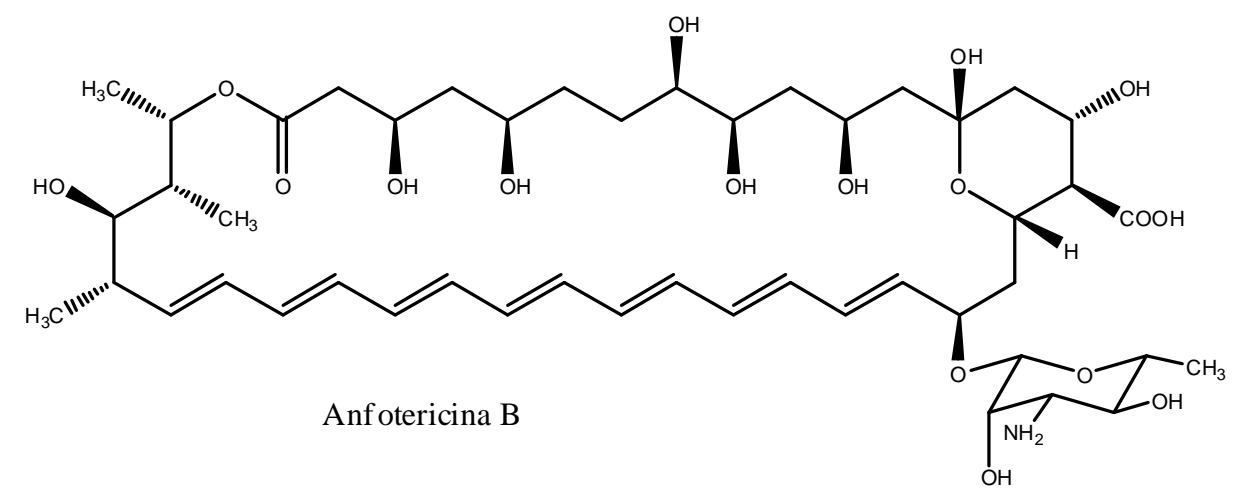

Figura 3 - Estrutura do composto utilizado como alternativa aos compostos de antimônio para o tratamento da leishmaniose

Existem também outros compostos utilizados para o tratamento da leishmaniose como isotionato de pentamidinana, miltefosina e sulfato de paromomicina [23] além de alguns extratos de produtos naturais que também apresentaram ação leishmanicida [27]. 


\section{4 - Compostos metálicos utilizados como agentes quimioterápicos contra os}

parasitos Trypanosoma e Leishmania

Diversos complexos metálicos têm sido reportados na literatura por apresentarem atividade antiparasitária [32,35-36]. Os trabalhos com compostos de cobre, zinco e [6] são os primeiros relatos sobre a utilização de metais de transição contra Chagas [6]. Um novo direcionamento foi dado às pesquisas, quando se começou a utilizar compostos com conhecida ação antitumoral como tripanocida[6,37]. Essa estratégia de combate à doença de Chagas baseou-se no fato de que havia semelhanças bioquímicas entre os metabolismos dos tripanossomas e o de células tumorais [6,38]. Assim, a carboplatina e a cisplatina (Figura 4) destacavam-se dentre os compostos mais promissores [6,37]

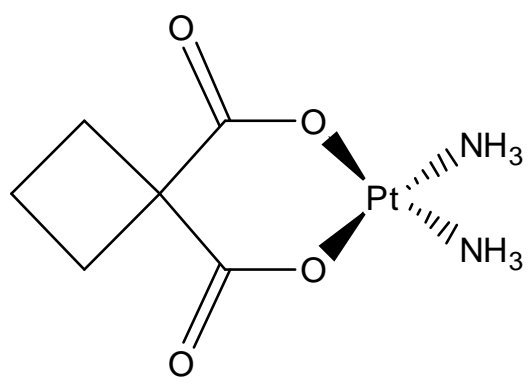

Carboplatina

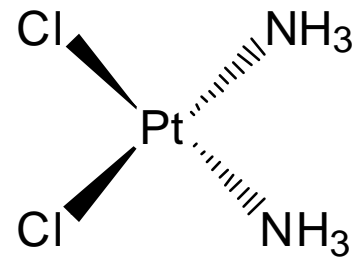

Cisplatina

Figura 4 - Compostos de Platina com atividade anti-T. cruzi

Uma série de compostos de rutênio $(\mathrm{Ru})$, Figura 5, dentre eles $\left[\mathrm{Ru}\left(\mathrm{NH}_{3}\right)_{6}\right] \mathrm{Cl}_{3}$, $\left[\mathrm{Ru}\left(\mathrm{NH}_{3}\right)_{5} \mathrm{Cl}\right] \mathrm{Cl}_{2}, \quad\left[\mathrm{Ru}(\mathrm{DMSO})_{4} \mathrm{Cl}_{2}\right], \quad\left[\mathrm{Ru}(\mathrm{DMSO})_{2} \mathrm{en}\right]$ também foram avaliados quanto a atividade tripanocida[6,37,39]. 


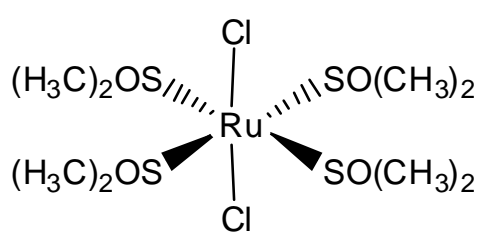

$\left[\mathrm{Ru}(\mathrm{DMSO})_{4} \mathrm{Cl}_{2}\right]$

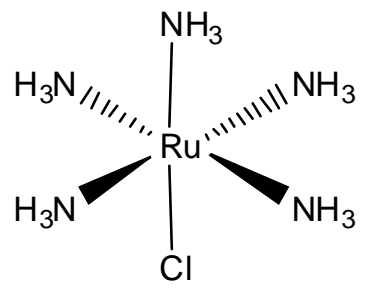

$\left[\mathrm{Ru}\left(\mathrm{NH}_{3}\right)_{5} \mathrm{Cl}\right] \mathrm{Cl}_{2}$<smiles></smiles>

$\left[\mathrm{Ru}(\mathrm{DMSO})_{2} \mathrm{en}\right]$

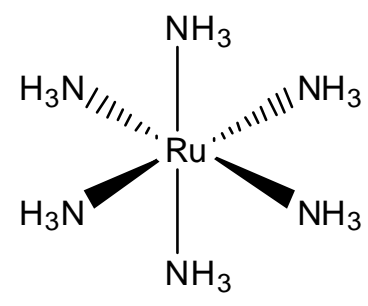

$\left[\mathrm{Ru}\left(\mathrm{NH}_{3}\right)_{6}\right] \mathrm{Cl}_{3}$

Figura 5 - Compostos de rutênio com ação anti-T.cruzi

Desde então, alguns trabalhos com rutênio e outros metais como por exemplo ródio, irídio, platina e paládio, têm sido publicados com a finalidade de se obter metalodrogas com ação antiparasitária [32,36,39-41]. Mais recentemente, Gambino e colaboradores desenvolveram compostos de platina, cobre e manganês que também apresentaram atividade antiparasitária [32,40,42-45].

Um panorama diferente é encontrado no tratamento da leishmaniose, pois a utilização de metais na formulação de compostos com potencial antileishmanicida ainda foi pouco estudada [32]. Além dos compostos de antimônio, também foram obtidos resultados satisfatórios com sulfato de zinco no tratamento da leishmaniose cutânea [29]. Fricker e colaboradores desenvolveram diversos compostos de paládio (II), ouro (II) e rênio (V) que apresentaram-se como potenciais inibidores das cisteino-proteases dos parasitos $T$. cruzi e leishmania [35]. Alguns compostos de cobre (II) com ligantes fluorados também tiveram atividade in vitro contra Leishmania amazonensis [46]. 
Nesse contexto, o grupo de Química Inorgânica e Analítica do Instituto de Química de São Carlos - USP tem desenvolvido diversos compostos de rutênio (tetraaminas de rutênio) com comprovada ação tripanocida e leishmanicida em ensaios in vitro e in vivo [11,16,47-50]. Esses compostos são solúveis em água e sua ação antiparasitária está associada à liberação de óxido nítrico, $\mathrm{NO}$ (que para esses compostos está ligado a $\mathrm{Ru}(\mathrm{II})$ na forma de nitrosilo, $\mathrm{NO}^{+}$) uma molécula com importantes funções fisiológicas e patofisiológicas [51-53].

Dentre esses compostos, também merece destaque trans- $\left[\mathrm{Ru}(\mathrm{Bz})\left(\mathrm{NH}_{3}\right)_{4} \mathrm{SO}_{2}\right]\left(\mathrm{CF}_{3} \mathrm{SO}_{3}\right)_{2}$ (em que $\mathrm{Bz}=$ benznidazol) [16], RuBz, (Figura 6), que também apresentou ação tripanocida. Os resultados obtidos para esse complexo são promissores, pois a mesma atividade contra $T$. cruzi foi obtida em uma concentração aproximadamente mil vezes menor que a dose recomendada para $\mathrm{Bz}$ livre (não coordenado ao rutênio) [16]. Além disso, RuBz é aproximadamente nove vezes mais solúvel em água que Bz, o que poderia explicar a menor toxicidade observada nos resultados dos ensaios in vivo [16], com relação ao composto original $(\mathrm{Bz})$
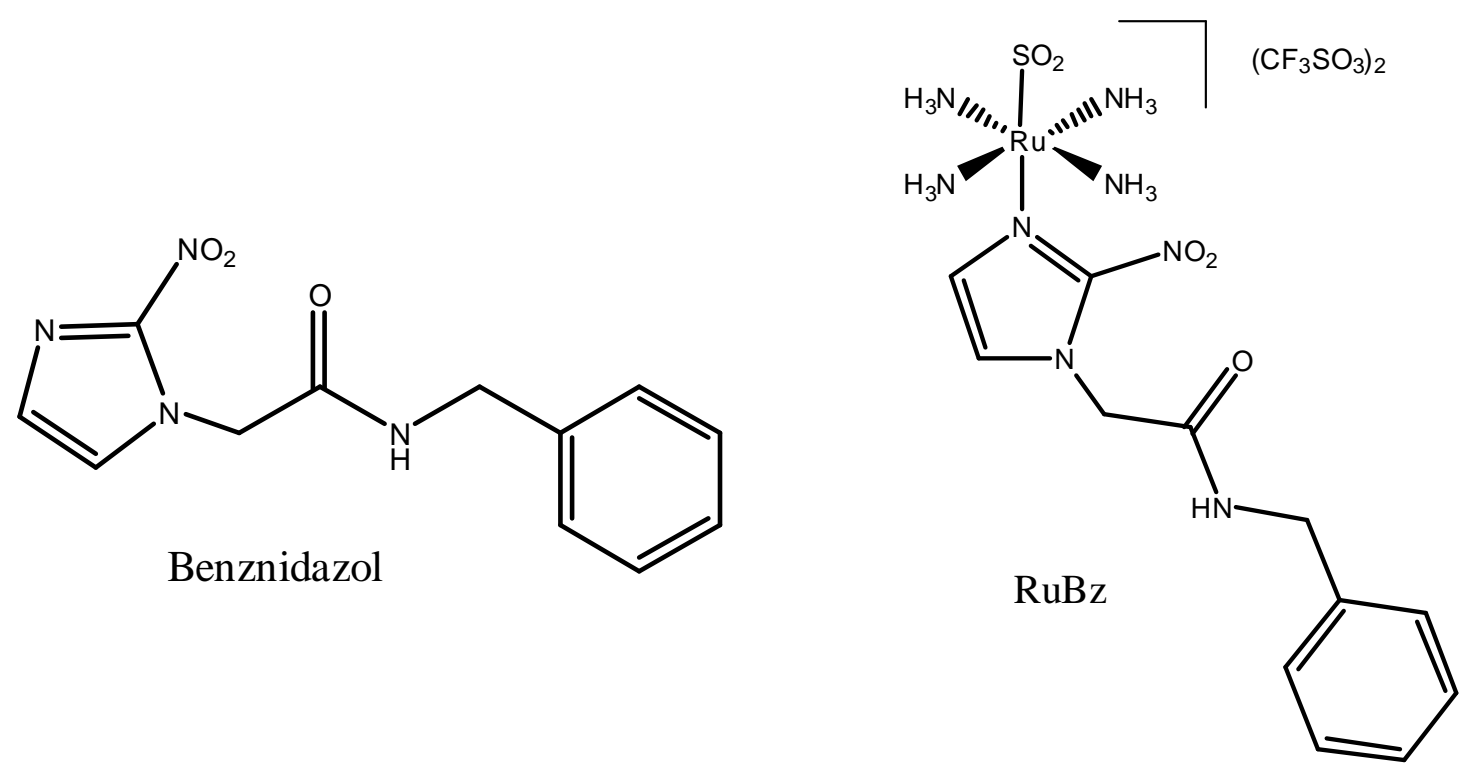

Figura 6 - Estruturas químicas dos compostos Bz e RuBz. 


\section{5 - Óxido Nítrico}

Até meados da década de 1980 os estudos sobre a molécula de óxido nítrico (NO) eram basicamente sobre poluição atmosférica[54]. Hoje sabe-se que o óxido nítrico apresenta diversas funções fisiológicas e patofisiológicas, o que renovou o interesse sobre a química fundamental dessa molécula[55]. O NO pode ser produzido endogenamente por duas vias: redução de íons nitrito em meio ácido e a oxidação da L-arginina a L-citrulina. Esta última reação é catalisada pela enzima NO-sintase (NOS) na presença de NADPH e oxigênio[56] (Figura 7).

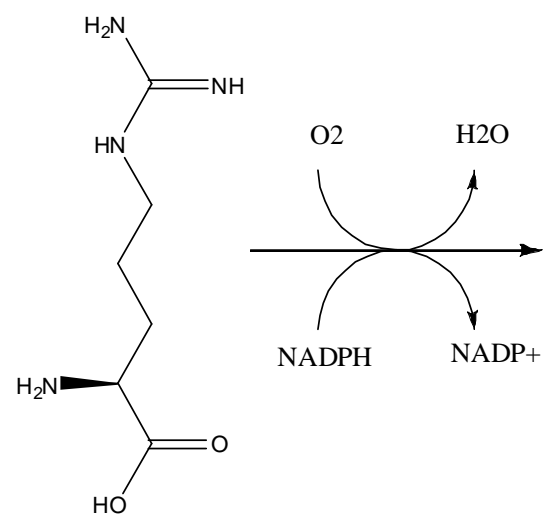

L-Arg

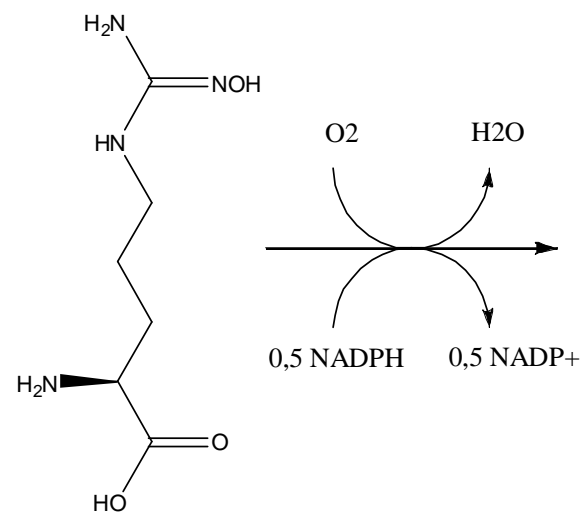

NOH-L-Arg

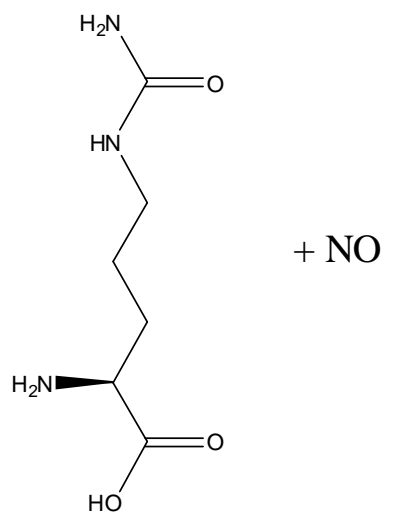

L-Cit

Figura 7 - Produção de NO via oxidação de L-arginina a L-citrulina [57-58].

O óxido nítrico é um radical e apresenta em sua configuração eletrônica um elétron desemparelhado no orbital $\pi^{*}$, fato que explica a elevada reatividade dessa molécula com espécies de oxigênio $\left(\mathrm{O}_{2}, \mathrm{O}_{2}{ }^{\circ}\right)$, metais de transição e tióis[59-60]. Devido a essa reatividade, o NO possui um pequeno tempo de meia vida, estimado entre 5 e 15 s [61-62]. Apesar disso, a molécula de NO tem a capacidade de difundir-se por meio da membrana celular, dispensando transportadores específicos ou canais[63] devido a sua pequena dimensão, solubilidade em água e em tecidos lipídicos, e neutralidade elétrica[61,63].

O NO também reúne as propriedades de neurotransmissor[53], atua na vasodilatação e reperfusão[64], apresenta atividade antimicrobiana[49], atua como agente de defesa 
imunológico[65], na ereção peniana[66] e na broncodilatação[67], além de ter atividades em no fígado, útero, pulmões e cérebro[63]. O óxido nítrico também está relacionado a doenças neurodegenerativas e disfunções fisiológicas como o choque séptico (falência circulatória aguda) e efeitos pró e antiapoptóticos[68].

Adicionalmente, tem-se reportado na literatura que a principal forma de defesa do sistema imunológico em infecções causadas por parasitas [48,69-70] como Plasmodium[71], Toxoplasma[72], Trypanosoma[73] e Leishmania[70] é provavelmente a produção de NO. Alguns estudos também correlacionam o aumento na concentração de NO no organismo, como forma de resposta imunológica durante infecções causadas por vírus e bactérias, como por exemplo a Tuberculose [74] e Herpes[75].

Resultados obtidos por Mauël \& Ransijn [76] indicam que o tratamento com doadores de NO induziram a inibição da respiração mitocondrial das formas amastigota e promastigota do parasito Leishmania. A molécula de óxido nítrico também está envolvida no controle das infecções por $T$. cruzi em hospedeiros vertebrados [50,77]. Compostos doadores de NO tem a capacidade de inibir a cruzipaína, principal proteína da família das cisteíno proteases do $T$. cruzi $[6,78]$, por meio de nitrosilação [79]

\section{6 - Complexos transportadores de NO - Tetraaminas de Rutênio}

Em ambientes de hipoxia (ambiente redutor), comum em infecções, a ação da enzima NOS é normalmente inibida e nessas condições a geração de NO por uma via alternativa que envolve a redução de íons nitrito aumenta [80]. Dessa forma, torna-se importante um suprimento extra de óxido nítrico no organismo, que pode ocorrer por meio da utilização de sistemas doadores externos de NO. Isto encoraja pesquisas nessa direção, visando o desenvolvimento de novos compostos com capacidade de atuarem como transportadores de óxido nítrico [55,81-82]. 
Complexos metálicos de rutênio (II) têm sido estudados como possíveis liberadores de NO em meio fisiológico [83]. Em particular, um grupo de compostos conhecidos como tetraaminas de rutênio(II) (Figura 8) de fórmula trans- $-\left[\mathrm{Ru}^{\mathrm{II}}\left(\mathrm{NO}^{+}\right)\left(\mathrm{NH}_{3}\right)_{4}(\mathrm{~L})\right]^{3+}[\mathrm{em}$ que $\mathrm{L}=$ isonicotinamida (isn), picolina (pic), nicotinamida (nic), piridina (py), pirazina (pz), LHistidina (L-Hist), imidazol (imN), 4-picolina (4-pic), trietilfosfito $\left(\mathrm{P}(\mathrm{OEt})_{3}\right)$ e também os compostos $\left[\mathrm{Ru}\left(\mathrm{NO}^{+}\right) \mathrm{Hedta}\right]^{0}$ e $\left.\operatorname{trans}-[\mathrm{Ru}(\mathrm{NO}) \mathrm{Cl}(\text { cyclam })]^{2+}\right]$, apresentam propriedades importantes como solubilidade em água, robustez quanto a reações de substituição e capacidade de liberar $\mathrm{NO}^{0}$ por via química ou fotoquímica segundo o esquema[55,84] :

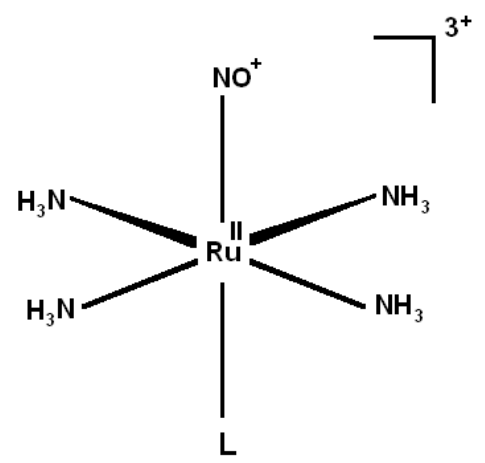

Figura 8 - Estrutura geral para as tetraaminas de $\mathrm{Ru}(\mathrm{II})$

$$
\text { trans- }\left[\mathrm{Ru}^{\mathrm{II}}\left(\mathrm{NO}^{+}\right)\left(\mathrm{NH}_{3}\right)_{4}(\mathrm{~L})\right]^{3+}+\mathrm{e}^{-} \stackrel{\text { rápida }}{\longrightarrow} \text { trans- }\left[\mathrm{Ru}^{\mathrm{II}}\left(\mathrm{NO}^{0}\right)\left(\mathrm{NH}_{3}\right)_{4}(\mathrm{~L})\right]^{2+}
$$

$$
\begin{aligned}
& \text { trans- }\left[\mathrm{Ru}^{\mathrm{II}}\left(\mathrm{NO}^{0}\right)\left(\mathrm{NH}_{3}\right)_{4}(\mathrm{~L})\right]^{2+}+\mathrm{H}_{2} \mathrm{O} \stackrel{\mathrm{k}_{-\mathrm{NO}}}{\longrightarrow} \text { trans- }\left[\mathrm{Ru}^{\mathrm{II}}\left(\mathrm{H}_{2} \mathrm{O}\right)\left(\mathrm{NH}_{3}\right)_{4}(\mathrm{~L})\right]^{2+}+\mathrm{NO}^{0} \\
& \text { trans-[Ru } \left.{ }^{\mathrm{II}}\left(\mathrm{NO}^{+}\right)\left(\mathrm{NH}_{3}\right)_{4}(\mathrm{~L})\right]^{3+} \underset{\mathrm{H}_{2} \mathrm{O}, \mathrm{H}+}{\stackrel{\mathrm{h} v}{\longrightarrow}} \operatorname{trans}-\left[\mathrm{Ru}^{\mathrm{III}}\left(\mathrm{H}_{2} \mathrm{O}\right)\left(\mathrm{NH}_{3}\right)_{4}(\mathrm{~L})\right]^{3+}+\mathrm{NO}^{0}
\end{aligned}
$$

Reações 1 a 3 - Reação de redução monoeletrônica (1) e liberação de óxido nítrico via aquação dos nitrosilo complexos de rutênio (2) e liberação de NO por via fotoquímica (3) [55]

Uma característica interessante na utilização dos nitrosilo complexos de rutênio é que o ligante L trans-posicionado exerce um papel importante sobre a reatividade do grupo NO, 
permitindo modular, em função de $\mathrm{L}$, a constante de velocidade específica $\left(\mathrm{k}_{-\mathrm{NO}}\right)$ com que ocorre a liberação do óxido nítrico[55] e o potencial de redução $\left(\mathrm{NO}^{+} / \mathrm{NO}^{0}\right)$, tornando-o acessível a diversos redutores encontrados em meio biológico[85], como NADH, tióis e $\alpha$ acetoglutarato $[84,86]$.

Estudos de biodistribuição do composto $\left[\mathrm{Ru}^{\mathrm{II}}\left(\text { edta) } \mathrm{NO}^{+}\right]^{-}\right.$foram realizados por Zanichelli et al.[87] nos quais verificou-se que após 8h de administração desse complexo não foi detectado rutênio no plasma, urina ou em outros órgãos dos animais utilizados nos testes, ou seja, todo o composto foi eliminado do organismo. Esse resultado é interessante, pois indica que não ocorreu acúmulo de rutênio no organismo dos animais. Porém, em determinadas circunstâncias esse resultado pode ser indesejado. Por exemplo, ao empregar-se os nitrosilo complexos de rutênio contra parasitos (T. cruzi e L. major), o aumento no tempo de permanência desses compostos na circulação dos animais utilizados nos testes poderia aumentar a eficiência do tratamento e/ou diminuir o número de doses administradas. Esse aumento de tempo de permanência poderia ser alcançado ancorando-se os compostos de rutênio a matrizes como, por exemplo, dendrímeros. Margerum e colaboradores[88] demonstraram que quelatos de gadolínio (utilizados como contraste em ressonância magnética de imagem) quando ligados a dendrímeros PAMAM (poliamidoamina) permaneceram no organismo por períodos de tempo mais longos do que os quelatos monoméricos.

O aumento no tempo de permanência dos compostos de rutênio na circulação também poderia propiciar condições mais favoráveis para a regeneração dos nitrosilo complexos através da reação com nitrito $\left(\mathrm{NO}_{2}^{-}\right)$, presente na corrente sanguínea. Após a liberação de NO e formação do respectivo aqua complexo, o composto original pode ser regenerado[49,89], conforme o ciclo apresentado na Figura 9. 


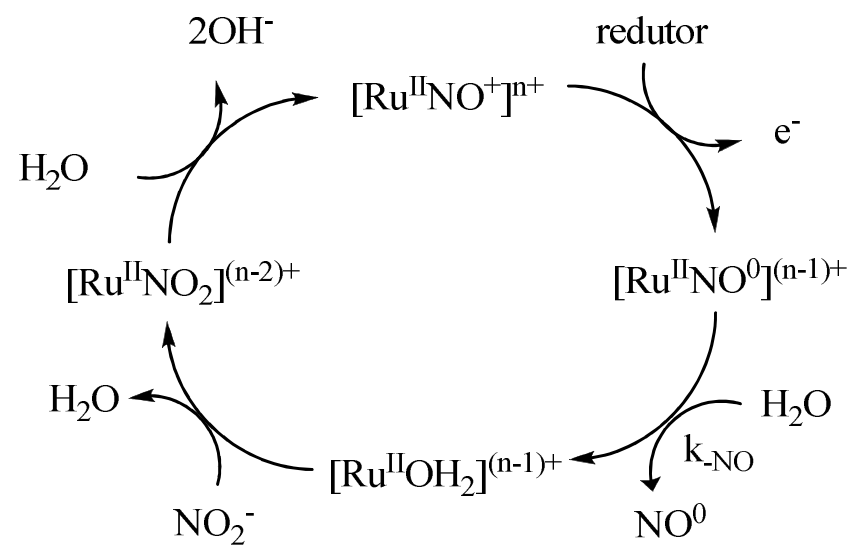

Figura 9 - Esquema do ciclo catalítico para a conversão de nitrito a óxido nítrico promovido pelos complexos de rutênio[49,89].

Os complexos do tipo trans- $\left[\mathrm{Ru}^{\mathrm{II}}\left(\mathrm{NH}_{3}\right)_{4}(\mathrm{~L})\left(\mathrm{H}_{2} \mathrm{O}\right)\right]^{2+}$, designados na Figura 9 como $\left[\mathrm{Ru}^{\mathrm{II}} \mathrm{H}_{2} \mathrm{O}\right]$ demonstraram a capacidade de poder converter nitrito $\left(\mathrm{NO}_{2}^{-}\right)$em nitrosilo $\left(\mathrm{NO}^{+}\right)[49]$ por meio de equilíbrio ácido-base in vitro. Como a concentração de $\mathrm{NO}_{2}^{-}$no plasma sanguíneo é próxima a $1 \mu \mathrm{M}[90]$, a reação entre as espécies $\left[\mathrm{Ru}^{\mathrm{II}} \mathrm{H}_{2} \mathrm{O}\right]^{2+}{\mathrm{e} \mathrm{NO}_{2}}^{-}$poderia produzir espécies do tipo $\left[\mathrm{Ru}^{\mathrm{II}} \mathrm{NO}_{2}{ }^{-}\right]$, seguindo o ciclo catalítico representado pela Figura 9 $[49,89]$.

Nesse contexto, os complexos do tipo trans- $\left[\mathrm{Ru}^{\mathrm{II}}\left(\mathrm{NO}^{+}\right)\left(\mathrm{NH}_{3}\right)_{4}(\mathrm{~L})\right]^{3+}$, ligados a dendrímeros constituem-se um modelo promissor no tocante à liberação controlada de NO em meio biológico.

\section{7 - Imobilização de complexos: a utilização dos dendrímeros}

Complexos metálicos podem ser imobilizados e incorporados em diferentes matrizes e utilizados em biomateriais, na medicina[88], como catalisadores[91] e no transporte de fármacos[89]. Dentre os materiais utilizados como suporte para moléculas, destacam-se a sílica[92-94], os xerogéis[95] e os dendrímeros[96-97]. A imobilização de espécies doadoras de óxido nítrico nessas matrizes[92,94-97] com a finalidade de se obter sistemas que biodisponibilizem NO de forma controlada[89] é conhecida. 
Os dendrímeros PAMAM (poliamidoamina), conforme estrutura apresentada na Figura 10, são moléculas que merecem destaque dentre as matrizes supracitadas, devido a sua estrutura ramificada, baixa toxicidade [98] e solubilidade em água [99]. Os dendrímeros são moléculas que possuem três componentes essenciais: núcleo inicial, camadas interiores e a camada exterior[99-103].

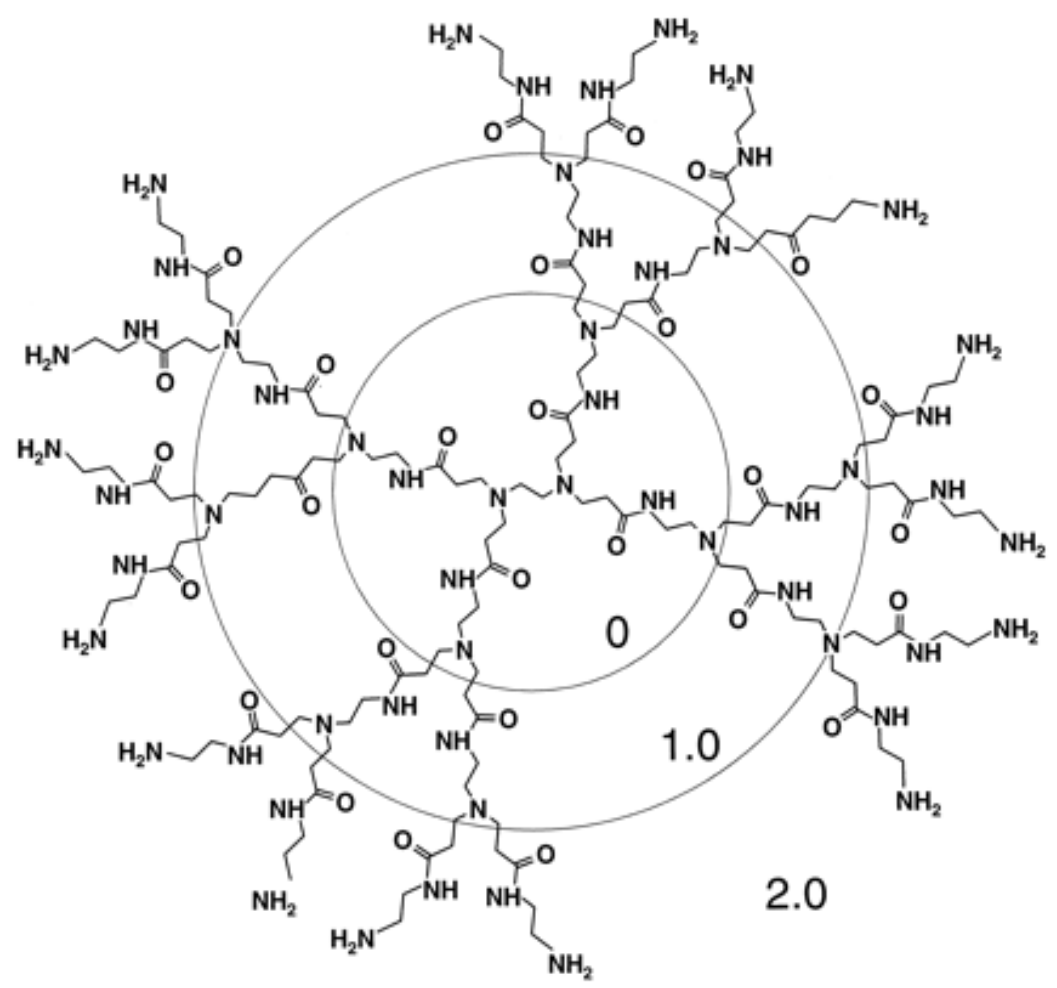

Figura 10 - Estrutura do dendrímero PAMAM com grupos terminais amina - os círculos representam as gerações 0,1 e 2 do dendrímero[104].

Os dendrímeros PAMAM são macromoléculas que possuem grupos terminais (amina e carboxila) que podem participar de diversos tipos de reações[96]. Devido às suas características biomiméticas, ou seja, sua estrutura imita a estrutura de proteínas globulares, a utilização deste material na medicina tem sido investigada e reportada pela literatura[105106]. Conforme pode ser observado na Figura 10, os dendrímeros são classificados por "gerações" dependendo do número de grupos terminais presentes. Assim, o PAMAM de geração 0 (zero), apresenta 4 grupos amina superficiais, o de geração 1 apresenta 8 , enquanto o de geração 2 apresenta 16 grupos. 
A presença de grupos funcionais nas extremidades do PAMAM permite a formação de ligações com outras moléculas de interesse. Benini e colaboradores [96] descrevem a funcionalização do complexo [Ru ${ }^{\text {II }}(\text { edta)(NO) }]^{-}$em PAMAM de geração 0,2 e 3 . Os resultados demonstraram que o complexo ligado ao dendrímero apresentou atividade tripanocida (in vitro) superior ao do composto não ligado ao PAMAM, e que as propriedades químicas dos compostos ancorados não foram alteradas quando comparadas às do complexo não ligado ao dendrímero.

Dessa forma, as tetraaminas de rutênio ligadas a dendrímeros PAMAM podem se constituir em promissores sistemas liberadores de NO, de forma controlada. Entre os possíveis ligantes que tem a capacidade de se coordenar ao rutênio e ao mesmo tempo efetuar uma ligação com os grupos terminais dos PAMAM, formando uma ligação peptídica, é possível destacar os N-heterocíclicos isonicotinamida e ácido isonicotínico (Figura 11). A isonicotinamida pode ligar-se aos PAMAM que possuem grupos terminais carboxila, -COOH, (PAMAM de gerações intermediárias, como por exemplo, G 0,5 e G 1,5), enquanto o ácido isonicotínico pode ligar-se a dendrímeros PAMAM que possuem grupos terminais amina, $-\mathrm{NH}_{2}(\mathrm{G} 0, \mathrm{G} 1, \mathrm{G} 2)$. Em adição, esses ligantes, quando trans posicionados a $\mathrm{NO}^{+}$(nitrosilo complexos) em tetraaminas de rutênio, deram origem a compostos ativos em testes preliminares contra o parasita T. cruzi[49].<smiles>O=C(O)c1ccncc1</smiles>

Ácido isonicotínico (ina)<smiles>NC(=O)c1ccncc1</smiles>

Isonicotinamida (isn)

Figura 11 - Fórmulas estruturais do ácido isonicotínico e isonicotinamida. 


\section{II - OBJETIVO E JUSTIFICATIVA}

Sintetizar e caracterizar o complexo trans- $\left[\mathrm{Ru}^{\mathrm{II}}\left(\mathrm{NO}^{+}\right)\left(\mathrm{NH}_{3}\right)_{4}\right.$ ina $]\left(\mathrm{BF}_{4}\right)_{3}$ e ancorá-lo a dendrímeros PAMAM de geração 0 e 2 e testar estes complexos in vitro contra os parasitas $T$. cruzi e L. major.

Pretende-se com o ancoramento aumentar o tempo de permanência dos complexos na corrente sanguínea dos animais nos testes in vivo contra os parasitos supracitados (que serão realizados posteriormente) o que poderia aumentar a eficiência no tratamento. 


\section{III - METODOLOGIA}

\section{1 - Reagentes}

Todos os reagentes utilizados foram de pureza analítica (P.A). Os solventes (acetona e etanol) foram destilados e tratados de acordo com a literatura [107]. Éter etílico foi tratado com sódio metálico por uma noite, com sulfato ferroso amoniacal, destilado e estocado em frasco escuro para evitar a formação de peróxido[107]. Os demais reagentes, tricloreto de rutênio, monohidrato de hidrazina, ácido clorídrico, metabissulfito de sódio, ácido tetrafluorbórico, dimetilformamida (DMF), óxido de deutério, ácido trifluoroacético deuterado, nitrito de sódio, ácido trifluoracético, bicarbonato de sódio, peróxido de hidrogênio, ácido isonicotínico e dedrímeros PAMAM foram utilizados sem prévia purificação, devido ao alto grau de pureza informado pelos fabricantes (Merck, Acros, J.T. Baker ou Aldrich).

Nos ensaios eletroquímicos foi utilizada como eletrólito de suporte uma solução aquosa $\mathrm{pH}$ 2,0 e força iônica $\mu=0,10 \mathrm{~mol} \mathrm{~L}-1\left(\mathrm{CF}_{3} \mathrm{COOH} / \mathrm{CF}_{3} \mathrm{COONa}\right)$. Nos experimentos de espectroscopia eletrônica também se fez uso dessa solução.

Argônio (White Martins, grau de pureza 4.8) foi utilizado como gás inerte nos procedimentos de síntese que demandavam atmosfera inerte. Antes de seu borbulhamento na solução, o argônio é purificado por lavagem em dois vasos lavadores contento solução ácida de $\mathrm{Cr}$ (II), preparada a partir de $\mathrm{CrCl}_{3}$ em solução $1 \mathrm{M}$ de ácido clorídrico, juntamente com amálgama de $\mathrm{Zn}(\mathrm{Hg})$. Este processo envolvendo $\mathrm{Cr}(\mathrm{II})$ tem por objetivo retirar traços de oxigênio presentes no gás. Em seguida o gás passou por um vaso contento ácido sulfúrico concentrado para promover sua secagem. Todos os procedimentos que demandavam ausência de oxigênio foram realizados em sistemas fechados, utilizando-se balões borbulhadores, balões de fundo redondo e cânulas de teflon para condução do gás e transferência das 
soluções. Todas as soluções utilizadas foram previamente desoxigenadas antes do início dos procedimentos.

\section{2 - Instrumentação e Técnicas Experimentais}

\subsection{1 - Análise Elementar}

As Análises Elementar de carbono, nitrogênio e hidrogênio foram realizadas no Laboratório de Análise Elementar do Instituto de Química da USP, São Paulo.

\subsection{2 - Determinação de Rutênio}

O equipamento empregado nas determinações de rutênio foi um Espectrômetro de Emissão por Plasma Indutivo - ICP Marca/Modelo: Perkin Elmer/Optima 3000DV. A metodologia utilizada é a proposta por Rowston e Ottaway, modificado por Clarke[108]. Para tanto, foram preparadas soluções padrão de cloreto de hexaminrutênio(III) na faixa de 5 a 25 ppm. Para mascarar substâncias interferentes, as soluções dos padrões e das amostras continham 5\% (V/V) de uma solução de sulfato de cobre(II) e cádmio(II). Esta solução foi preparada dissolvendo-se 9,81 g de $\mathrm{CuSO}_{4} .5 \mathrm{H}_{2} \mathrm{O}$ e $16,62 \mathrm{~g}$ de $\mathrm{CdSO}_{4} .8 / 3 \mathrm{H}_{2} \mathrm{O}$ em $100 \mathrm{~mL}$ de $\mathrm{HCl}$ 1,0 $\mathrm{molL}^{-1}[108]$.

\subsection{3 - Espectroscopia vibracional}

Os espectros foram obtidos em um espectrofotômetro BOMEM FTIR MB-102 na região de $4000-250 \mathrm{~cm}^{-1}$. As amostras foram preparadas no momento das análises sob forma de pastilha de brometo de potássio $(\mathrm{KBr})$, utilizando-se a concentração do analito de $1 \%$ em relação a massa de $\mathrm{KBr}$. 


\subsection{4 - Espectroscopia eletrônica}

Os ensaios de espectroscopia eletrônica (UV-Vis) foram realizados utilizando um espectrofotômetro Hitachi, modelo U-3501, e celas de quartzo de caminho óptico de 1,0 cm. Solução aquosa, pH 2,0 e $\mu=0,10 \mathrm{~mol} \mathrm{~L}^{-1}\left(\mathrm{CF}_{3} \mathrm{COOH} / \mathrm{CF}_{3} \mathrm{COONa}\right)$ foi utilizada como referência. As soluções foram previamente desaeradas e mantidas em atmosfera inerte antes das análises.

\subsection{5 - Espectroscopia de ressonância magnética nuclear (RMN)}

Todos os espectros de ressonância magnética nuclear de ${ }^{1} \mathrm{H}$ e ${ }^{13} \mathrm{C}$ foram obtidos em um espectrômetro BRUKER DRX400 9,4 Tesla 400 MHz. Utilizou-se $\mathrm{D}_{2} \mathrm{O}$ como solvente, e quando necessário o $\mathrm{pH}$ foi ajustado com ácido trifluoroacético deuterado $\left(\mathrm{CF}_{3} \mathrm{COOD}\right)$. $\mathrm{O}$ reagente 3-(trimetilsilil)propionato-2,2,3,3- $\mathrm{d}_{4}$ de sódio $\left(\mathrm{TSP}-\mathrm{d}_{4}\right)$ foi utilizado como sinal de referência (deslocamento químico = 0 ppm).

As soluções contendo as amostras foram desaeradas e transferidas por meio de tubo de teflon sob fluxo de argônio para o tubo de RMN previamente desaerado.

\subsection{6 - Medidas de ressonância paramagnética de elétrons (RPE)}

Os ensaios de RPE foram efetuadas em um espectrômetro Bruker modelo EMX, operando na faixa de microondas de 9,0 à 10,0 GHz (banda - X). Os ensaios foram realizados na temperatura $=-196^{\circ} \mathrm{C}$ e potência de $2 \mathrm{~mW}$.

\subsection{7 - Voltametria Cíclica}

Os experimentos de voltametria cíclica foram efetuados utilizando um potenciostato EG\&G PAR (Princeton Applied Research), modelo 264A. Utilizou-se uma célula eletroquímica constituída por um sistema de três eletrodos, sendo o eletrodo de trabalho de 
carbono vítreo, um contra-eletrodo de platina e um eletrodo de referência de calomelano saturado, $\mathrm{ECS}\left(\mathrm{Hg}_{2} \mathrm{Cl}_{2} / \mathrm{Hg} / \mathrm{KCl}_{\mathrm{sat}}\right)$. Os voltamogramas foram obtidos em solução aquosa, $\mathrm{pH}$ 2,0, $\mu=0,10 \mathrm{~mol} \mathrm{~L}{ }^{-1}\left(\mathrm{CF}_{3} \mathrm{COOH} / \mathrm{CF}_{3} \mathrm{COONa}\right)$, com temperatura controlada por banho termostático $\left(25 \pm 0,5^{\circ} \mathrm{C}\right)$. Os voltamogramas foram registrados em microcomputador conectado ao potenciostato.

\section{3 - Sínteses}

As sínteses dos compostos $\left[\mathrm{Ru}^{\mathrm{III}}\left(\mathrm{NH}_{3}\right)_{5} \mathrm{Cl}\right] \mathrm{Cl}_{2}$ e trans- $\left[\mathrm{Ru}^{\mathrm{II}}\left(\mathrm{NH}_{3}\right)_{4}\left(\mathrm{SO}_{2}\right) \mathrm{Cl}\right] \mathrm{Cl}$ seguiram procedimento descrito na literatura [109-110]. A Figura 12 apresenta um fluxograma ilustrando as principais etapas do processo de síntese.

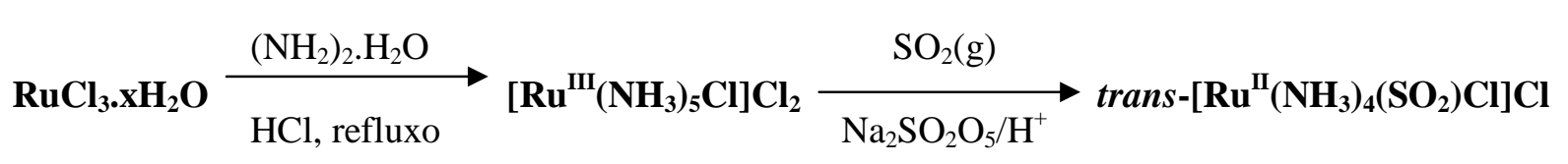

Figura 12 - Rota de síntese do complexo trans- $\left[\mathrm{Ru}^{\mathrm{II}}\left(\mathrm{NH}_{3}\right)_{4}\left(\mathrm{SO}_{2}\right) \mathrm{Cl}\right] \mathrm{Cl}$

Para esses complexos o controle da pureza foi verificado por meio da comparação dos respectivos coeficientes de absortividade molar $(\varepsilon)$ de seus espectros de UV-vis, por bandas características nos espectros de infravermelho e pelos potenciais de oxirredução dos voltamogramas, com os dados da literatura.

\subsection{1 - Síntese do complexo trans- $\left[\mathrm{Ru}^{\mathrm{III}}\left(\mathrm{NH}_{3}\right)_{4}\left(\mathrm{SO}_{4}\right)\right.$ ina $] \mathrm{Cl}$}

O complexo trans-[Ru ${ }^{\text {IIII }}\left(\mathrm{NH}_{3}\right)_{4}\left(\mathrm{SO}_{4}\right)$ ina $] \mathrm{Cl}$ foi sintetizado de forma análoga a procedimento descrito na literatura para outras tetraaminas de rutênio com ligantes $\mathrm{N}$ heterocíclos e sulfato[111-112]. A Figura 13 apresenta as reações envolvidas na obtenção desse complexo, e em seguida está descrito de forma detalhado o procedimento realizado. 


\begin{tabular}{|c|c|}
\hline trans $-\left[\mathrm{Ru}^{\mathrm{II}}\left(\mathrm{NH}_{3}\right)_{4}\left(\mathrm{SO}_{2}\right) \mathrm{Cl}\right]^{+}$ & 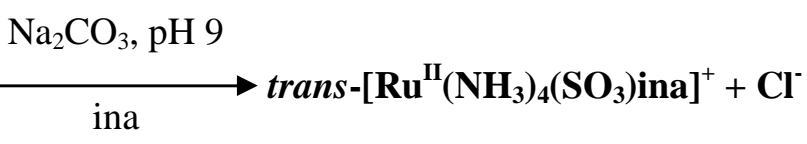 \\
\hline trans $-\left[\mathrm{Ru}^{\mathrm{II}}\left(\mathrm{NH}_{3}\right)_{4}\left(\mathrm{SO}_{3}\right) \mathrm{ina}^{+}\right.$ & $\stackrel{\mathrm{HCl}, \mathrm{H}_{2} \mathrm{O}_{2}}{\longrightarrow}$ trans-[ $\mathbf{R u}^{\mathrm{III}}\left(\mathbf{N H}_{3}\right)_{4}\left(\mathbf{S O}_{4}\right)$ ina $] \mathrm{Cl}_{(\mathrm{s})}$ \\
\hline
\end{tabular}

Figura 13 - Reações envolvidas na síntese do complexo trans-[ $\mathrm{Ru}^{\mathrm{III}}\left(\mathrm{NH}_{3}\right)_{4}\left(\mathrm{SO}_{4}\right)$ ina $] \mathrm{Cl}$

Procedimento: $150 \mathrm{mg}$ do complexo trans-[ $\left.\mathrm{Ru}^{\mathrm{II}}\left(\mathrm{NH}_{3}\right)_{4}\left(\mathrm{SO}_{2}\right) \mathrm{Cl}\right] \mathrm{Cl}$ foram dissolvidos em 10 mL de água destilada previamente desaerada e em seguida adicionou-se carbonato de sódio $\left(\mathrm{Na}_{2} \mathrm{CO}_{3}\right)$ até a solução atingir pH 9,0. A solução final tem coloração amarelada. Uma segunda solução foi preparada pela dissolução de 400 mg de ácido isonicotínico (ina) em 10,5 mL água destilada desaerada e com $\mathrm{pH}$ final ajustado para 9,0 utilizando-se $\mathrm{Na}_{2} \mathrm{CO}_{3}$. Esta solução foi adicionada vagarosamente à solução contendo rutênio, havendo mudança na coloração de amarela para alaranjada. Então foram adicionados 4,5 mL de $\mathrm{HCl} 6 \mathrm{M}$, resultando em uma solução de coloração marrom, seguido da adição de 4,5 mL, gota a gota, de solução $30 \%$ de $\mathrm{H}_{2} \mathrm{O}_{2}$ sob agitação. A solução de cor amarela claro permaneceu sob agitação por 5 minutos, quando então foram adicionados $40 \mathrm{~mL}$ de acetona. A solução foi acondicionada em refrigerador por 12 horas. O sólido obtido foi coletado por filtração, lavado com acetona, seco e estocado sob vácuo e ao abrigo da luz. Rendimento: $67 \%$

\subsection{2 - Síntese do complexo trans- $\left[\mathrm{Ru}^{\mathrm{II}}\left(\mathrm{NO}^{+}\right)\left(\mathrm{NH}_{3}\right)_{4}\right.$ ina $]\left(\mathrm{BF}_{4}\right)_{3}$}

A rota de síntese para o complexo trans- $\left[\mathrm{Ru}^{\mathrm{II}}\left(\mathrm{NO}^{+}\right)\left(\mathrm{NH}_{3}\right)_{4}\right.$ ina $]\left(\mathrm{BF}_{4}\right)_{3}$ seguiu procedimento descrito na literatura para outros nitrosilos de rutênio[55,113].

A Figura 14 apresenta as reações envolvidas na obtenção desse complexo, e em seguida está descrito de forma detalhado o procedimento realizado. 


$$
\text { trans-[Ru } \left.{ }^{\mathrm{III}}\left(\mathrm{NH}_{3}\right)_{4}\left(\mathrm{SO}_{4}\right) \text { ina }\right]^{+} \stackrel{\mathrm{H}^{+}, \mathrm{NO}_{(\mathrm{g})}}{\longrightarrow} \text { trans }-\left[\mathrm{Ru}^{\mathrm{II}}\left(\mathrm{NO}^{+}\right)\left(\mathrm{NH}_{3}\right)_{4} \mathrm{ina}\right]^{3+}
$$

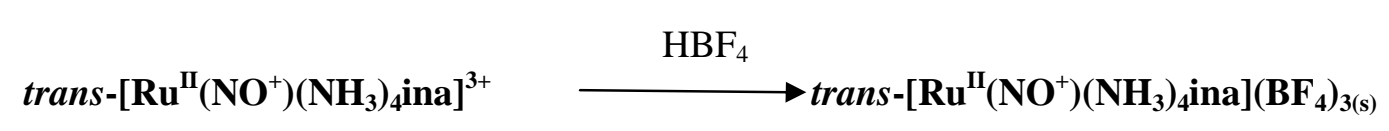

Figura 14 - Reações envolvidas na síntese do complexo trans- $\left[\mathrm{Ru}^{\mathrm{II}}\left(\mathrm{NO}^{+}\right)\left(\mathrm{NH}_{3}\right)_{4}\right.$ ina $]\left(\mathrm{BF}_{4}\right)_{3}$

Procedimento: dissolveram-se 100mg de trans- $\left[\mathrm{Ru}^{\mathrm{III}}\left(\mathrm{NH}_{3}\right)_{4}\left(\mathrm{SO}_{4}\right)\right.$ ina $] \mathrm{Cl}$ em 5,0 mL de solução desaerada de $\mathrm{HBF}_{4}\left(10^{-2}\right.$ mol. $\left.\mathrm{L}^{-1}\right)$ com $\mathrm{pH}$ previamente ajustado para 5,5. O complexo foi reduzido com amálgama de zinco, $\mathrm{Zn}(\mathrm{Hg})$, sob fluxo de argônio por 30 minutos. Então, essa solução foi transferida por cânula de teflon para um frasco contendo uma solução 4,9 M de $\mathrm{HBF}_{4}$. Em seguida, foi adicionado a esta solução, $150 \mathrm{mg}$ de $\mathrm{NaNO}_{2}$. A solução permaneceu em agitação por 1 hora e então foi adicionado excesso de etanol desaerado (30 $\mathrm{mL}$ ), o que conduziu a precipitação de um sólido de cor rósea, que foi coletado por filtração, lavado com etanol, seco e estocado a vácuo.

\subsection{3 - Ancoramento dos complexos de rutênio nos dendrímeros poliamidoamina}

(PAMAM) de geração 0 e 2

$\mathrm{O}$ ancoramento do complexo de rutênio (trans- $\left[\mathrm{Ru}^{\mathrm{III}}\left(\mathrm{NH}_{3}\right)_{4}\left(\mathrm{SO}_{4}\right)\right.$ ina $\left.] \mathrm{Cl}\right)$ nos dendrímeros foi realizado adaptando-se procedimentos descritos na literatura $[92,96]$. Para efetuar a ligação peptídica entre o grupo carboxila (do ligante acido isonicotínico coordenado ao metal) com o grupo amina do dendrímero PAMAM, utilizou-se o reagente de acoplamento dicicloexilcarbodiimida (DCC). O mecanismo dessa reação de acoplamento é ilustrado na Figura 15 [114] e na Figura 16 é apresentado a rota de síntese resumida até a obtenção do nitrosilo complexo ligado ao dendrímero: $\mathrm{GX} /$ trans- $\left[\mathrm{Ru}^{\mathrm{II}}\left(\mathrm{NO}^{+}\right)\left(\mathrm{NH}_{3}\right)_{4} \mathrm{ina}\left(\mathrm{BF}_{4}\right)_{3}(\mathrm{em}\right.$ que $\mathrm{X}=$ 0 e 2, e representa a geração do dendrímero). Em seguida o procedimento é descrito detalhadamente. 


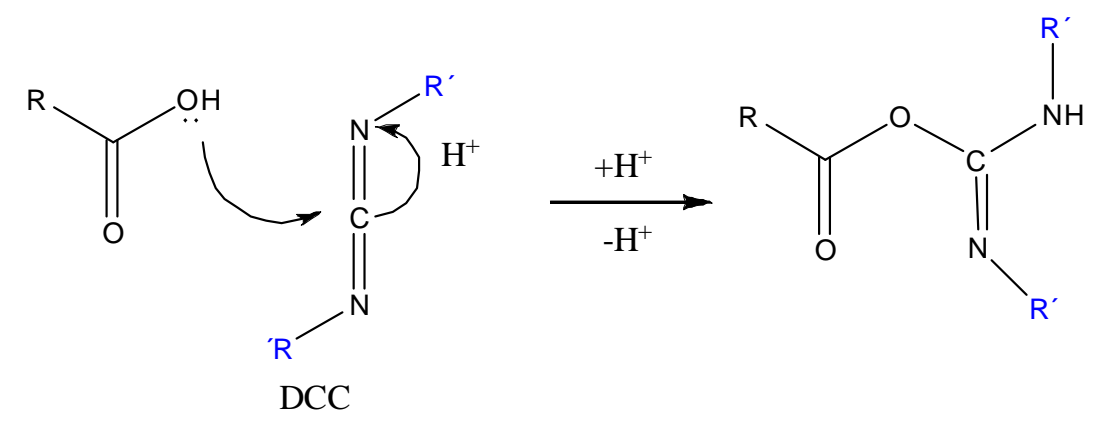

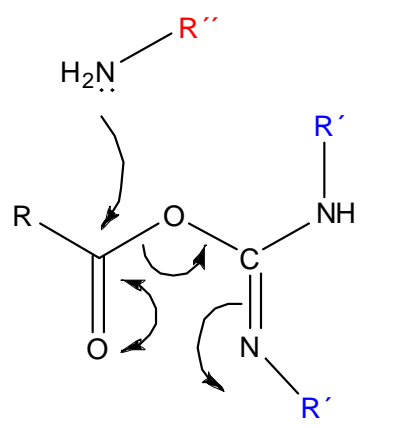

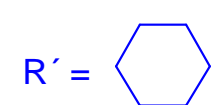<smiles>[R]C(=O)N[13CH][IH+](C)[IH+]</smiles>

$$
\mathrm{R}^{\prime \prime}=\text { PAMAM }
$$<smiles>[3H]NC(=O)N[B]</smiles>

DCU

Figura 15 - Conjunto de reação para formação de ligação peptídica [114]

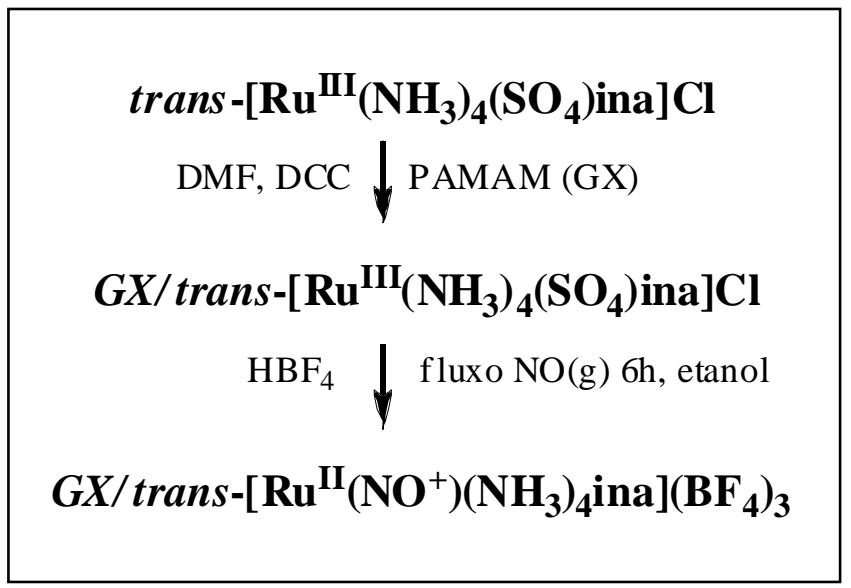

Figura 16 - Rota de síntese do complexo GX/trans- $\left[\mathrm{Ru}^{\mathrm{II}}\left(\mathrm{NO}^{+}\right)\left(\mathrm{NH}_{3}\right)_{4}\right.$ ina $]\left(\mathrm{BF}_{4}\right)_{3}$ em que $\mathrm{X}$ representa a geração do dendrímero (0 ou 2). 
A metodologia utilizada nas sínteses para a ligação dos complexos de rutênio em ambos os dendrímeros, G0 e G2, foi similar. Dessa forma, primeiramente será descrito o procedimento para o dendrímero G0 e em seguida, de forma resumida, para o G2.

Os dendrímeros G0 e G2 são comercializados em solução $20 \%$ em metanol, e por esse motivo, esse solvente foi evaporado antes do uso desses reagentes nas sínteses. Dessa forma, $441 \mu \mathrm{L}$ de solução contendo G0 (aproximadamente $5,8 \times 10^{-4}$ mol de grupos $\mathrm{NH}_{2}$ superficiais do dendrímero) foram evaporados sob vácuo até obter-se volume constante. Em seguida a solução resultante (óleo) foi solubilizada em $5 \mathrm{~mL}$ de dimetilformamida anidra (DMF) e desaerada sob fluxo de argônio. Em outro balão dissolveu-se $295 \mathrm{mg}$ do complexo trans- $\left[\mathrm{Ru}^{\mathrm{III}}\left(\mathrm{NH}_{3}\right)_{4}\left(\mathrm{SO}_{4}\right)\right.$ ina $] \mathrm{Cl}\left(\mathrm{n}=6,4 \times 10^{-4} \mathrm{~mol}\right.$, excesso $\sim 10 \%$ em relação a $\left.\mathrm{G} 0\right)$ em $50 \mathrm{~mL}$ de DMF anidra previamente desaerada. Em seguida adicionou-se $132 \mathrm{mg}$ do reagente de acoplamento DCC $\left(\mathrm{n}=6,4 \times 10^{-4} \mathrm{~mol}\right)$ e a solução foi mantida sob agitação por aproximadamente 30 minutos a temperatura ambiente. Então, transferiu-se a solução contendo o dendrímero à solução contendo o complexo e DCC, mantendo-se a agitação em atmosfera de argônio durante 18h. Ao final da reação a solução foi filtrada e o sólido lavado com DMF e seco sob vácuo. No sobrenadante isolou-se e caracterizou-se por infravermelho o composto dicicloexiluréia (DCCU), um subproduto esperado na reação peptídica. Em seguida, aproximadamente $30 \mathrm{~mL}$ de água destilada foram adicionadas ao sólido obtido, ocorrendo a formação de um precipitado insolúvel de coloração branca, que por infravermelho foi identificado como sendo uma mistura entre DCCU e de parte do complexo precursor utilizado na reação. O sobrenadante da filtração foi seco em evaporador rotativo ocorrendo a formação de um óleo (complexo G0/trans-[Ru ${ }^{\mathrm{III}}\left(\mathrm{NH}_{3}\right)_{4}\left(\mathrm{SO}_{4}\right)$ ina $] \mathrm{Cl}$ ). Foram então adicionados ao óleo $20 \mathrm{~mL}$ de solução $10^{-2} \mathrm{~mol} \mathrm{~L}^{-1}$ de $\mathrm{HBF}_{4}$, permanecendo essa solução sob fluxo de $\mathrm{NO}_{(\mathrm{g})}$ (gerado pela reação de $\mathrm{NaNO}_{2}$ em meio ácido) por 6 horas. Em seguida, a solução foi mantida sob fluxo de argônio por $1 \mathrm{~h}$, prosseguindo com a redução do volume para aproximadamente 5 
$\mathrm{mL}$ em evaporador rotativo, quando então foram adicionados $30 \mathrm{~mL}$ de etanol previamente desaerado. O sólido de cor rósea foi coletado por filtração, lavado com etanol, seco e estocado a vácuo. Esse sólido foi purificado em coluna de exclusão por tamanho, utilizando-se como fase estacionária Sephadex G-25 e água destilada como fase móvel. Ao final da corrida, a solução coletada foi evaporada em evaporador rotativo até aproximadamente $5 \mathrm{~mL}$, em seguida adicionou-se $2 \mathrm{~mL}$ de $\mathrm{HBF}_{4}$ concentrado $(7,65 \mathrm{M})$ e excesso de etanol (aproximadamente $30 \mathrm{~mL})$. O sólido de cor rósea $\left(\mathrm{G} 0 /\right.$ trans- $\left[\mathrm{Ru}^{\mathrm{II}}\left(\mathrm{NO}^{+}\right)\left(\mathrm{NH}_{3}\right)_{4}\right.$ ina $\left.]\left(\mathrm{BF}_{4}\right)_{3}\right)$ foi coletado por filtração, lavado com etanol, seco e estocado a vácuo.

Para a reação com o dendrímero $\mathrm{G} 2$, foram utilizados $661 \mu \mathrm{L}$ de solução contendo $\mathrm{G} 2$ (aproximadamente $5,6 \times 10^{-4} \mathrm{~mol}$ de grupos $\mathrm{NH}_{2}$ superficiais do dendrímero), $515 \mathrm{mg}$ do complexo trans-[ $\left[\mathrm{Ru}^{\mathrm{III}}\left(\mathrm{NH}_{3}\right)_{4}\left(\mathrm{SO}_{4}\right)\right.$ ina $] \mathrm{Cl}\left(\mathrm{n}=1,12 \times 10^{-3} \mathrm{~mol}\right.$, duas vezes de excesso em relação a G2) dissolvidos em $85 \mathrm{~mL}$ de dimetilformamida anidra (DMF) previamente desaerada e $231 \mathrm{mg}$ do reagente de acoplamento DCC ( $\left.\mathrm{n}=1,12 \times 10^{-3} \mathrm{~mol}\right)$. A solução foi mantida sob agitação em atmosfera de argônio e à temperatura ambiente durante 48 horas. $\mathrm{O}$ produto obtido nessa etapa da síntese também apresentou características de um óleo (complexo G2/trans-[Ru ${ }^{\mathrm{III}}\left(\mathrm{NH}_{3}\right)_{4}\left(\mathrm{SO}_{4}\right)$ ina $] \mathrm{Cl}$ ), da mesma forma que observado anteriormente na reação com o dendrímero G0. Esse produto foi solubilizado em $20 \mathrm{~mL}$ de solução $10^{-2} \mathrm{~mol}$ $\mathrm{L}^{-1}$ de $\mathrm{HBF}_{4}$, permanecendo sob fluxo de $\mathrm{NO}_{(\mathrm{g})}$ por 6 horas. Em seguida, a solução foi mantida sob fluxo de argônio por 1h, prosseguindo com a redução do volume para aproximadamente $5 \mathrm{~mL}$ em evaporador rotativo, quando então foram adicionados $30 \mathrm{~mL}$ de etanol previamente desaerado. O sólido de cor rósea foi coletado por filtração, lavado com etanol, seco e estocado a vácuo. Esse sólido $\left(\mathrm{G} 2 /\right.$ trans- $\left[\mathrm{Ru}^{\mathrm{II}}\left(\mathrm{NO}^{+}\right)\left(\mathrm{NH}_{3}\right)_{4}\right.$ ina $\left.]\left(\mathrm{BF}_{4}\right)_{3}\right)$ foi purificado em coluna de exclusão por tamanho, utilizando-se o mesmo procedimento descrito anteriormente para o dendrímero G0. 


\section{4 - Ensaios Biológicos}

Os experimentos biológicos foram realizados em parceria com o Prof. Dr. João Santana da Silva e o Prof. Dr. Fernando Q. Cunha, da Faculdade de Medicina de Ribeirão Preto (FMRP-USP). Foram realizados testes com os complexos livres e ancorados ao dendrímero contra os parasitos Trypanosoma cruzi e Leishmania major.

\subsection{1 - Citotoxicidade dos compostos in vitro}

Células do baço de camundongos C57BL6 foram isoladas macerando-se o tecido em meio RPMI 1640 (Gibco-BRL Life Technologies, Grand Island, NY) sobre um filtro com poro de $100 \mu \mathrm{m}$. As células isoladas foram centrifugadas a $1500 \mathrm{rpm}$ por $10 \mathrm{~min}$ e as hemáceas foram lisadas com tampão de lise por 5 minutos à temperatura ambiente. As células foram lavadas, contadas e ressuspensas a $6,5 \times 10 \% \mathrm{~mL}$ em RPMI contendo $10 \%$ de soro fetal bovino. Em uma placa de 96 poços, as células do baço foram plaqueadas em triplicata e incubadas por 24 horas com os compostos de rutênio em três concentrações diluídas em PBS $(200 \mu \mathrm{M}, 100 \mu \mathrm{M}, 50 \mu \mathrm{M})$. O benznidazol (Roche) foi utilizado como droga de referência para mortalidade das células. Após o período de incubação, as células foram lavadas e incubadas com iodeto de propídio na concentração de $10 \mu \mathrm{g} / \mathrm{mL}$. A aquisição das células foi realizada dentro de 15 minutos utilizando-se um citômetro de fluxo FACSCantoII (Becton-Dickinson Immunocytometry System Inc., San Jose, CA) e a análise dos dados foi feita através do programa FloowJo (Tree Star).

\subsection{2 - Avaliação da atividade tripanocida in vitro sobre as formas tripomastigotas}

A atividade tripanocida in vitro dos diferentes compostos foi avaliada contra a forma tripomastigota da cepa $\mathrm{Y}$ do $T$. cruzi. Culturas de formas tripomastigotas foram ressuspendidas na concentração de $6,5 \times 10^{6}$ parasitos/mL em meio RPMI suplementado com 
$10 \%$ soro fetal bovino. Em seguida, um volume de $200 \mu \mathrm{L}$ de parasitos foi plaqueado em duplicata em placas de 96 poços na presença ou não dos compostos de rutênio dissolvidos em PBS (tampão fosfato). As duplicatas foram tratadas em três concentrações $200 \mu \mathrm{M}, 100 \mu \mathrm{M}$, $50 \mu \mathrm{M}$ dos compostos e as culturas foram mantidas à $37^{\circ} \mathrm{C}, 5 \% \mathrm{CO}_{2}$ por 24 horas. $\mathrm{O}$ benznidazol (Roche) foi utilizado como droga tripanocida de referência (controle positivo). Posteriormente, a viabilidade dos parasitos foi determinada contando-se o número de parasitos móveis em câmara de Neubauer, de acordo com Brener [115] e a porcentagem da atividade tripanocida (\% AT) foi calculada de acordo com a seguinte equação:

$$
\% \mathrm{AT}=\left[1-\left(\mathrm{L}_{\mathbf{D}} / \mathrm{L}_{\mathrm{Ct}}\right)\right] \times 100
$$

em que $\mathrm{L}_{\mathrm{Dt}}$ é a média do número de formas móveis no poço contendo os complexos de rutênio e $\mathrm{L}_{\mathrm{Ct}}$ é a média de formas móveis no poço não contendo qualquer composto (apenas o meio de cultura).

\subsection{3 - Determinação da atividade leishmanicida dos compostos}

Formas promastigotas de Leishmania major cepa LV39 foram dispostas em placas de 96 poços de fundo chato $\left(1 \times 10^{5}\right.$ parasitas por poço), em $200 \mu \mathrm{L}$ de meio Schneider (Sigma) contendo $20 \%$ de soro fetal bovino (Gibco), $2 \%$ de urina humana masculina, $100 \mathrm{U} / \mathrm{ml}$ Penicilina, $100 \mu \mathrm{g} / \mathrm{ml}$ Estreptomicina (Gibco) e $2 \mathrm{mM}$ de L-glutamina (Sigma), na presença ou

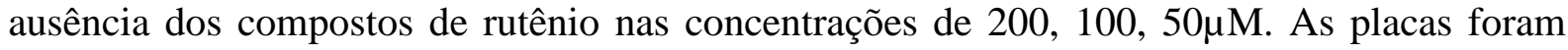
incubadas a $25^{\circ} \mathrm{C}$ por $24 \mathrm{~h}$, e o número de parasitas viáveis foi determinado por contagem de promastigotas móveis ou imóveis em microscópio óptico após 24 horas. A atividade leishmanicida (AL\%) foi determinada da mesmo forma que a atividade tripanocida (AT\%). 


\section{IV - RESULTADOS E DISCUSSÃO}

\section{1 - Caracterização do complexo trans- $\left[\mathrm{Ru}^{\mathrm{III}}\left(\mathrm{NH}_{3}\right)_{4}\left(\mathrm{SO}_{4}\right)\right.$ ina $] \mathrm{Cl}$}

O complexo obtido na síntese, trans-[ $\mathrm{Ru}^{\mathrm{III}}\left(\mathrm{NH}_{3}\right)_{4}\left(\mathrm{SO}_{4}\right)$ ina $] \mathrm{Cl}$, é um sólido de coloração amarelo claro, cuja provável fórmula estrutural é apresentada na Figura 17 e o resultado da análise elementar de C, H e N está apresentado na Tabela 1.

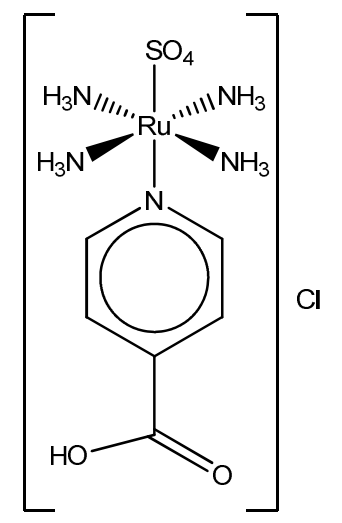

Figura 17 - Fórmula estrutural proposta para o complexo trans- $\left[\mathrm{Ru}^{\mathrm{III}}\left(\mathrm{NH}_{3}\right)_{4}\left(\mathrm{SO}_{4}\right)\right.$ ina $] \mathrm{Cl}$

Tabela 1 - Dados de análise elementar do complexo trans- $-\left[\mathrm{Ru}^{\mathrm{III}}\left(\mathrm{NH}_{3}\right)_{4}\left(\mathrm{SO}_{4}\right)\right.$ ina $] \mathrm{Cl} 2 \mathrm{H}_{2} \mathrm{O}$

\begin{tabular}{cccc}
\hline Elemento & Teórico & Experimental & Desvio(\%) \\
\hline \% $\mathbf{C}$ & 15,67 & 15,90 & $+1,5$ \\
\% H & 4,60 & 4,68 & $+1,7$ \\
\% N & 15,29 & 14,92 & $-2,5$ \\
\hline Relação C/H & 3,41 & 3,39 & 0,6 \\
Relação C/N & 1,02 & 1,06 & 3,9 \\
\hline
\end{tabular}

Os resultados obtidos são condizentes com a estrutura sugerida para o complexo trans- $-\left[\mathrm{Ru}^{\mathrm{III}}\left(\mathrm{NH}_{3}\right)_{4}\left(\mathrm{SO}_{4}\right)\right.$ ina $] \mathrm{Cl} \cdot 2 \mathrm{H}_{2} \mathrm{O}$. 


\subsection{1 - Espectroscopia vibracional}

$\mathrm{O}$ espectro vibracional do composto trans- $-\left[\mathrm{Ru}^{\mathrm{III}}\left(\mathrm{NH}_{3}\right)_{4}\left(\mathrm{SO}_{4}\right)\right.$ ina $] \mathrm{Cl}^{2} 2 \mathrm{H}_{2} \mathrm{O}$, ilustrado na Figura 18, apresentou freqüências de estiramento $v\left(\mathrm{SO}_{4}{ }^{2-}\right)$ em região compatível ao reportado na literatura[112] para o ligante $\mathrm{SO}_{4}{ }^{2-}$ coordenado ao fragmento $\mathrm{Ru}\left(\mathrm{NH}_{3}\right)_{4}$. O espectro vibracional desse complexo mostrou-se semelhante aos de compostos com estrutura similar, do tipo trans- $\left[\mathrm{Ru}^{\mathrm{III}}\left(\mathrm{NH}_{3}\right)_{4}\left(\mathrm{SO}_{4}\right)(\mathrm{L})\right] \mathrm{Cl}$ em que $\mathrm{L}=$ isonicotinamida (isn) e nicotinamida (nia) [112]. Outras bandas consideradas relevantes estão resumidas na Tabela 2.

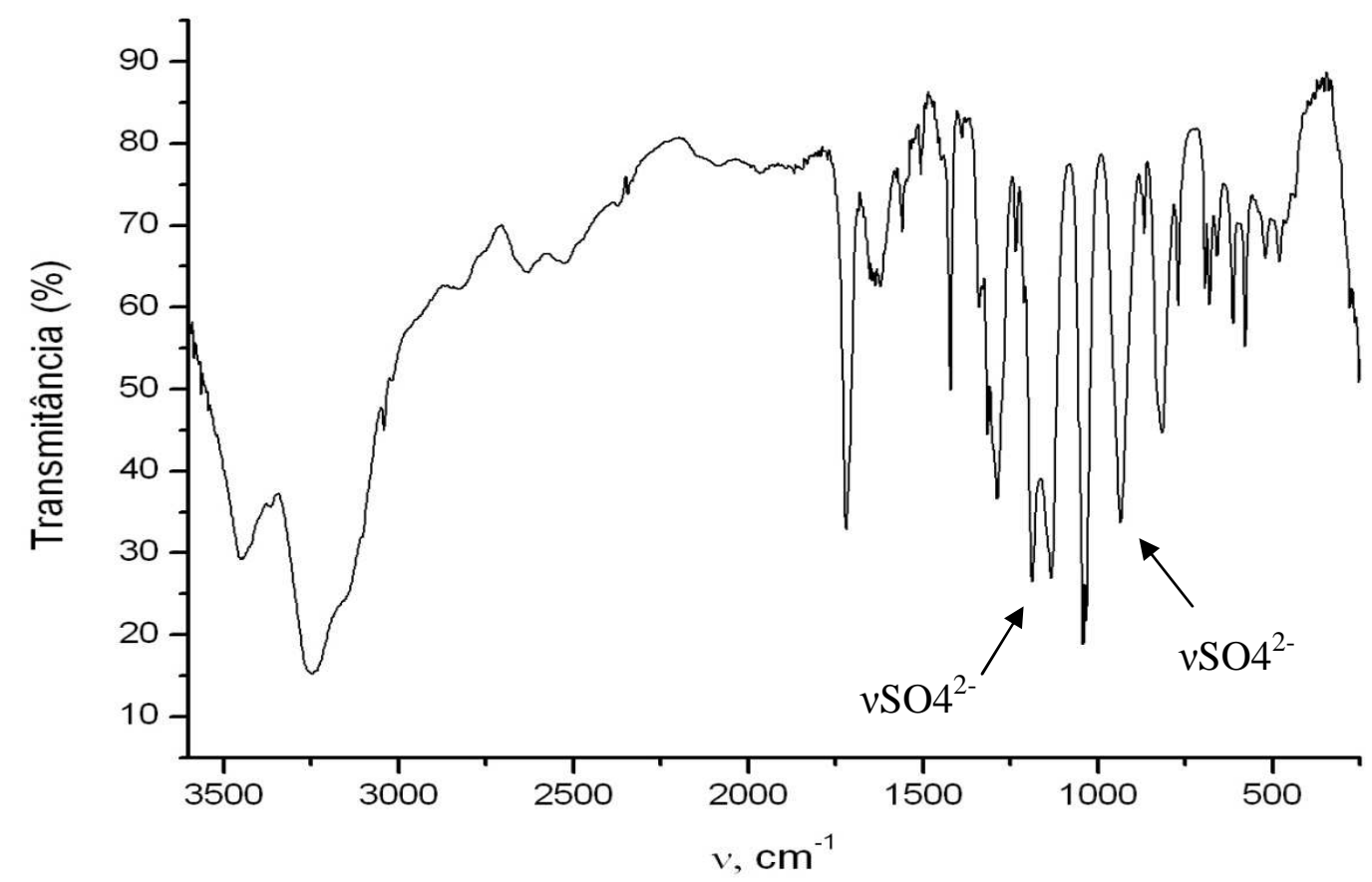

Figura 18 - Espectro na região de infravermelho do sólido trans-[ $\mathrm{Ru}{ }^{\mathrm{III}}\left(\mathrm{NH}_{3}\right)_{4}\left(\mathrm{SO}_{4}\right)$ ina $] \mathrm{Cl}$ em pastilha de $\mathrm{KBr}$. 
Tabela 2 - Principais frequências vibracionais e respectivas atribuições propostas para o complexo trans- $-\left[\mathrm{Ru}^{\mathrm{III}}\left(\mathrm{NH}_{3}\right)_{4}\left(\mathrm{SO}_{4}\right)\right.$ ina $] \mathrm{Cl}^{2} 2 \mathrm{H}_{2} \mathrm{O}$

\begin{tabular}{cc}
\hline Principais freqüências vibracionais $\left(\mathbf{c m}^{-1}\right)^{*}$ & Atribuições \\
\hline $3240 \mathrm{~F}$ & $v(\mathrm{NH}), v(\mathrm{CH})$ \\
$1720 \mathrm{~F}$ & $v(\mathrm{COOH})$ \\
$1131,1185 \mathrm{~F}$ & $v\left(\mathrm{SO}_{4}{ }^{2-}\right)$ \\
$945 \mathrm{~F}$ & $v\left(\mathrm{SO}_{4}{ }^{2-}\right)$ \\
$482 \mathrm{f}$ & $v\left(\mathrm{SO}_{4}{ }^{2-}\right)$ \\
*Pastilha de $\mathrm{KBr}$; resolução +/- 4cm ${ }^{-1}$; Intensidades $\mathrm{F}=$ forte, $\mathrm{m}=\mathrm{média} \mathrm{f}=$ fraca.
\end{tabular}

\subsection{2 - Voltametria Cíclica}

Por meio de voltametria cíclica, conforme apresentado na Figura 19, foi possível observar dois pares redox para o complexo trans- $\left[\mathrm{Ru}^{\mathrm{III}}\left(\mathrm{NH}_{3}\right)_{4}\left(\mathrm{SO}_{4}\right) \mathrm{ina}\right] \mathrm{Cl} 2 \mathrm{H}_{2} \mathrm{O}$. O primeiro, com $\left(\mathrm{E}_{1 / 2}\right)_{1}=0,055 \mathrm{~V}$ vs ECS (representado na Figura 19 por a1/a2), foi atribuído por comparação com sistemas semelhantes [112] ao par $\operatorname{Ru(III)/Ru(II)~em~}$ trans- $-\left[\mathrm{Ru}^{\mathrm{III}}\left(\mathrm{NH}_{3}\right)_{4}\left(\mathrm{SO}_{4}\right) \text { ina }\right]^{3+/ 2+}$ e o segundo com $\left(\mathrm{E}_{1 / 2}\right)_{2}=0,190 \mathrm{~V}$ vs ECS, a $\mathrm{Ru}(\mathrm{III}) / \mathrm{Ru}(\mathrm{II})$ em trans- $\left[\mathrm{Ru}^{\mathrm{III}}\left(\mathrm{NH}_{3}\right)_{4}\left(\mathrm{H}_{2} \mathrm{O}\right) \text { ina }\right]^{3+/ 2+}$ (representado na Figura 19 por b1/b2). 


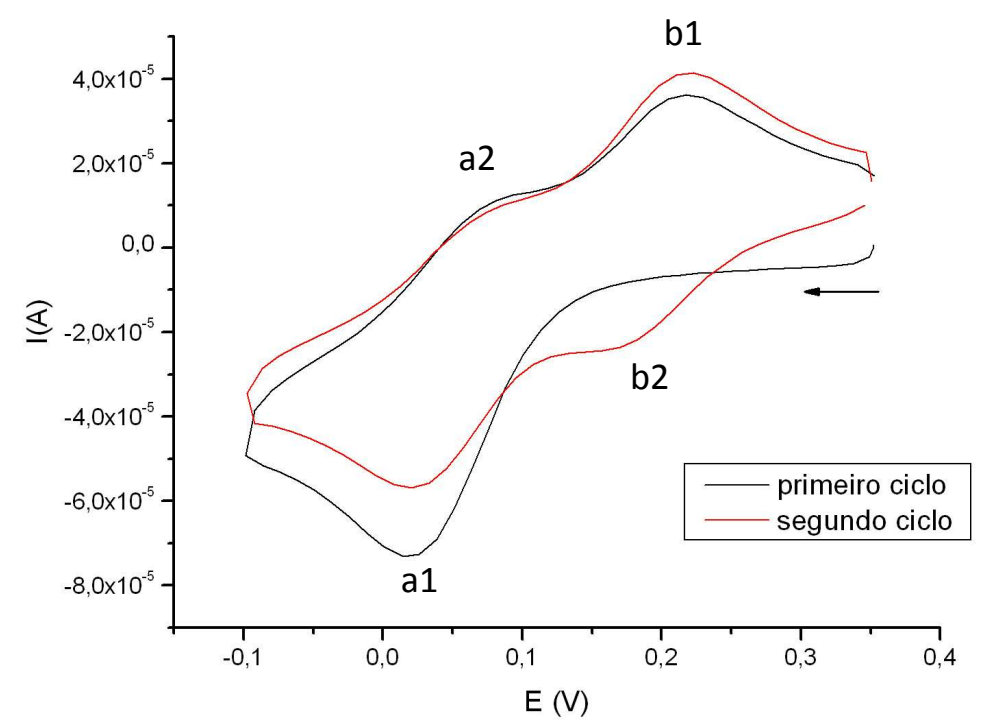

Figura 19 - Voltamograma cíclico para o íon trans $-\left[\mathrm{Ru}^{\mathrm{IIII}}(\mathrm{NH} 3) 4(\mathrm{SO} 4) \text { ina }\right]^{+}$em solução aquosa. Eletrólito $\mu=0,10 \mathrm{~mol} \mathrm{~L}-1\left(\mathrm{CF}_{3} \mathrm{COOH} / \mathrm{CF}_{3} \mathrm{COONa}\right), \mathrm{pH} 2,0$, temperatura de $25^{\circ} \mathrm{C}, \mathrm{v}$ $=200 \mathrm{mV} \mathrm{s}^{-1}$.

Os voltamogramas cíclicos apresentados na Figura 19 podem ser explicados pela sequência de equações [112]:

trans-[Ru $\left.{ }^{\mathrm{III}}\left(\mathrm{NH}_{3}\right)_{4}\left(\mathrm{SO}_{4}\right)(\mathrm{L})\right]^{+}+\mathrm{e}^{-} \stackrel{\text { rápido }}{\rightleftharpoons} \operatorname{trans}-\left[\mathrm{Ru}^{\mathrm{II}}\left(\mathrm{NH}_{3}\right)_{4}\left(\mathrm{SO}_{4}\right)(\mathrm{L})\right]^{0}$

trans- $\left[\mathrm{Ru}^{\mathrm{II}}\left(\mathrm{NH}_{3}\right)_{4}\left(\mathrm{SO}_{4}\right)(\mathrm{L})\right]^{0}+\mathrm{H}_{2} \mathrm{O} \stackrel{\mathrm{k}-\mathrm{sO} 4}{\longrightarrow}$ trans $-\left[\mathrm{Ru}^{\mathrm{II}}\left(\mathrm{NH}_{3}\right)_{4}\left(\mathrm{H}_{2} \mathrm{O}\right)(\mathrm{L})\right]^{2+}+\mathrm{SO}_{4}{ }^{2-}$

trans- $\left[\mathrm{Ru}^{\mathrm{II}}\left(\mathrm{NH}_{3}\right)_{4}\left(\mathrm{H}_{2} \mathrm{O}\right)(\mathrm{L})\right]^{2+} \stackrel{\text { rápido }}{\rightleftharpoons} \operatorname{trans}-\left[\mathrm{Ru}^{\mathrm{III}}\left(\mathrm{NH}_{3}\right)_{4}\left(\mathrm{H}_{2} \mathrm{O}\right)(\mathrm{L})\right]^{3+}+\mathrm{e}^{-}$

Reações 4 a 6 - Reação de redução monoeletrônica (4), representado na Figura 19 por a1/a2, e saída do ligante sulfato via aquação dos complexos de rutênio (5). Em (6) observa-se a oxidação $\mathrm{Ru}(\mathrm{II}) / \mathrm{Ru}(\mathrm{III})$ do aqua complexo, representado por b1/b2 na Figura 19.

Conforme pode ser visualizado na Figura 19 o par redox $\mathrm{Ru}(\mathrm{III}) / \mathrm{Ru}(\mathrm{II})$ do íon trans-[Ru ${ }^{\mathrm{III}}\left(\mathrm{NH}_{3}\right)_{4}\left(\mathrm{SO}_{4}\right)$ ina $]^{+}$é observado em potenciais mais negativos que as 
correspondentes espécies trans- $-\left[\mathrm{Ru}^{\mathrm{III}}\left(\mathrm{NH}_{3}\right)_{4}\left(\mathrm{H}_{2} \mathrm{O}\right) \text { ina }\right]^{3+}$, devido ao caráter $\sigma$ doador do ligante $\mathrm{SO}_{4}{ }^{2-}[112]$, que estabiliza o estado de oxidação III do centro metálico.

\subsection{3 - Espectroscopia Eletrônica}

O espectro eletrônico do íon complexo trans- $-\left[\mathrm{Ru}^{\mathrm{III}}\left(\mathrm{NH}_{3}\right)_{4}\left(\mathrm{SO}_{4}\right) \text { ina }\right]^{+}$apresentaram um perfil similar a de outros complexos com estrutura trans $-\left[\mathrm{Ru}^{\mathrm{III}}\left(\mathrm{NH}_{3}\right)_{4}\left(\mathrm{SO}_{4}\right)(\mathrm{L})\right]^{+}(\mathrm{L}=$ isn, nic)[112], e por esse motivo as atribuições das bandas foram feitas baseando-se nos dados descritos na literatura para esses compostos[112].

O espectro eletrônico do íon trans- $\left[\mathrm{Ru}^{\mathrm{III}}\left(\mathrm{NH}_{3}\right)_{4}\left(\mathrm{SO}_{4}\right) \text { ina }\right]^{+}$está ilustrado na Figura 20. Esse complexo apresenta duas bandas, sendo uma em $325 \mathrm{~nm}\left(\varepsilon=3,0 \times 10^{3} \mathrm{M}^{-1} \mathrm{~cm}^{-1}\right)$, atribuída à transferência de carga do ligante ina para o metal (TCLM), e do ligante $\mathrm{SO}_{4}{ }^{2-} \rightarrow \mathrm{Ru}(\mathrm{III})$. A segunda banda, em $270 \mathrm{~nm}\left(\varepsilon=4,6 \times 10^{3} \mathrm{M}^{-1} \mathrm{~cm}^{-1}\right)$ foi atribuída à transição interna do ligante $\pi \rightarrow \pi^{*}$, do ligante ina.

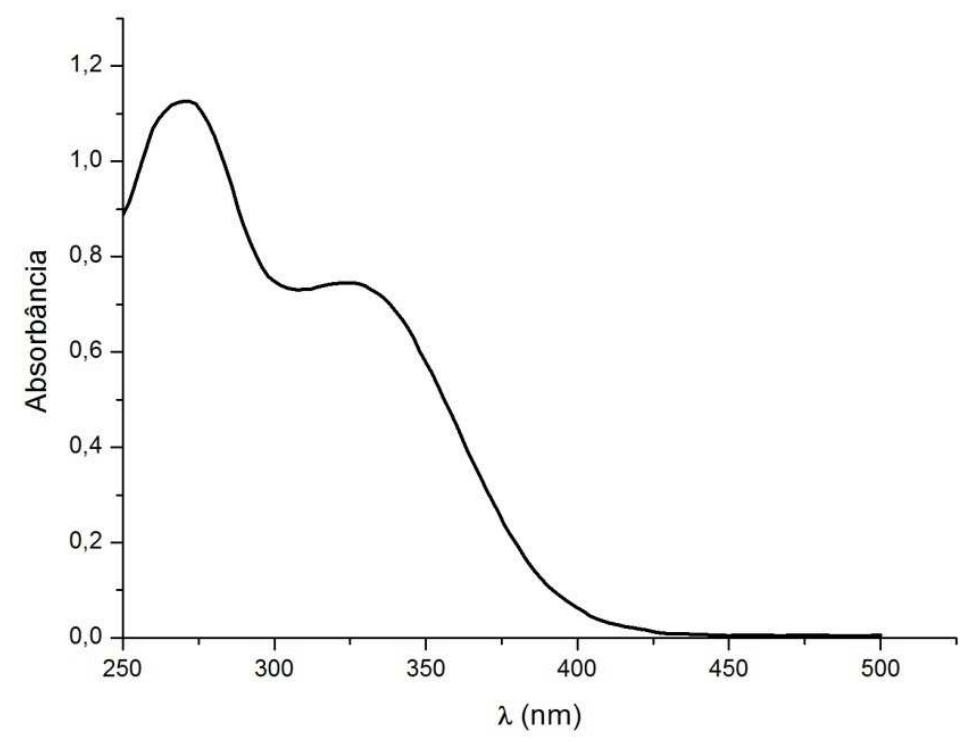

Figura 20 - Espectro eletrônico do íon trans- $\left[\mathrm{Ru}^{\mathrm{III}}\left(\mathrm{NH}_{3}\right)_{4}\left(\mathrm{SO}_{4}\right) \text { ina }\right]^{+}$em solução aquosa, $\mathrm{pH}$ 2,0 e $\mu=0,10 \mathrm{~mol} \mathrm{~L}^{-1}\left(\mathrm{CF}_{3} \mathrm{COOH} / \mathrm{CF}_{3} \mathrm{COONa}\right)$, temperatura de $25^{\circ} \mathrm{C}, \mathrm{C}_{\mathrm{Ru}}=1,75.10^{-4}$ molL ${ }^{-1}$. 


\section{2 - Caracterização do complexo trans- $\left[\mathrm{Ru}^{\mathrm{II}}\left(\mathrm{NO}^{+}\right)\left(\mathrm{NH}_{3}\right)_{4}\right.$ ina $]\left(\mathrm{BF}_{4}\right)_{3}$}

O produto trans-[Ru ${ }^{\text {II }}\left(\mathrm{NO}^{+}\right)\left(\mathrm{NH}_{3}\right)_{4}$ ina $]\left(\mathrm{BF}_{4}\right)_{3}$ trata-se de um sólido de coloração rósea clara, cuja provável estrutura é ilustrada na Figura 21.

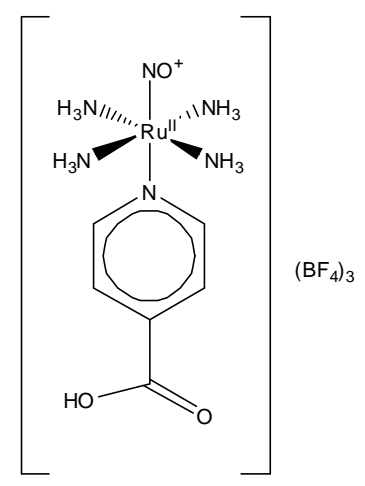

Figura 21 - Estrutura proposta para o complexo trans-[Ru $\left.{ }^{\mathrm{II}}\left(\mathrm{NO}^{+}\right)\left(\mathrm{NH}_{3}\right)_{4} \mathrm{ina}\right]\left(\mathrm{BF}_{4}\right)_{3}$

$\mathrm{O}$ resultado da análise elementar de $\mathrm{C}, \mathrm{H}, \mathrm{N}$ e $\mathrm{Ru}$ para o complexo trans-[Ru ${ }^{\mathrm{II}}\left(\mathrm{NO}^{+}\right)\left(\mathrm{NH}_{3}\right)_{4}$ ina $]\left(\mathrm{BF}_{4}\right)_{3}$ é apresentado na Tabela 3.

Tabela 3 - Dados de análise elementar para 0 complexo trans-[Ru ${ }^{\mathrm{II}}\left(\mathrm{NO}^{+}\right)\left(\mathrm{NH}_{3}\right)_{4}$ ina $]\left(\mathrm{BF}_{4}\right)_{3} \cdot 2 \mathrm{H}_{2} \mathrm{O}$

\begin{tabular}{cccc}
\hline Elemento & Teórico & Experimental & Desvio(\%) \\
\hline \% $\mathbf{~}$ & 11,64 & 11,31 & $-2,9$ \\
\% H & 3,40 & 3,22 & $-5,6$ \\
\% N & 13,58 & 12,96 & $-4,8$ \\
\% Ru & 16,33 & 16,94 & $+3,7$ \\
\hline Relação C/H & 3,42 & 3,51 & 2,6 \\
Relação C/N & 0,86 & 0,87 & 1,2 \\
Relação C/Ru & 0,71 & 0,67 & 6,0 \\
\hline
\end{tabular}


Os dados obtidos na análise elementar sugerem que existem duas águas de hidratação na estrutura do complexo, a qual foi então representada como sendo trans-[Ru ${ }^{\mathrm{II}}\left(\mathrm{NO}^{+}\right)\left(\mathrm{NH}_{3}\right)_{4}$ ina $]\left(\mathrm{BF}_{4}\right)_{3} \cdot 2 \mathrm{H}_{2} \mathrm{O}$.

\subsection{1 - Espectroscopia Vibracional}

Na Figura 22 é apresentado o espectro de infravermelho do complexo trans- $\left[\mathrm{Ru}^{\mathrm{II}}\left(\mathrm{NO}^{+}\right)\left(\mathrm{NH}_{3}\right)_{4}\right.$ ina $]\left(\mathrm{BF}_{4}\right)_{3} \cdot 2 \mathrm{H}_{2} \mathrm{O}$, onde é evidente a banda relativa ao estiramento $v\left(\mathrm{NO}^{+}\right)$em $1933 \mathrm{~cm}^{-1}$, região compatível ao reportado na literatura para outras tetraaminas de rutênio, da série trans- $\left[\mathrm{Ru}^{\mathrm{II}}\left(\mathrm{NO}^{+}\right)\left(\mathrm{NH}_{3}\right)_{4} \mathrm{~L}\right]\left(\mathrm{BF}_{4}\right)_{3}$, como por exemplo $\mathrm{L}=$ isn, nic, 4-pic e pz [55].

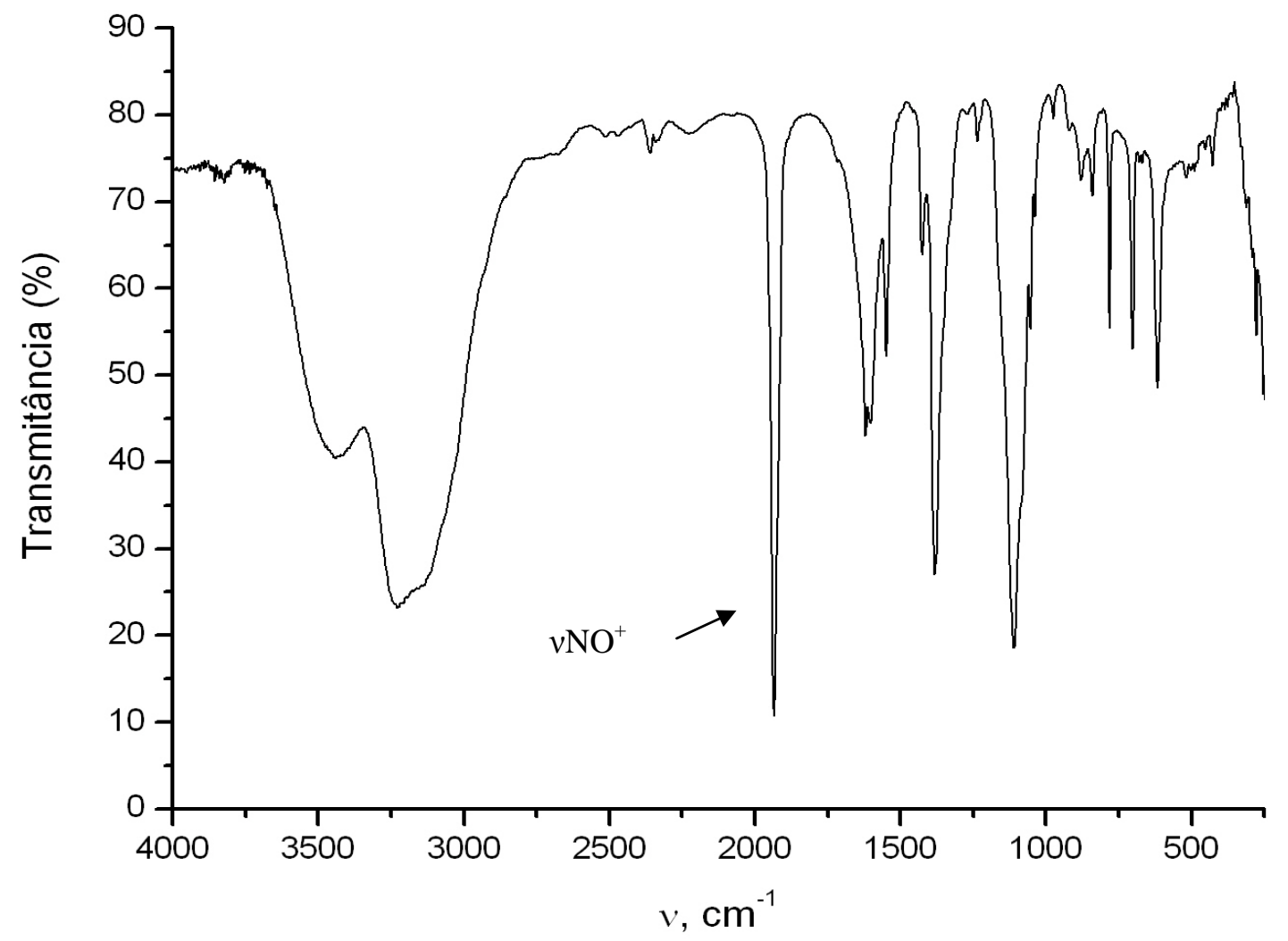

Figura 22 - Espectro na região do infravermelho para o complexo trans- $\left[\mathrm{Ru}^{\mathrm{II}}\left(\mathrm{NO}^{+}\right)(\mathrm{NH} 3)_{4}\right.$ ina $]\left(\mathrm{BF}_{4}\right)_{3} \cdot 2 \mathrm{H}_{2} \mathrm{O}$ em pastilhas de $\mathrm{KBr}$. 
Outras bandas relevantes no espectro de infravermelho para o complexo trans-[Ru ${ }^{\mathrm{II}}\left(\mathrm{NO}^{+}\right)\left(\mathrm{NH}_{3}\right)_{4}$ ina $]\left(\mathrm{BF}_{4}\right)_{3} \cdot 2 \mathrm{H}_{2} \mathrm{O}$ são apresentadas na Tabela 4[55].

Tabela 4 - Principais frequências vibracionais e respectivas atribuições para o complexo trans- $\left[\mathrm{Ru}^{\mathrm{II}}\left(\mathrm{NO}^{+}\right)\left(\mathrm{NH}_{3}\right)_{4}\right.$ ina $]\left(\mathrm{BF}_{4}\right)_{3} \cdot 2 \mathrm{H}_{2} \mathrm{O}$

\begin{tabular}{cc}
\hline Principais freqüências vibracionais $\left(\mathbf{c m}^{-1}\right)^{*}$ & Atribuições \\
\hline $3440 \mathrm{~F}$ & $v \mathrm{NH}, v(\mathrm{CH})$ \\
$3230 \mathrm{~F}$ & $v(\mathrm{NH}), v(\mathrm{CH})$ \\
$1650 \mathrm{~m}$ & $\delta(\mathrm{NH}), \delta(\mathrm{CH}), v(\mathrm{C}-\mathrm{N})$ \\
$1109 \mathrm{~F}$ & $v\left(\mathrm{BF}_{4}\right)$ \\
$618 \mathrm{~m}$ & $\delta \mathrm{Ru}-\mathrm{NO}$ \\
\hline
\end{tabular}

*Pastilha de $\mathrm{KBr} ;+/-4 \mathrm{~cm}^{-1}$; Intensidades $\mathrm{F}=$ forte, $\mathrm{m}=$ média, $\mathrm{f}=$ fraca.

\subsection{2 - Voltametria Cíclica}

Por meio de voltametria cíclica, conforme apresentado na Figura 23, foi possível observar dois pares redox para o complexo trans- $\left[\mathrm{Ru}^{\mathrm{II}}\left(\mathrm{NO}^{+}\right)\left(\mathrm{NH}_{3}\right)_{4}\right.$ ina $]\left(\mathrm{BF}_{4}\right)_{3} \cdot 2 \mathrm{H}_{2} \mathrm{O}$, sendo o primeiro com $\left(\mathrm{E}_{1 / 2}\right)_{1}=-0,175 \mathrm{~V}$ vs $\mathrm{ECS}$, referente à redução $\mathrm{NO}^{+} / \mathrm{NO}^{0} \mathrm{em}$ trans- $\left[\mathrm{Ru}^{\mathrm{II}}\left(\mathrm{NO}^{+}\right)\left(\mathrm{NH}_{3}\right)_{4} \mathrm{ina}\right]^{3+}$ (representado na Figura 23 por a1/a2), e o segundo com $\left(\mathrm{E}_{1 / 2}\right)_{2}=0,155 \mathrm{~V}$ vs ECS, referente a $\mathrm{Ru}(\mathrm{III}) / \mathrm{Ru}(\mathrm{II})$ em trans-[Ru ${ }^{\mathrm{II}}\left(\mathrm{NH}_{3}\right)_{4}\left(\mathrm{H}_{2} \mathrm{O}\right)$ ina $^{3+/ 2+}$ (representado na Figura 23 por b1/b2). 


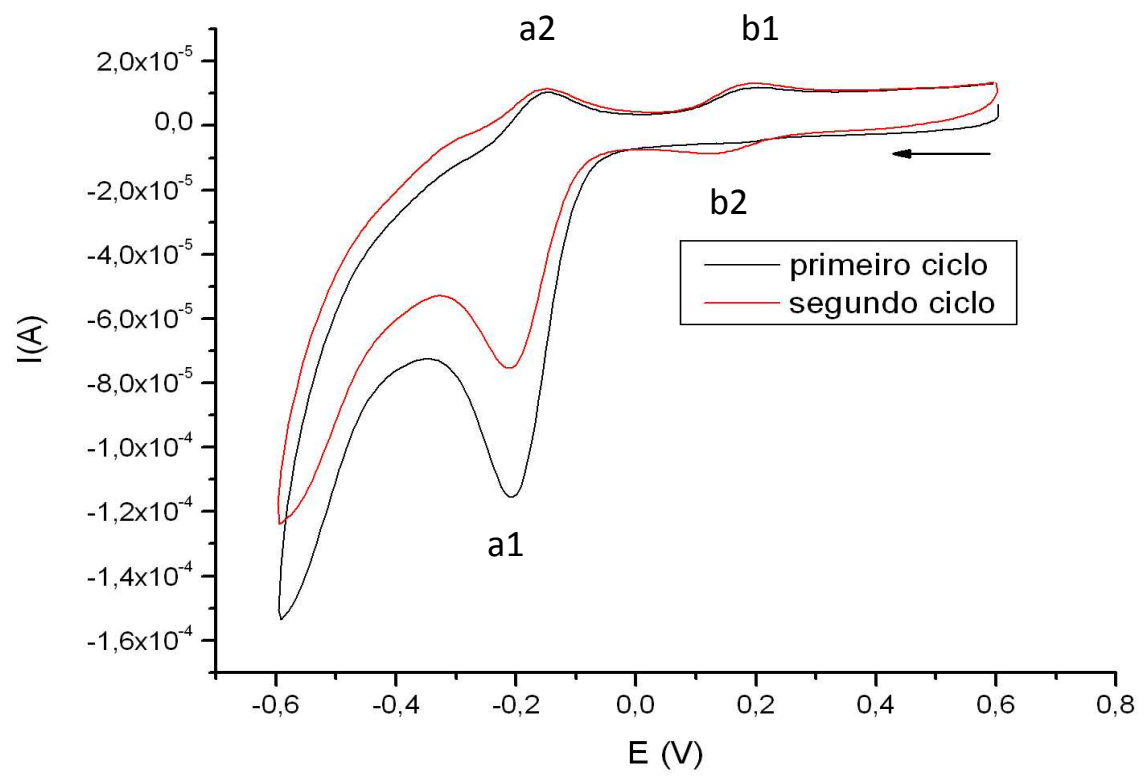

Figura 23 - Voltamogramas cíclicos do íon complexo trans- $\left[\mathrm{Ru}^{\mathrm{II}}\left(\mathrm{NO}^{+}\right)\left(\mathrm{NH}_{3}\right)_{4} \text { ina }\right]^{3+} \mathrm{em}$ solução aquosa, eletrólito $\mathrm{pH} 2,0 \mathrm{e} \mu=0,10 \mathrm{~mol} \mathrm{~L}{ }^{-1}\left(\mathrm{CF}_{3} \mathrm{COOH} / \mathrm{CF}_{3} \mathrm{COONa}\right)$, temperatura de $25^{\circ} \mathrm{C}, \mathrm{v}=100 \mathrm{mV} \mathrm{s}^{-1}$.

Os processos observados nos voltamogramas cíclicos podem ser explicados de acordo com as seguintes equações[55,83]:

trans- $\left[\mathrm{Ru}^{\mathrm{II}}\left(\mathrm{NO}^{+}\right)\left(\mathrm{NH}_{3}\right)_{4} \text { ina }\right]^{3+}+\mathrm{e}^{-} \stackrel{\text { rápido }}{\longrightarrow} \operatorname{trans}-\left[\mathrm{Ru}^{\mathrm{II}}\left(\mathrm{NO}^{0}\right)\left(\mathrm{NH}_{3}\right)_{4} \text { ina }\right]^{2+}$

trans- $\left[\mathrm{Ru}^{\mathrm{II}}\left(\mathrm{NO}^{0}\right)\left(\mathrm{NH}_{3}\right)_{4} \mathrm{ina}\right]^{2+}+\mathrm{H}_{2} \mathrm{O} \stackrel{\mathrm{k}_{-\mathrm{NO}}}{\longrightarrow}$ trans- $\left[\mathrm{Ru}^{\mathrm{II}}\left(\mathrm{H}_{2} \mathrm{O}\right)\left(\mathrm{NH}_{3}\right)_{4} \mathrm{ina}\right]^{2+}+\mathrm{NO}^{0}$

trans-[Ru ${ }^{\text {II }}\left(\mathrm{H}_{2} \mathrm{O}\right)\left(\mathrm{NH}_{3}\right)_{4}$ ina $]^{2+} \stackrel{\text { rápido }}{\longrightarrow}$ trans- $\left[\mathrm{Ru}^{\mathrm{III}}\left(\mathrm{H}_{2} \mathrm{O}\right)\left(\mathrm{NH}_{3}\right)_{4} \text { ina }\right]^{3+}+\mathrm{e}^{-}$

Reações 7 a 9 - Reação de redução monoeletrônica (7), representado na Figura 23 por a1/a2, e liberação de óxido nítrico via aquação dos nitrosilo complexos de rutênio (8). Em (9) observa-se a oxidação $\mathrm{Ru}(\mathrm{II}) / \mathrm{Ru}(\mathrm{III})$ do aqua complexo, representado por b1/b2 na Figura 23. 
Os valores obtidos por voltametria cíclica para o par $\mathrm{NO}^{+} / \mathrm{NO}^{0}$ são próximos aos reportados na literatura para os complexos de estrutura similar[116-117],

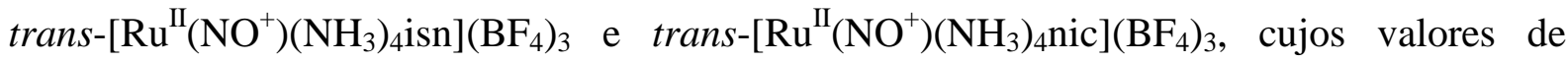
$\left(\mathrm{E}_{1 / 2}\right)\left(\mathrm{NO}^{+} / \mathrm{NO}^{0}\right)$ são, respectivamente $-0,190$ e $-0,170 \mathrm{~V}$ (vs ECS).

\subsection{3 - Espectroscopia Eletrônica}

$\mathrm{Na}$ Figura 24 está ilustrado o espectro eletrônico do íon trans-[Ru ${ }^{\mathrm{II}}\left(\mathrm{NO}^{+}\right)\left(\mathrm{NH}_{3}\right)_{4}$ ina $]^{3+}$, o qual apresentou três bandas de absorção. A banda em $230 \mathrm{~nm}$ $\left(\varepsilon=11,2 \times 10^{3} \mathrm{M}^{-1} \mathrm{~cm}^{-1}\right)$ foi atribuída à transferência de carga do metal para o ligante (TCML) $\mathrm{Ru}(\mathrm{II}) \rightarrow$ ina, a banda em $275 \mathrm{~nm}\left(\varepsilon=3,6 \times 10^{3} \mathrm{M}^{-1} \mathrm{~cm}^{-1}\right)$ foi atribuída à transição interna do ligante ina $\pi \rightarrow \pi^{*}(\mathrm{~L})$, e a banda em $\sim 330 \mathrm{~nm}\left(\varepsilon \sim 3,3 \times 10^{2} \mathrm{M}^{-1} \mathrm{~cm}^{-1}\right)$ é característica de transições d-d. As atribuições dessas bandas foram baseadas em dados da literatura para complexos similares ao apresentado neste trabalho [116-117].

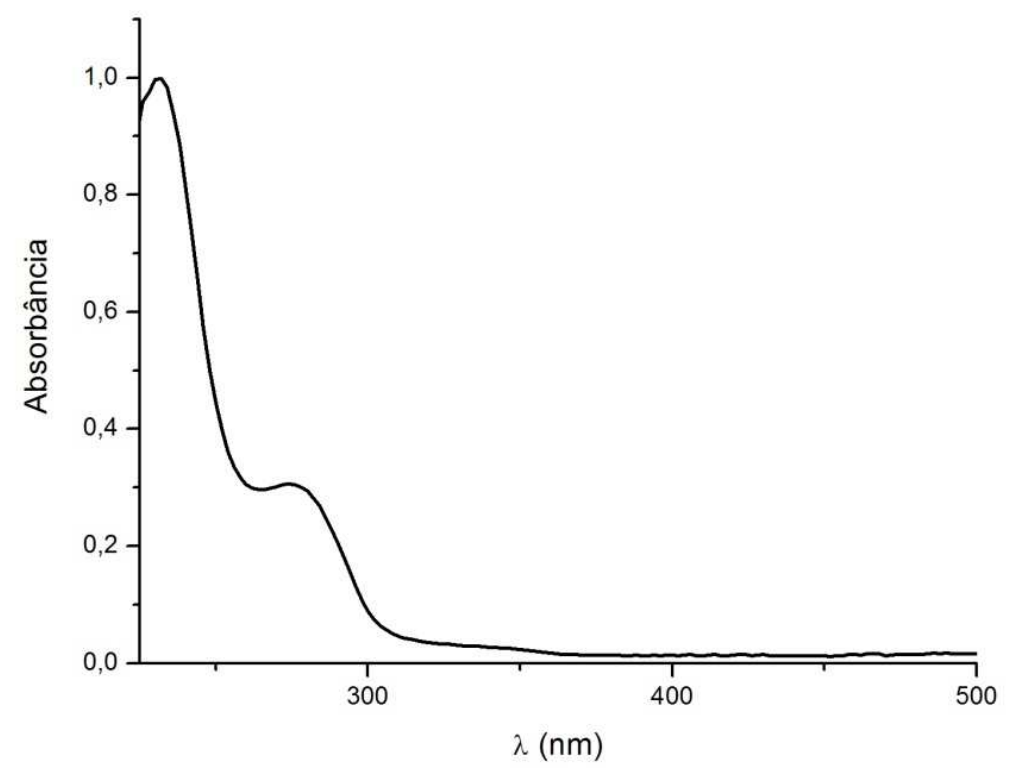

Figura 24 - Espectro eletrônico do íon trans- $\left[\mathrm{Ru}^{\mathrm{II}}\left(\mathrm{NO}^{+}\right)\left(\mathrm{NH}_{3}\right)_{4} \text { ina }\right]^{3+}$ em solução aquosa, $\mathrm{pH}$ 2,0 e $\mu=0,10 \mathrm{~mol} \mathrm{~L}{ }^{-1} \mathrm{CF}_{3} \mathrm{COOH} / \mathrm{CF}_{3} \mathrm{COONa}$, temperatura de $25^{\circ} \mathrm{C}$. 


\subsection{4 - Ressonância Magnética Nuclear de ${ }^{1} \mathrm{H}$ e ${ }^{13} \mathrm{C}$}

O espectro de Ressonância Magnética Nuclear (RMN) de ${ }^{1} \mathrm{H}$ para o complexo trans- $\left[\mathrm{Ru}^{\mathrm{II}}\left(\mathrm{NO}^{+}\right)\left(\mathrm{NH}_{3}\right)_{4}\right.$ ina $]\left(\mathrm{BF}_{4}\right)_{3}$ apresentou dois dubletos com deslocamentos químicos $(\delta)$ centrados em 8,35 e 8,73 ppm, conforme apresentado na Figura 25, referentes aos hidrogênios aromáticos respectivamente nas posições orto e meta do ligante ina coordenado ao metal. Na Figura 26 é apresentado o espectro de $\mathrm{RMN}$ de ${ }^{1} \mathrm{H}$ da molécula ina, no qual é possível observar dois dubletos referentes aos hidrogênios aromáticos das posições orto e meta, respectivamente centrados em $\delta=8,72$ e 8,02 ppm. O hidrogênio do grupo carboxilato não é observado em nenhum dos espectros apresentados (Figuras 25 e 26), conforme esperado, pelo fato de ocorrer uma troca rápida desses hidrogênios com $\mathrm{D}_{2} \mathrm{O}$. O mesmo ocorre para os hidrogênios dos ligantes $\mathrm{NH}_{3}$ coordenados ao $\mathrm{Ru}$ no plano equatorial, conforme descrito pela literatura[55].

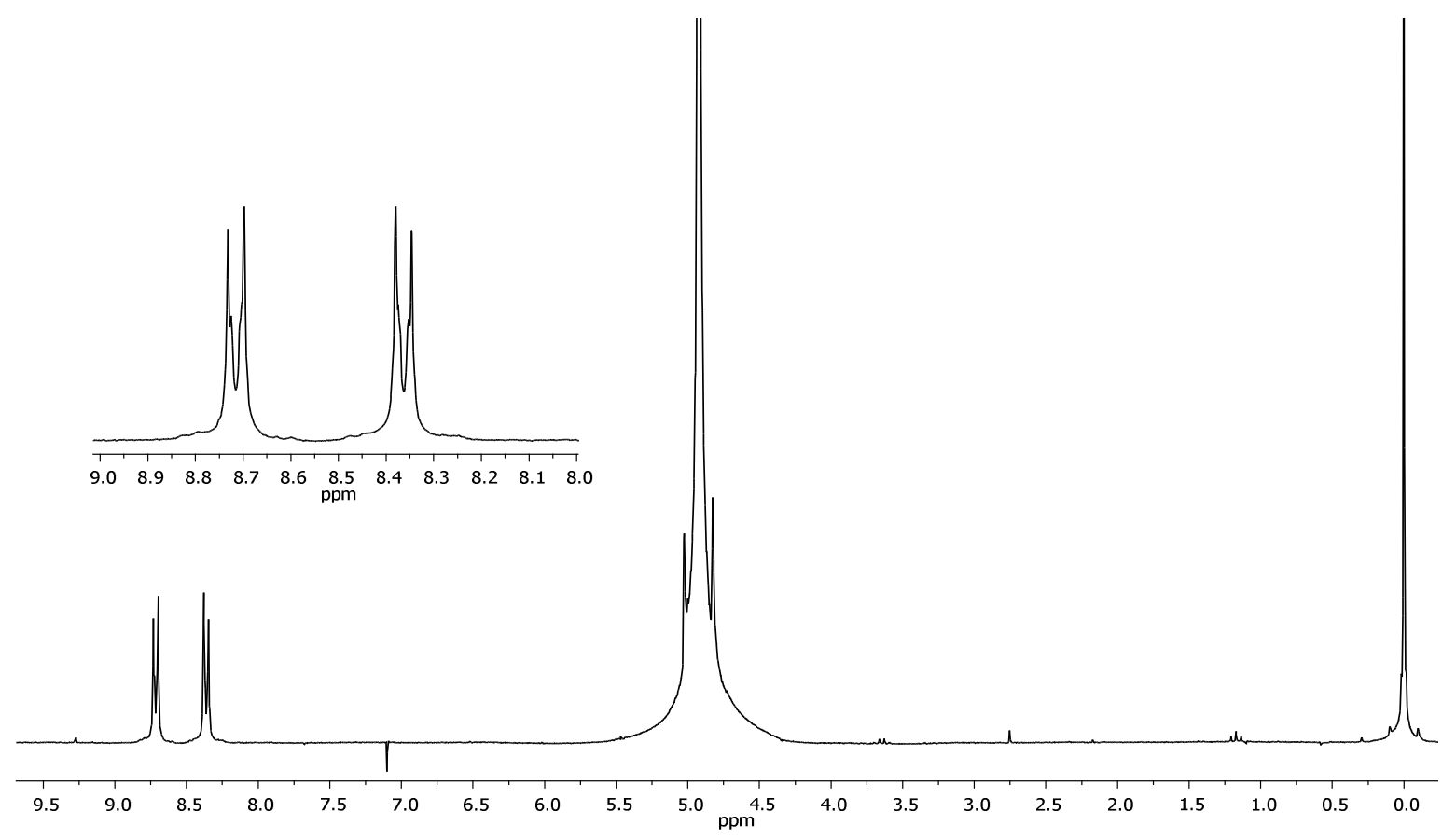

Figura 25 - Espectro de ${ }^{1} \mathrm{H} \mathrm{RMN}$ do complexo trans- $\left[\mathrm{Ru}^{\mathrm{II}}\left(\mathrm{NO}^{+}\right)\left(\mathrm{NH}_{3}\right)_{4} \text { ina }\right]_{4}\left(\mathrm{BF}_{4}\right)_{3}$ em $\mathrm{D}_{2} \mathrm{O}$, ( $\left.1 \mathrm{M} \mathrm{CF}_{3} \mathrm{COOD}\right)$. O espectro menor é uma ampliação do espectro na faixa de 8,0 a 9,0 ppm. 


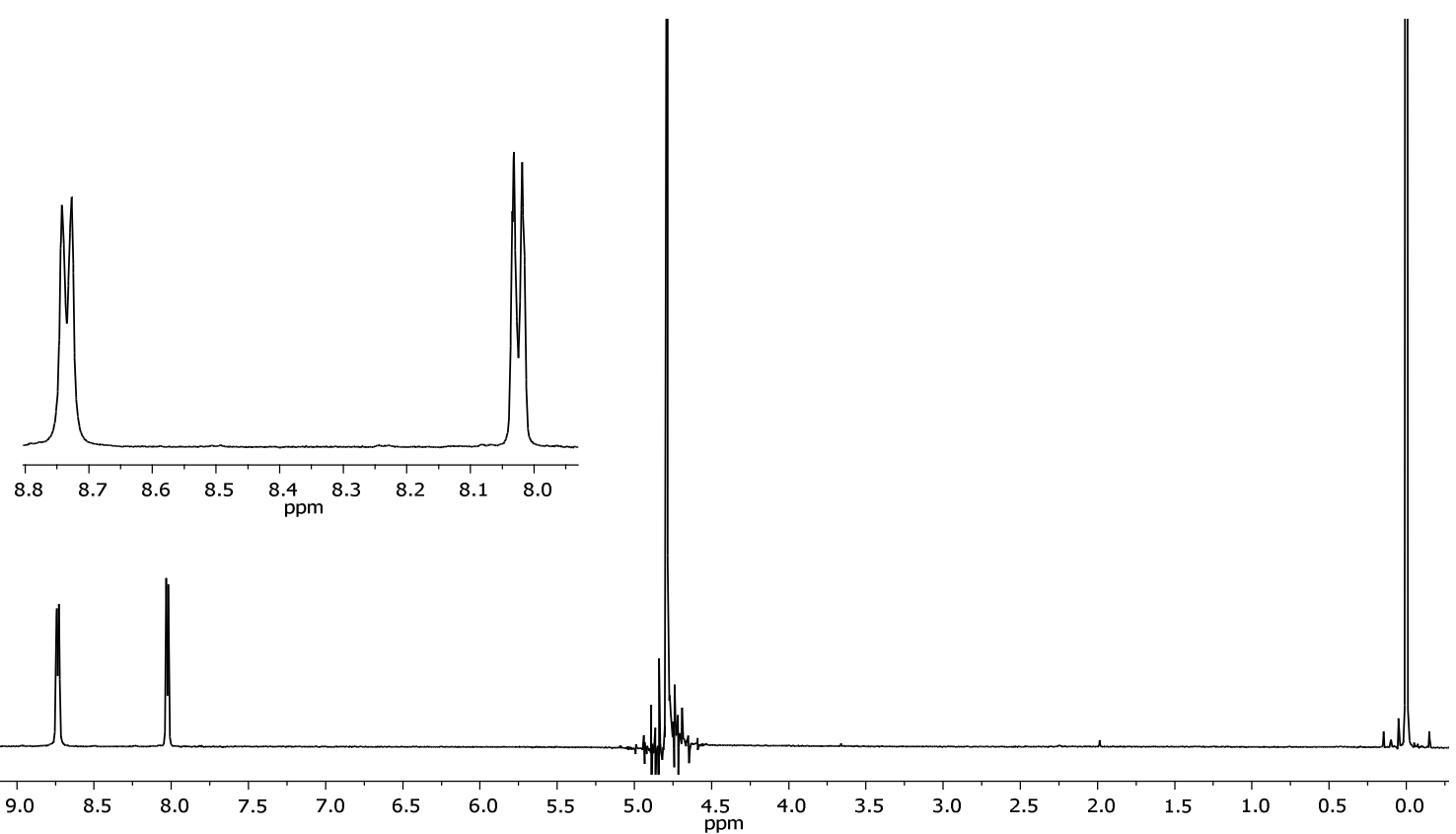

Figura 26 - Espectro de ${ }^{1} \mathrm{H}$ RMN do ácido isonicotínico (ina) em $\mathrm{D}_{2} \mathrm{O}$. O espectro menor é uma ampliação do espectro na faixa de 8,0 a 8,8 ppm.

$\mathrm{Na}$ Figura 27 está ilustrado o espectro de ${ }^{13} \mathrm{C} \quad \mathrm{RMN}$ do complexo trans-[Ru $\left.{ }^{\mathrm{II}}\left(\mathrm{NO}^{+}\right)\left(\mathrm{NH}_{3}\right)_{4} \mathrm{ina}\right]\left(\mathrm{BF}_{4}\right)_{3} \cdot 2 \mathrm{H}_{2} \mathrm{O}$. Os dois quartetos observados respectivamente em deslocamentos químicos entre 110 e 128 ppm e entre 163 e 167 ppm são referentes ao ácido trifluoroacético deuterado $\left(\mathrm{CF}_{3} \mathrm{COOD}\right)$ utilizado para ajustar o $\mathrm{pH}$ da solução. Os sinais em 130,4; 147,1; e 153,9 ppm foram atribuídos aos carbonos aromáticos do ligante ina, assim como o sinal em 169,7 ppm, referente ao carbono da carboxila desse ligante, conforme está ilustrado na Figura 27. Todos os sinais observados estão de acordo com a estrutura proposta para o complexo trans- $\left[\mathrm{Ru}^{\mathrm{II}}\left(\mathrm{NO}^{+}\right)\left(\mathrm{NH}_{3}\right)_{4} \mathrm{ina}\right]\left(\mathrm{BF}_{4}\right)_{3} \cdot 2 \mathrm{H}_{2} \mathrm{O}$. 


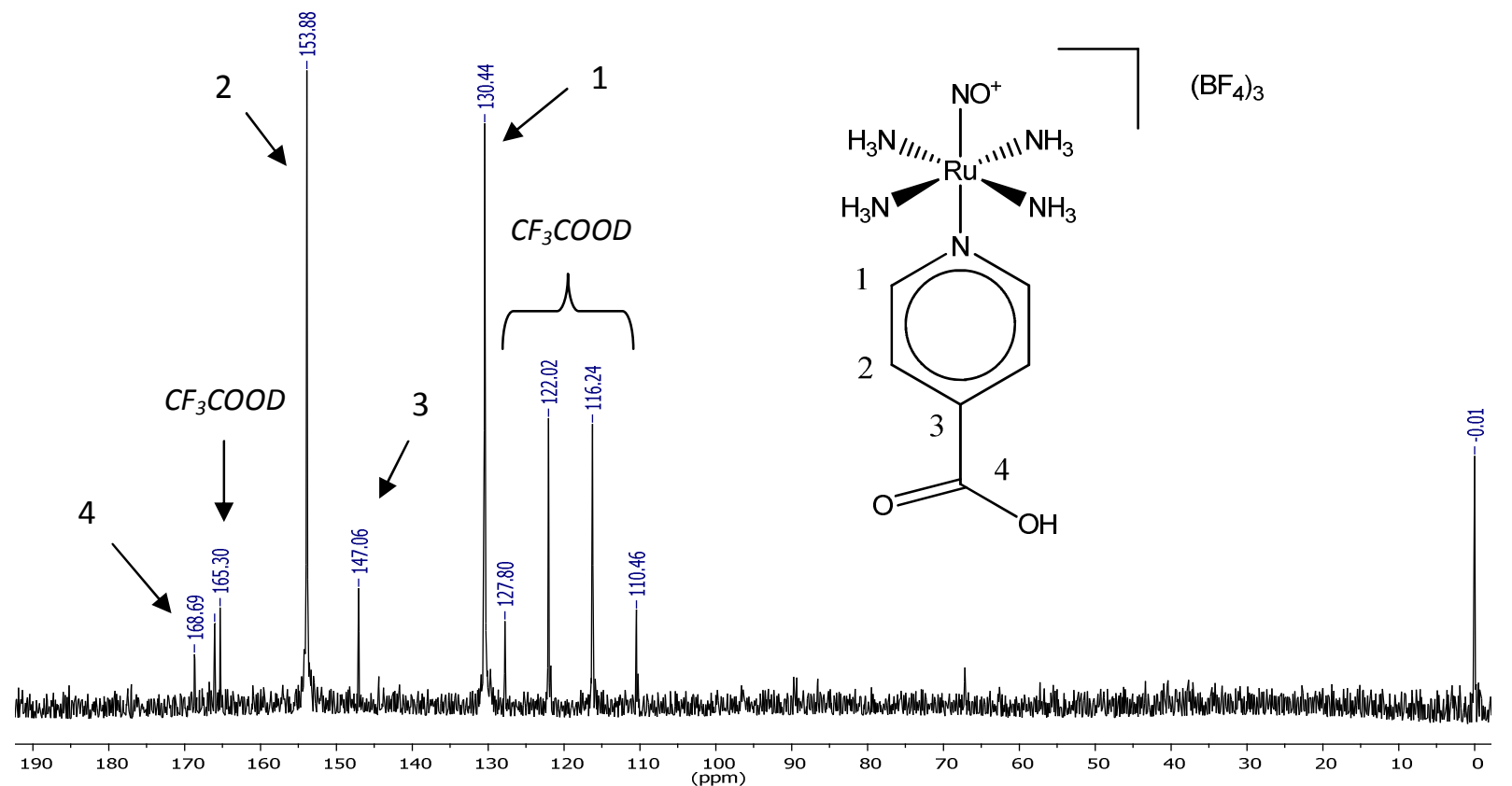

Figura 27 - Espectro de ${ }^{13} \mathrm{C}$ RMN do complexo trans- $\left[\mathrm{Ru}^{\mathrm{II}}\left(\mathrm{NO}^{+}\right)\left(\mathrm{NH}_{3}\right)_{4}\right.$ ina $]\left(\mathrm{BF}_{4}\right)_{3}$ em $\mathrm{D}_{2} \mathrm{O}$, (solução $1 \mathrm{M} \mathrm{CF}_{3} \mathrm{COOD}$ ). Os números $1,2,3,4$ correspondem aos carbonos na estrutura do complexo e os respectivos sinais no espectro.

\section{3 - Ancoramento dos complexos de rutênio nos dendrímeros PAMAM G0 e G2}

O ancoramento dos complexos de rutênio nos dendrímeros PAMAM foi realizado por meio da reação entre trans-[ $\left[\mathrm{Ru}^{\mathrm{III}}\left(\mathrm{NH}_{3}\right)_{4}\left(\mathrm{SO}_{4}\right)\right.$ ina $] \mathrm{Cl}$ e os dendrímeros $\mathrm{G} 0$ e G2. Os produtos obtidos nessas sínteses foram submetidos à reação com NO gasoso para a obtenção dos respectivos nitrosilo complexos de rutênio ligados aos dendrímeros. Ao final da reação com $\mathrm{NO}_{(\mathrm{g})}$, os compostos foram precipitados, secos sob vácuo e em seguida purificados por meio de cromatografia de exclusão por tamanho, utilizando-se Sephadex G-25 como fase estacionária. Nos tópicos seguintes, são apresentados os resultados de caracterização dos produtos obtidos na reação entre trans- $\left[\mathrm{Ru}^{\mathrm{III}}\left(\mathrm{NH}_{3}\right)_{4}\left(\mathrm{SO}_{4}\right)\right.$ ina $] \mathrm{Cl}$ e os dendrímeros G0 e G2 e posteriormente os resultados de caracterização dos respectivos nitrosilo complexos. 


\subsection{2 - Reação entre trans-[ $\left[\mathrm{Ru}^{\mathrm{III}}\left(\mathrm{NH}_{3}\right)_{4}\left(\mathrm{SO}_{4}\right)\right.$ ina $] \mathrm{Cl}$ e pamam G0 e G2}

Os produtos obtido pela reação entre o complexo trans- $\left[\mathrm{Ru}^{\mathrm{III}}\left(\mathrm{NH}_{3}\right)_{4}\left(\mathrm{SO}_{4}\right)\right.$ ina $] \mathrm{Cl}$ e os dendrímeros PAMAM de geração 0 e 2 levaram, respectivamente, aos produtos G0/trans-[Ru ${ }^{\mathrm{III}}\left(\mathrm{NH}_{3}\right)_{4}\left(\mathrm{SO}_{4}\right)$ ina $] \mathrm{Cl}$ (designado por simplicidade por G0/RuSO4) e G2/trans-[Ru ${ }^{\text {III }}\left(\mathrm{NH}_{3}\right)_{4}\left(\mathrm{SO}_{4}\right)$ ina $] \mathrm{Cl}$ (designado por G2/RuSO4), ambos os compostos com características de óleo. Por esse motivo não foi possível obter resultados de análise elementar para esses produtos. Na Figura 28 é apresentado o espectro de infravermelho do produto G0/RuSO4, do dendrímero PAMAM G0 e do complexo trans-[Ru ${ }^{\mathrm{III}}\left(\mathrm{NH}_{3}\right)_{4}\left(\mathrm{SO}_{4}\right)$ ina $] \mathrm{Cl}$.

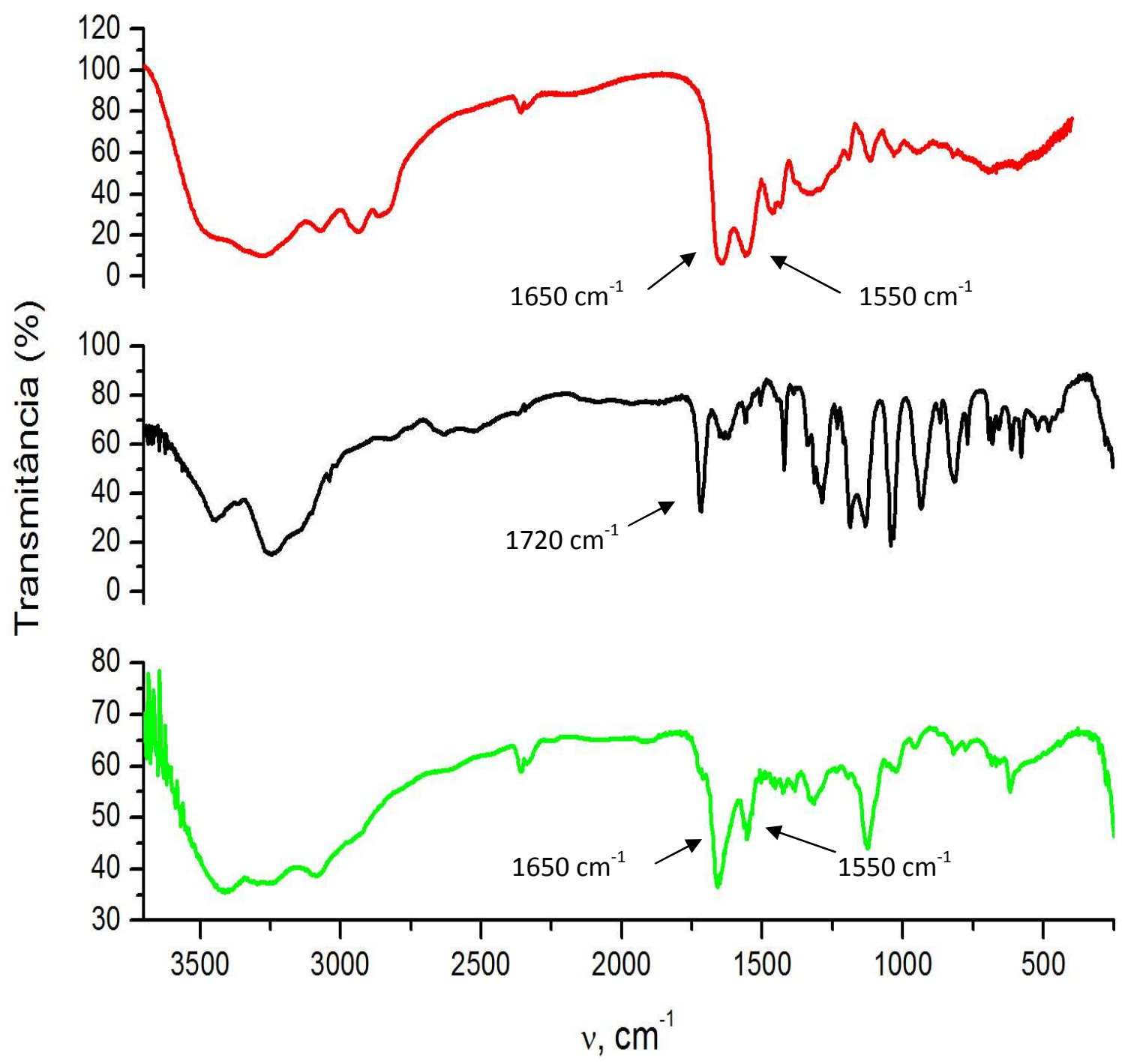

Figura 28 - Espectros de infravermelho do dendrímero PAMAM G0 (-) e dos complexos trans- $\left[\mathrm{Ru}^{\mathrm{III}}\left(\mathrm{NH}_{3}\right)_{4}\left(\mathrm{SO}_{4}\right)\right.$ ina $] \mathrm{Cl}(-)$ e G0/RuSO4 (-), em pastilha de $\mathrm{KBr}$. 
Comparando-se esses espectros foi possível verificar que para o complexo trans-[ $\left[\mathrm{Ru}^{\mathrm{III}}\left(\mathrm{NH}_{3}\right)_{4}\left(\mathrm{SO}_{4}\right)\right.$ ina $] \mathrm{Cl}$ existe uma banda em $1720 \mathrm{~cm}^{-1}$ atribuída ao grupo carboxila do ligante ina (conforme apresentado anteriormente na Tabela 2), a qual é ausente no espectro do PAMAM G2 e do produto G0/RuSO4. Esse é um forte indício do ancoramento do complexo no dendrímero por meio da formação da ligação peptídica (amida). Uma segunda observação importante é a alteração nas intensidades relativas das bandas em 1650 e 1550 $\mathrm{cm}^{-1}$, atribuídas, respectivamente às vibrações amida $\mathrm{I}(\mathrm{vCO})$ e amida II $\left(\delta_{\mathrm{N}-\mathrm{H}}\right)$, as quais estão presentes no espectro do PAMAM G0 e do produto G0/RuSO4. Utilizando-se a banda em $1650 \mathrm{~cm}^{-1}$ como referência, é possível verificar que a banda em $1550 \mathrm{~cm}^{-1}$ tem menor intensidade no produto G0/RuSO4 do que no PAMAM G0 (Figura 28). Essa mudança pode ser atribuída à diminuição do número ligações N-H no PAMAM após o ancoramento do complexo. Esses resultados corroboram com dados reportados na literatura para compostos similares[96]. Outras bandas de infravermelho relevantes para o composto G0/RuSO4 são os estiramento $v\left(\mathrm{SO}^{2-}\right)$ em $1125 \mathrm{~cm}^{-1}$ e $v(\mathrm{NH})$ em 3290 e $3250 \mathrm{~cm}^{-1}$.

Na Figura 29 são apresentados os espectros de infravermelho do composto G2/RuSO4, PAMAM G2 e do complexo trans-[Ru ${ }^{\mathrm{III}}\left(\mathrm{NH}_{3}\right)_{4}\left(\mathrm{SO}_{4}\right)$ ina $] \mathrm{Cl}$. As interpretações para esses espectros foram elaboradas de forma análoga às realizadas, anteriormente, para o ancoramento no PAMAM G0 (Figura 28). Assim, no espectro referente ao produto G2/RuSO4 (Figura 29) também é possível verificar a ausência da banda em $1720 \mathrm{~cm}^{-1}$, a qual está presente no espectro do composto trans-[ $\left[\mathrm{Ru}^{\mathrm{III}}\left(\mathrm{NH}_{3}\right)_{4}\left(\mathrm{SO}_{4}\right)\right.$ ina $] \mathrm{Cl}$, sendo este um indício da formação da ligação peptídica. Além disso, ao comparar-se as intensidades relativas das bandas em 1550 e $1650 \mathrm{~cm}^{-1}$ do PAMAM G2 e do produto G2/RuSO4, também observou-se uma ligeira diminuição da banda em $1550 \mathrm{~cm}^{-1}$ para o composto G2/RuSO4. Essa alteração não ocorreu de forma tão significativa quanto foi observado para o ancoramento no PAMAM G0. Isso pode ter acontecido devido ao ancoramento incompleto dos complexos de rutênio, ou 

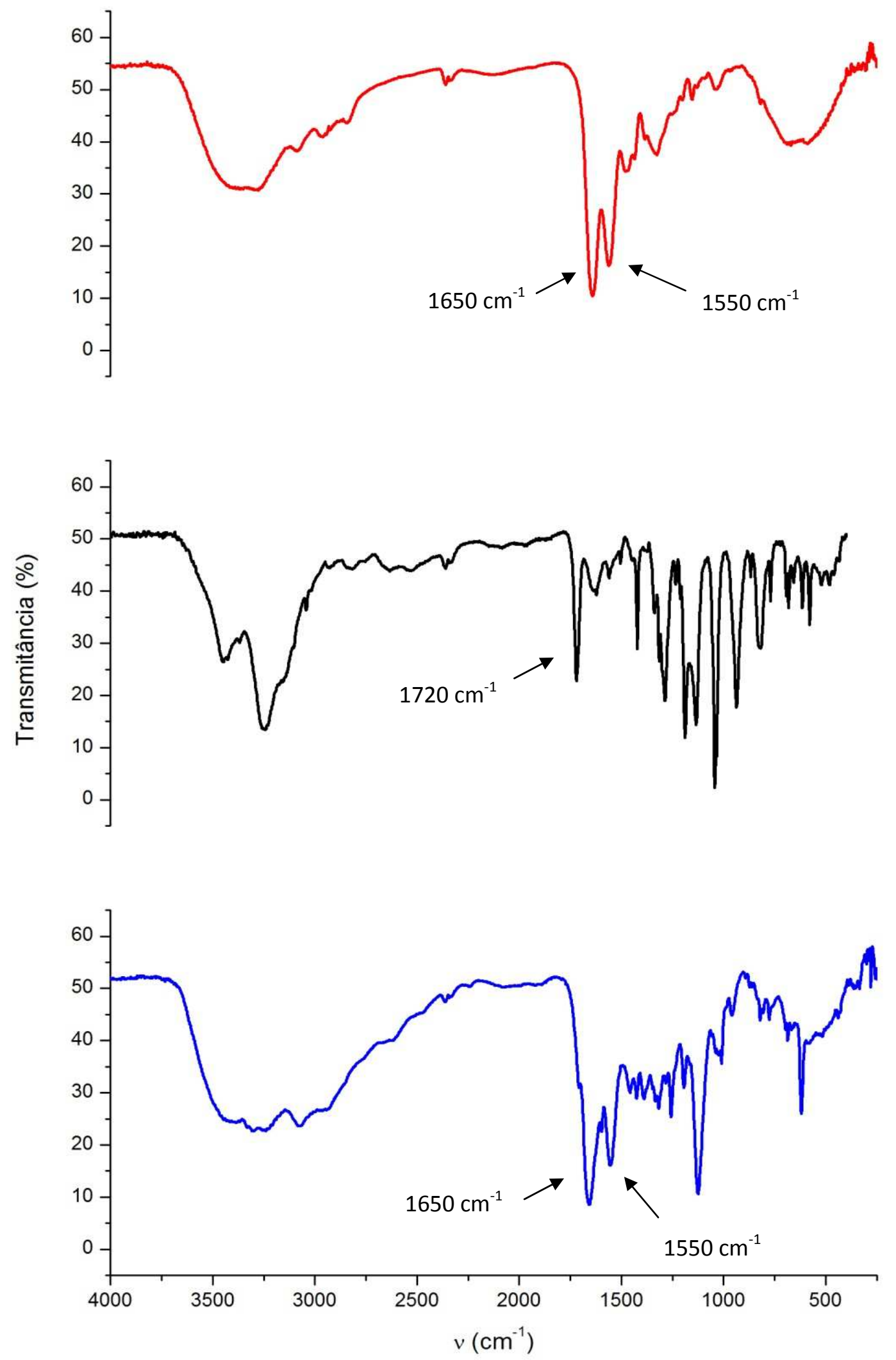

Figura 29 - Espectros de infravermelho do dendrímero PAMAM G2 (-), do complexo trans-[ $\mathrm{Ru}^{\mathrm{III}}\left(\mathrm{NH}_{3}\right)_{4}\left(\mathrm{SO}_{4}\right)$ ina $] \mathrm{Cl}$ (-) e do composto G0/RuSO4 e (-), em pastilha de $\mathrm{KBr}$. 
seja, possivelmente não ocorreu a reação entre todos os grupos $-\mathrm{NH}_{2}$ do PAMAM G2 e o complexo trans-[Ru ${ }^{\mathrm{III}}\left(\mathrm{NH}_{3}\right)_{4}\left(\mathrm{SO}_{4}\right)$ ina $] \mathrm{Cl}$. Dessa forma, a diminuição da intensidade da banda em $1550 \mathrm{~cm}^{-1}$, que é resultado da redução no número de ligações N-H após o ancoramento, não ficou tão evidente para o produto G2/RuSO4 como foi observado para G0/RuSO4. Outras bandas de infravermelho relevantes para o composto G2/RuSO4 são os estiramento v( $\mathrm{SO}^{2-}{ }^{2-}$ em $1125 \mathrm{~cm}^{-1}$ e $v(\mathrm{NH})$ em 3290 e $3250 \mathrm{~cm}^{-1}$.

As Figura 30 e 31 ilustram o comportamento eletroquímico dos compostos G0/RuSO4 e G2/RuSO4. É possível observar um comportamento similar para ambos os compostos: dois processos redox, sendo o primeiro $\left(\mathrm{E}_{1 / 2}\right)_{1}=0,055$ vs ECS (a1/a2 na Figura 30) referente ao par $\mathrm{Ru}(\mathrm{III}) / \mathrm{Ru}(\mathrm{II})$ em GX/trans-[Ru ${ }^{\mathrm{III}}\left(\mathrm{NH}_{3}\right)_{4}\left(\mathrm{SO}_{4}\right) \mathrm{ina}^{3+/ 2+}$ (em que $\mathrm{X}=0$ e 2, representa a geração do dendrímero) e o segundo $\left(\mathrm{E}_{1 / 2}\right)_{2}=0,190 \mathrm{~V}$ vs ECS (b1/b2 na Figura 31), referente ao par $\mathrm{Ru}(\mathrm{III}) / \mathrm{Ru}(\mathrm{II})$ em $\mathrm{GX} /$ trans- $-\left[\mathrm{Ru}^{\mathrm{III}}\left(\mathrm{NH}_{3}\right)_{4}\left(\mathrm{H}_{2} \mathrm{O}\right) \mathrm{ina}\right]^{3+/ 2+}$. Esses resultados foram similares aos obtidos para o complexo trans-[ $\mathrm{Ru}{ }^{\mathrm{III}}\left(\mathrm{NH}_{3}\right)_{4}\left(\mathrm{SO}_{4}\right)$ ina $] \mathrm{Cl}$ não ligado ao dendrímero (conforme apresentado no item 4.1.2, Figura 19).

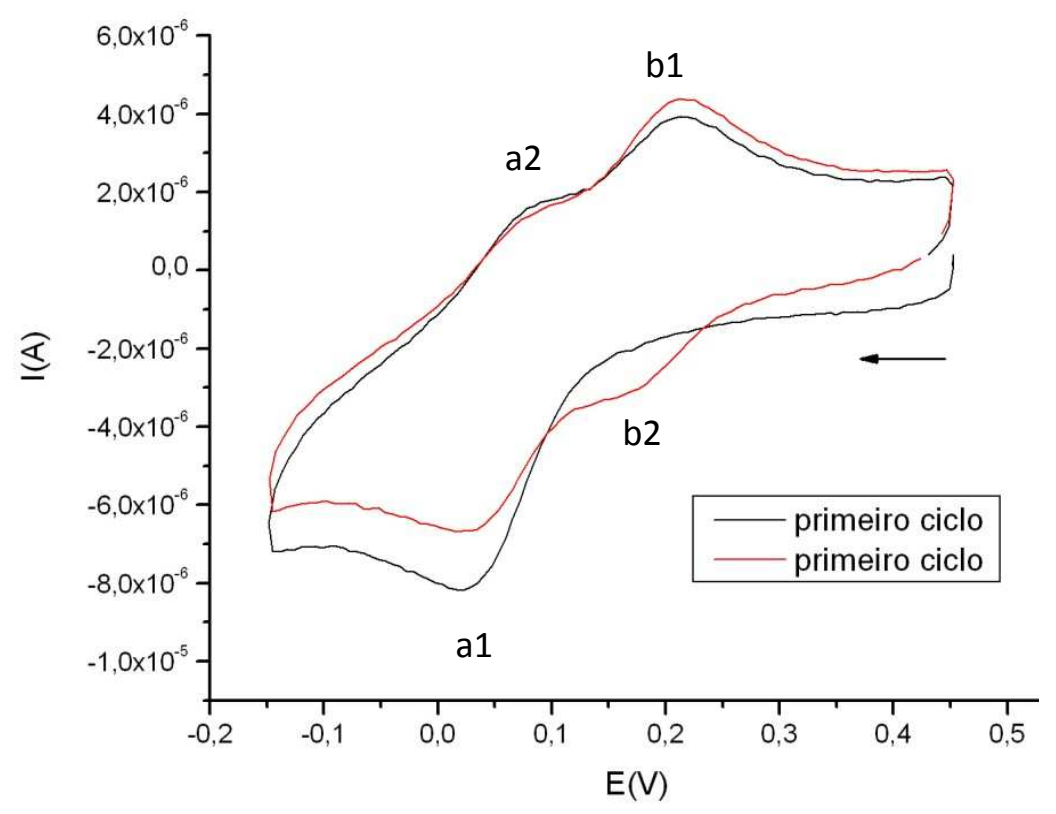

Figura 30 - Voltamograma cíclico do complexo G0/RuSO4 em solução aquosa, pH 2,0 e $\mu=$ $0,10 \mathrm{~mol} \mathrm{~L}^{-1} \mathrm{CF}_{3} \mathrm{COOH} / \mathrm{CF}_{3} \mathrm{COONa}$, temperatura de $25^{\circ} \mathrm{C}, \mathrm{v}=200 \mathrm{mV} \mathrm{s}^{-1}$. 


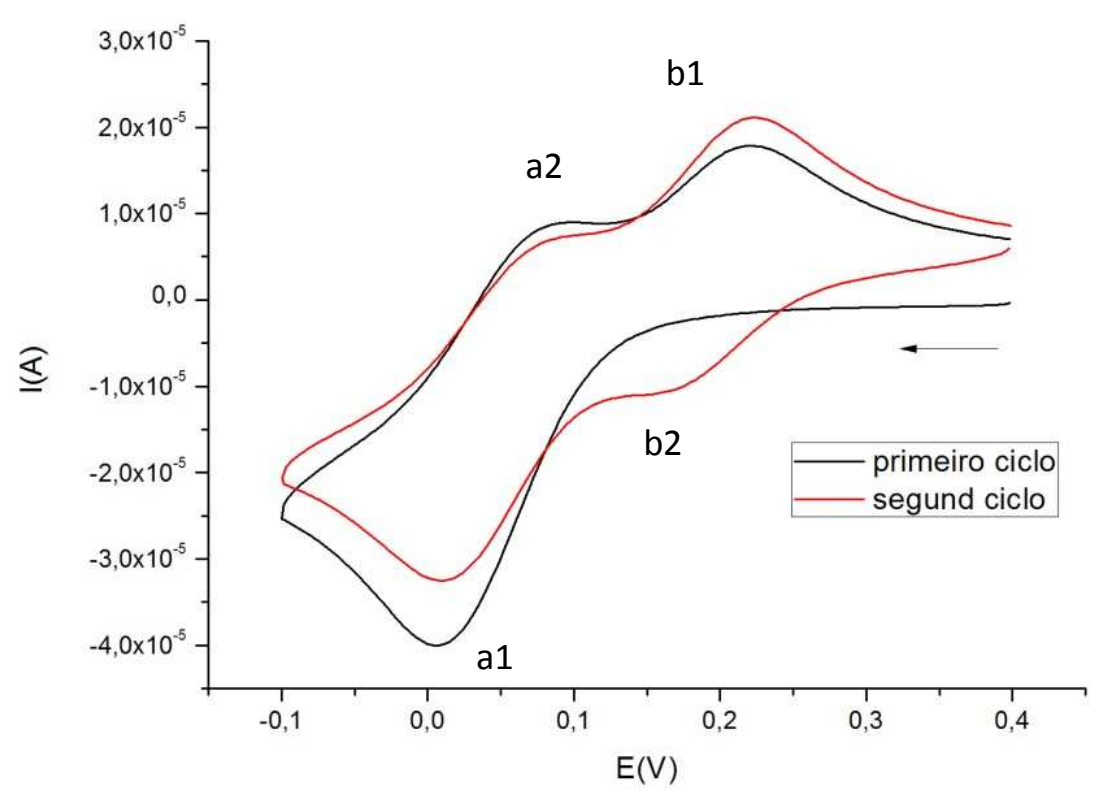

Figura 31 - Voltamograma cíclico do complexo G0/RuSO4 em solução aquosa, pH 2,0 e $\mu=$ $0,10 \mathrm{~mol} \mathrm{~L}^{-1} \mathrm{CF}_{3} \mathrm{COOH} / \mathrm{CF}_{3} \mathrm{COONa}$, temperatura de $25^{\circ} \mathrm{C}, \mathrm{v}=200 \mathrm{mV} \mathrm{s}^{-1}$

\section{4 - Caracterização dos compostos G0/trans- $\left[\mathrm{Ru}^{\mathrm{II}}\left(\mathrm{NO}^{+}\right)\left(\mathrm{NH}_{3}\right)_{4}\right.$ ina $]\left(\mathrm{BF}_{4}\right)_{3}$ e} G2/trans-[Ru $\left.{ }^{\text {II }}\left(\mathrm{NO}^{+}\right)\left(\mathrm{NH}_{3}\right)_{4} \mathrm{ina}\right]\left(\mathrm{BF}_{4}\right)_{3}$

\subsection{1 - Análise Elementar de C, H, N e Ru}

A fórmula estrutural proposta tentativamente para o complexo G0/trans- $\left[\mathrm{Ru}^{\mathrm{II}}\left(\mathrm{NO}^{+}\right)\left(\mathrm{NH}_{3}\right)_{4}\right.$ ina $]\left(\mathrm{BF}_{4}\right)_{3}$ (designado por simplicidade como G0/RuNO) é apresentada na Figura 32. Os resultados de análise elementar de C, H, N e Ru para esse composto está exposto na Tabela 5. 


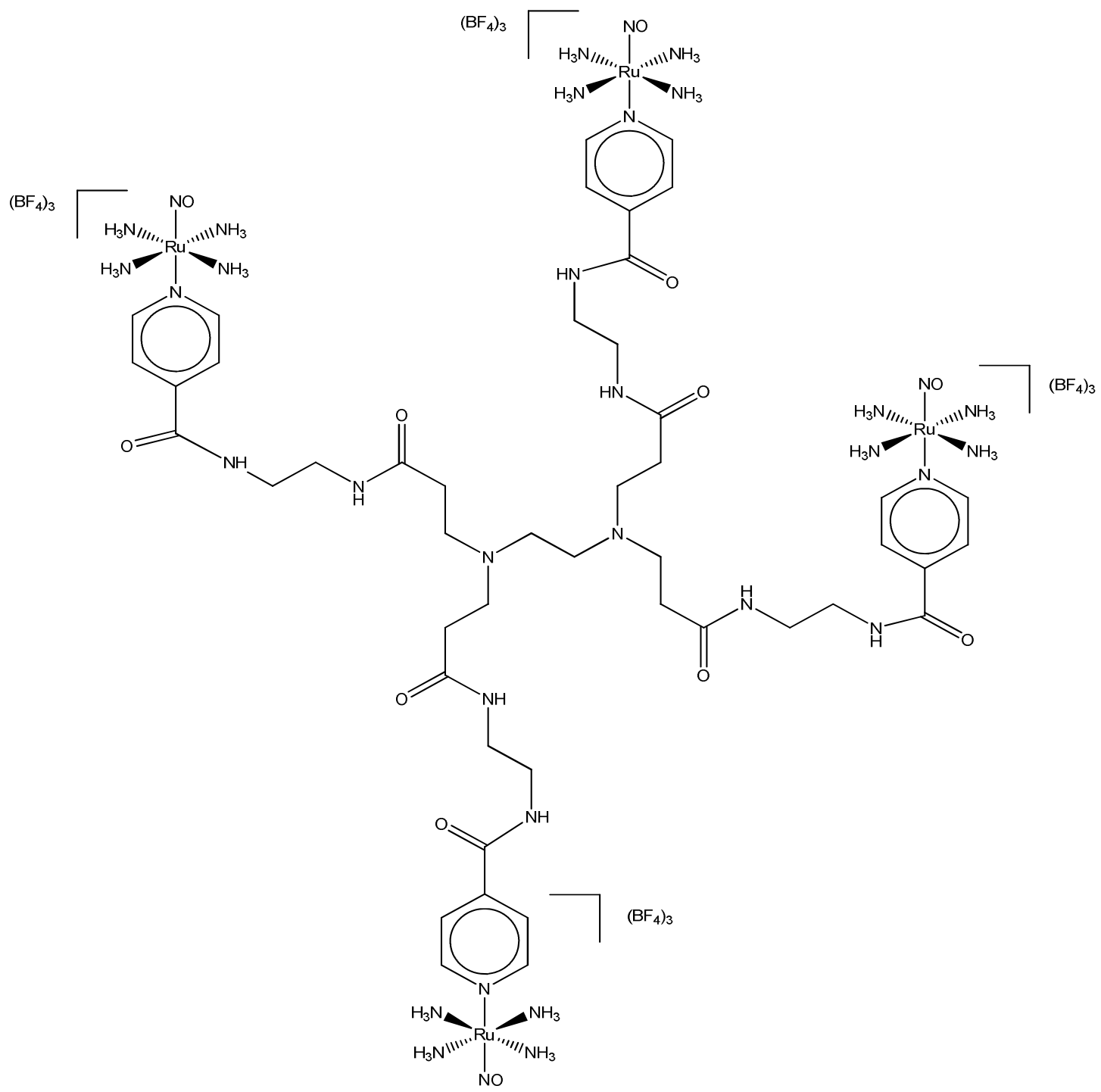

Figura 32 - Fórmula estrutural proposta para o complexo G0/RuNO

Tabela 5 - Dados de análise elementar de C, H, N e Ru para o complexo G0/RuNO

\begin{tabular}{cccc}
\hline Elemento & Teórico & Experimental & Desvio (\%) \\
\hline \% C & 19,91 & 20,46 & 2,8 \\
\% H & 3,92 & 4,80 & 7,0 \\
\% N & 17,16 & 16,24 & $-5,4$ \\
\% Ru & 14,57 & 13,70 & $-6,0$ \\
\hline Relação C/H & 5,08 & 4,26 & $-16,10$ \\
Relação C/N & 1,16 & 1,26 & 8,60 \\
Relação C/Ru & 1,37 & 1,49 & 8,80 \\
\hline
\end{tabular}


A Figura 33 é ilustra a fórmula estrutural do PAMAM G2, que tem 16 aminas superficiais, as quais podem reagir com a carboxila do ligante ina coordenado ao rutênio. E a Tabela 6 apresenta dos resultados de análise elementar de $\mathrm{C}, \mathrm{H}$ e $\mathrm{N}$ para o composto G2/trans-[Ru ${ }^{\mathrm{II}}\left(\mathrm{NO}^{+}\right)\left(\mathrm{NH}_{3}\right)_{4}$ ina $]\left(\mathrm{BF}_{4}\right)_{3}$ (representado por simplicidade por $\mathrm{G} 2 / \mathrm{RuNO}$ ).

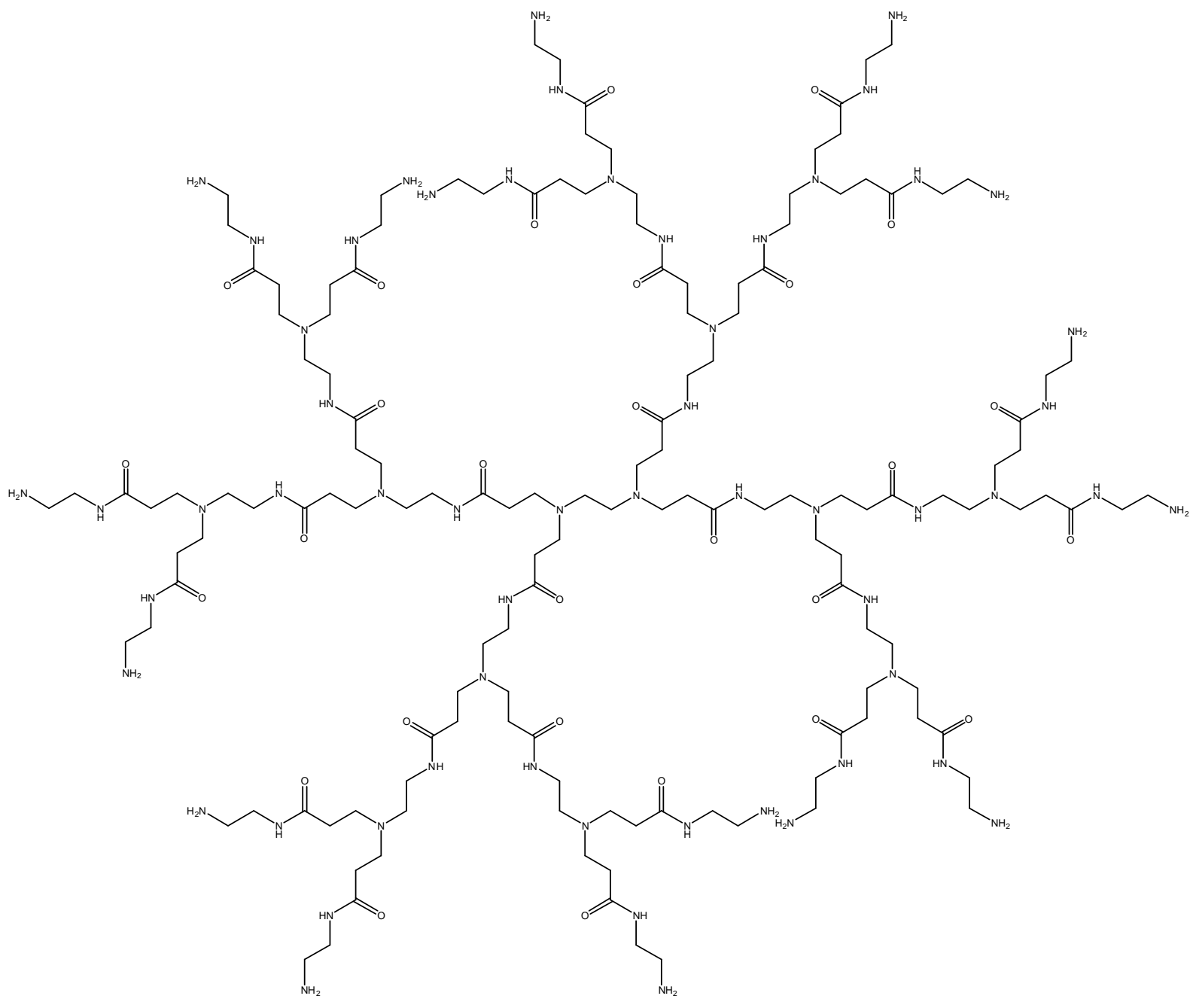

Figura 33 - Fórmula Estrutural do dendrímero PAMAM geração 2

Tabela 6 - Dados de análise elementar de C, H, N e Ru para o complexo G2/RuNO

\begin{tabular}{cccc}
\hline Elemento & Teórico & Experimental & Desvio (\%) \\
\hline \% C & 23,26 & 18,94 & $-18,57$ \\
\% H & 4,30 & 4,00 & $-6,98$ \\
\% N & 17,55 & 12,73 & $-27,46$ \\
\% Ru & 13,16 & 10,20 & $-22,49$ \\
\hline Relação C/H & 5,41 & 4,74 & $-11,00$ \\
Relação C/N & 1,32 & 1,49 & $+14,1$ \\
Relação C/Ru & 1,76 & 1,85 & $+4,86$ \\
\hline
\end{tabular}


É possível observar desvios consideráveis entre os valores teóricos e experimentais nos resultados de análise elementar apresentados na Tabela 5 para o composto G0/RuNO, principalmente em relação aos teores de H. Para o composto G2/RuNO, os desvios na análise elementar de $\mathrm{C}$, $\mathrm{H}$ e $\mathrm{N}$ (Tabela 6) foram ainda maiores que os observados para o composto G0/RuNO. Isso pode ser atribuído ao ancoramento incompleto (menos que 16 complexos de rutênio ligados a cada G2, que apresenta 16 aminas superficiais) possivelmente ocasionado por impedimento estérico. A literatura relata dificuldades na caracterização de moléculas ramificadas[118], como dendrímeros[119]. Alguns autores notam discrepâncias entre os valores calculados e os obtidos experimentalmente nas análises elementares de compostos ligados a dendrímeros, devido a presença de impurezas e solventes na estrutura dessas moléculas [96,120-122].

Apesar dos resultados de análise elementar apresentarem desvios consideráveis entre os valores teóricos e experimentais, as demais técnicas instrumentais utilizadas na caracterização desses compostos sugerem que a síntese ocorreu de forma satisfatória, conforme será apresentado a seguir.

\subsection{2 - Espectroscopia Eletrônica}

O espectro eletrônico do complexo G0/RuNO é similar ao do complexo livre (não ligado ao dendrímero), com bandas em $232 \mathrm{~nm}\left(\varepsilon=4,0 \times 10^{4} \mathrm{M}^{-1} \mathrm{~cm}^{-1}\right), 270 \mathrm{~nm}(\varepsilon=1,48 \mathrm{x}$ $\left.10^{4} \mathrm{M}^{-1} \mathrm{~cm}^{-1}\right)$ e $\sim 330 \mathrm{~nm}\left(\varepsilon \sim 1,1 \times 10^{3} \mathrm{M}^{-1} \mathrm{~cm}^{-1}\right)$, conforme apresentado na Figura 34. 


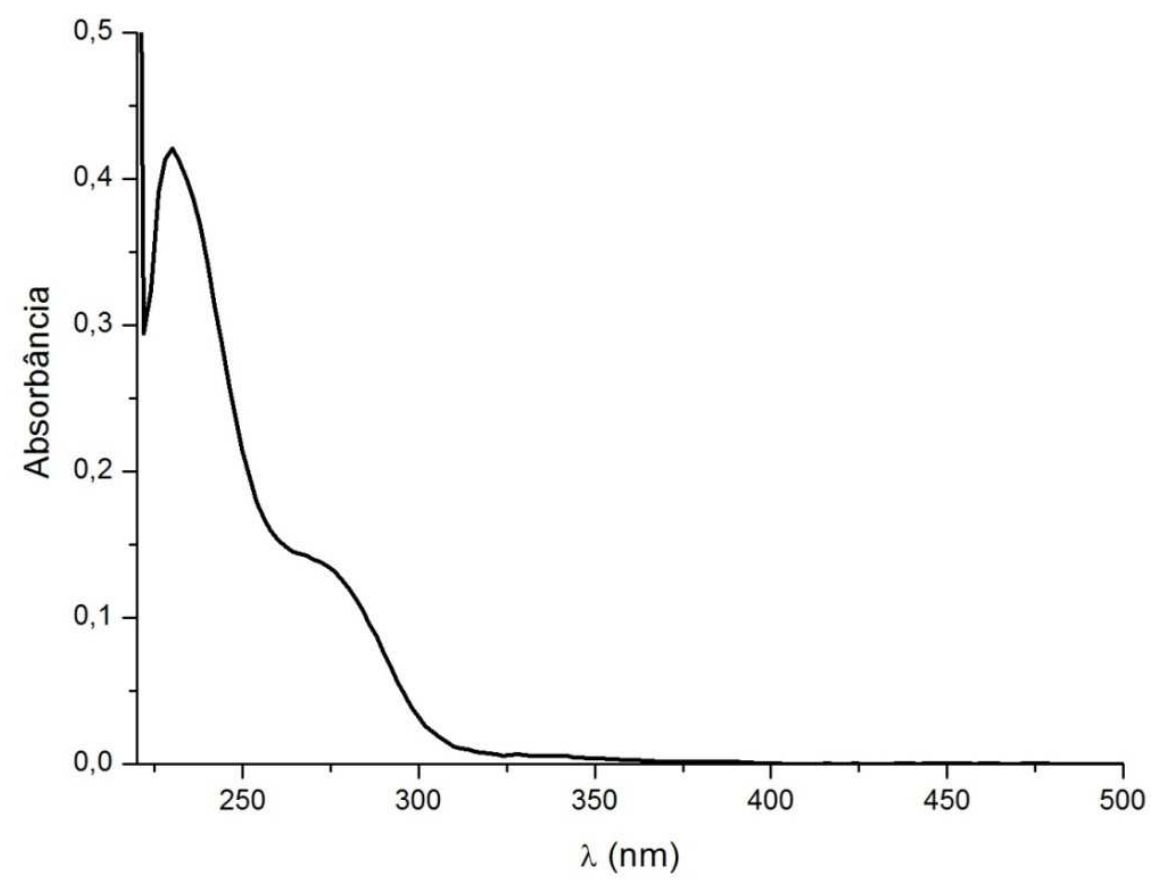

Figura 34 - Espectro eletrônico para o complexo G0/RuNO em solução aquosa, pH 2,0 e $\mu=$ $0,10 \mathrm{~mol} \mathrm{~L}-1\left(\mathrm{CF}_{3} \mathrm{COOH} / \mathrm{CF}_{3} \mathrm{COONa}\right)$, temperatura de $25^{\circ} \mathrm{C}$.

A comparação entre os valores de $\varepsilon$ do complexo livre e ancorado pode ser utilizada como um indício do número de ligações efetuadas entre os complexos de rutênio e o dendrímero G0. Este apresenta quatro pontos para ligação peptídica (quatro grupos amina superficiais), assim, admitindo-se que não ocorra interação entre os complexos ancorados, o valore de $\varepsilon$ para G0/RuNO, seria em princípio aproximadamente igual a quatro vezes o valor de $\varepsilon$ para o complexo livre, trans-[Ru $\left.{ }^{\mathrm{II}}\left(\mathrm{NO}^{+}\right)\left(\mathrm{NH}_{3}\right)_{4} \mathrm{ina}\right]\left(\mathrm{BF}_{4}\right)_{3}$. A Tabela 7 apresenta a comparação entre esses valores, com exceção da banda em $330 \mathrm{~nm}$, a qual não é tão bem definida em comparação às bandas em 232 e 270 nm. 
Tabela 7 - Resultados de espectroscopia eletrônica obtidos para os nitrosilo complexos livre e ancorado ao dendrímero G0. (Solução aquosa, pH 2,0 e $\mu=0,10 \mathrm{~mol} \mathrm{~L}^{-1}$ $\left(\mathrm{CF}_{3} \mathrm{COOH} / \mathrm{CF}_{3} \mathrm{COONa}\right)$, temperatura de $\left.25^{\circ} \mathrm{C}\right)$

\begin{tabular}{ccc}
\hline Composto & $\boldsymbol{\lambda}_{\max },\left(\boldsymbol{\varepsilon} \times \mathbf{1 0}^{\mathbf{3}}\right)$ & $\boldsymbol{\lambda}_{\max },\left(\boldsymbol{\varepsilon} \mathbf{x} \mathbf{1 0}^{\mathbf{3}}\right)$ \\
\hline trans- $\left[\mathrm{Ru}^{\mathrm{II}}\left(\mathrm{NO}^{+}\right)\left(\mathrm{NH}_{3}\right)_{4}\right.$ ina $]\left(\mathrm{BF}_{4}\right)_{3}$ & $230 \mathrm{~nm},(11,2)$ & $275 \mathrm{~nm},(3,6)$ \\
$\mathrm{G} 0 / \mathrm{RuNO}$ & $232 \mathrm{~nm},(40,0)$ & $270 \mathrm{~nm},(14,8)$ \\
\hline Razão $\left(\boldsymbol{\varepsilon}\right.$ complexo livre $\left./ \boldsymbol{\varepsilon}_{\text {complexo ancorado }}\right)$ & $\mathbf{3 , 6}$ & $\mathbf{4 , \mathbf { 1 }}$ \\
\hline
\end{tabular}

Os resultados observados na Tabela 7 sugerem o ancoramento de quatro unidades do complexo trans-[Ru ${ }^{\text {II }}\left(\mathrm{NO}^{+}\right)\left(\mathrm{NH}_{3}\right)_{4}$ ina $]\left(\mathrm{BF}_{4}\right)_{3}$ no dendrímero $\mathrm{G} 0$, pois as razões da absortividade molar ( $\varepsilon$ complexo ancorado $/ \varepsilon$ complexo livre) são próximas ao valor teórico, 4 , sendo que o melhor resultado foi obtido para a razão entre as bandas em 270nm/275nm.

Na Figura 35 está ilustrado o espectro eletrônico para o composto G2/RuNO, em que observa-se três bandas de absorção, em 232, 270 e 330 nm.

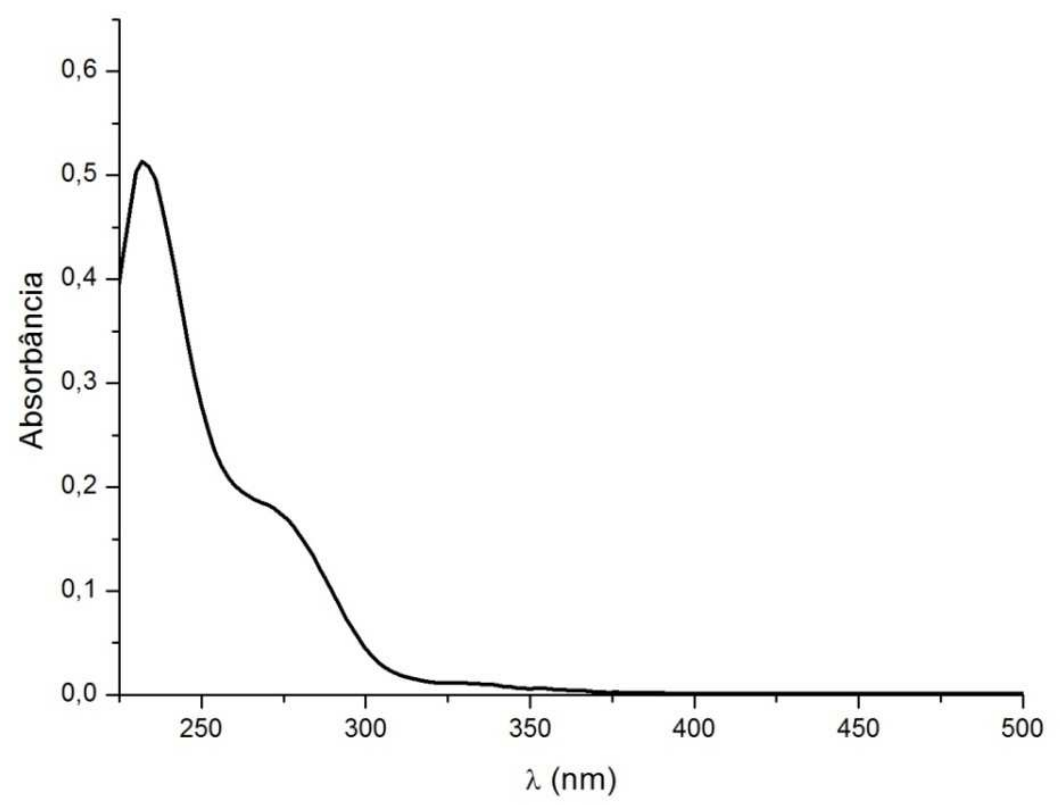

Figura 35 - Espectro eletrônico para o complexo G2/RuNO em solução aquosa, pH 2,0 e $\mu=$ $0,10 \mathrm{~mol} \mathrm{~L}^{-1}\left(\mathrm{CF}_{3} \mathrm{COOH} / \mathrm{CF}_{3} \mathrm{COONa}\right)$, temperatura de $25^{\circ} \mathrm{C}$. 
Como os resultados de análise elementar para G2/RuNO apresentaram desvios significativos entre o valor teórico e experimental, não foi possível determinar a massa molecular desse produto, conseqüentemente tornando inviável a determinação da absortividade molar, como foi realizado para G0/RuNO. Entretanto, foi possível estabelecer uma relação entre a quantidade de rutênio presente em G2/RuNO e a absorbância medida experimentalmente. Para isso, por meio de análises por ICP, verificou-se a quantidade de rutênio no produto G2/RuNO, e em seguida preparou-se uma solução com concentração conhecida de $\mathrm{Ru}$, procedendo-se com análises de espectroscopia eletrônica. $\mathrm{O}$ coeficiente angular da curva $[\mathrm{Ru}]$ vs absorbância, resultou em um valor de absortividade molar (em função da concentração de rutênio e não da concentração do composto G2/RuNO) próximo ao verificado para o composto livre, conforme apresentado na Tabela 8.

Tabela 8 - Resultados de espectroscopia eletrônica para os nitrosilo complexos livre e ancorado ao dendrímero G2. (Solução aquosa, pH 2,0 e $\mu=0,10 \mathrm{~mol}^{-1}$ $\left(\mathrm{CF}_{3} \mathrm{COOH} / \mathrm{CF}_{3} \mathrm{COONa}\right)$, temperatura de $\left.25^{\circ} \mathrm{C}\right)$

\begin{tabular}{ccc}
\hline Composto & $\boldsymbol{\lambda}_{\max },\left(\boldsymbol{\varepsilon} \mathbf{x} \mathbf{1 0}^{\mathbf{3}}\right)$ & $\left.\boldsymbol{\lambda}_{\max },(\boldsymbol{\varepsilon} \mathbf{x ~ 1 0})^{\mathbf{3}}\right)$ \\
\hline trans- $\left[\mathrm{Ru}^{\mathrm{II}}\left(\mathrm{NO}^{+}\right)\left(\mathrm{NH}_{3}\right)_{4}\right.$ ina $\left._{(}\right]\left(\mathrm{BF}_{4}\right)_{3}$ & $230 \mathrm{~nm},(11,2)$ & $275 \mathrm{~nm},(3,6)$ \\
G2/RuNO & $232 \mathrm{~nm},(10,9)^{*}$ & $270 \mathrm{~nm},(3,8)^{*}$
\end{tabular}

*valor de $\varepsilon$ calculado em função da concentração de Ru

Assim, os resultados sugerem que as bandas observadas por espectroscopia eletrônica para o composto G2/RuNO têm pouca contribuição das transições existentes na molécula do PAMAM G2, sendo então referentes às transições do complexo RuNO ligado à superfície do dendrímero. Essas bandas podem ser atribuídas, da mesma forma que realizado para o complexo livre, em $230 \mathrm{~nm}$ à transferência de carga do metal para o ligante (TCML) $\mathrm{Ru}(\mathrm{II}) \rightarrow$ ina, em $275 \mathrm{~nm}$ à transição interna do ligante ina $\pi \rightarrow \pi^{*}(\mathrm{~L})$, e $\sim 330 \mathrm{~nm}$ às transições d-d. 


\subsection{3 - Voltametria Cíclica}

Os voltamogramas cíclicos obtidos para G0/RuNO e G2/RuNO foram similares e apresentaram dois pares redox (Figura 36 a1/a2, b1/b2), com valores de $\mathrm{E}_{1 / 2}$ próximos aos obtidos para o íon complexo livre trans- $\left[\mathrm{Ru}^{\mathrm{II}}\left(\mathrm{NO}^{+}\right)\left(\mathrm{NH}_{3}\right)_{4} \text { ina }\right]^{3+}$, conforme apresentado na Tabela 9.
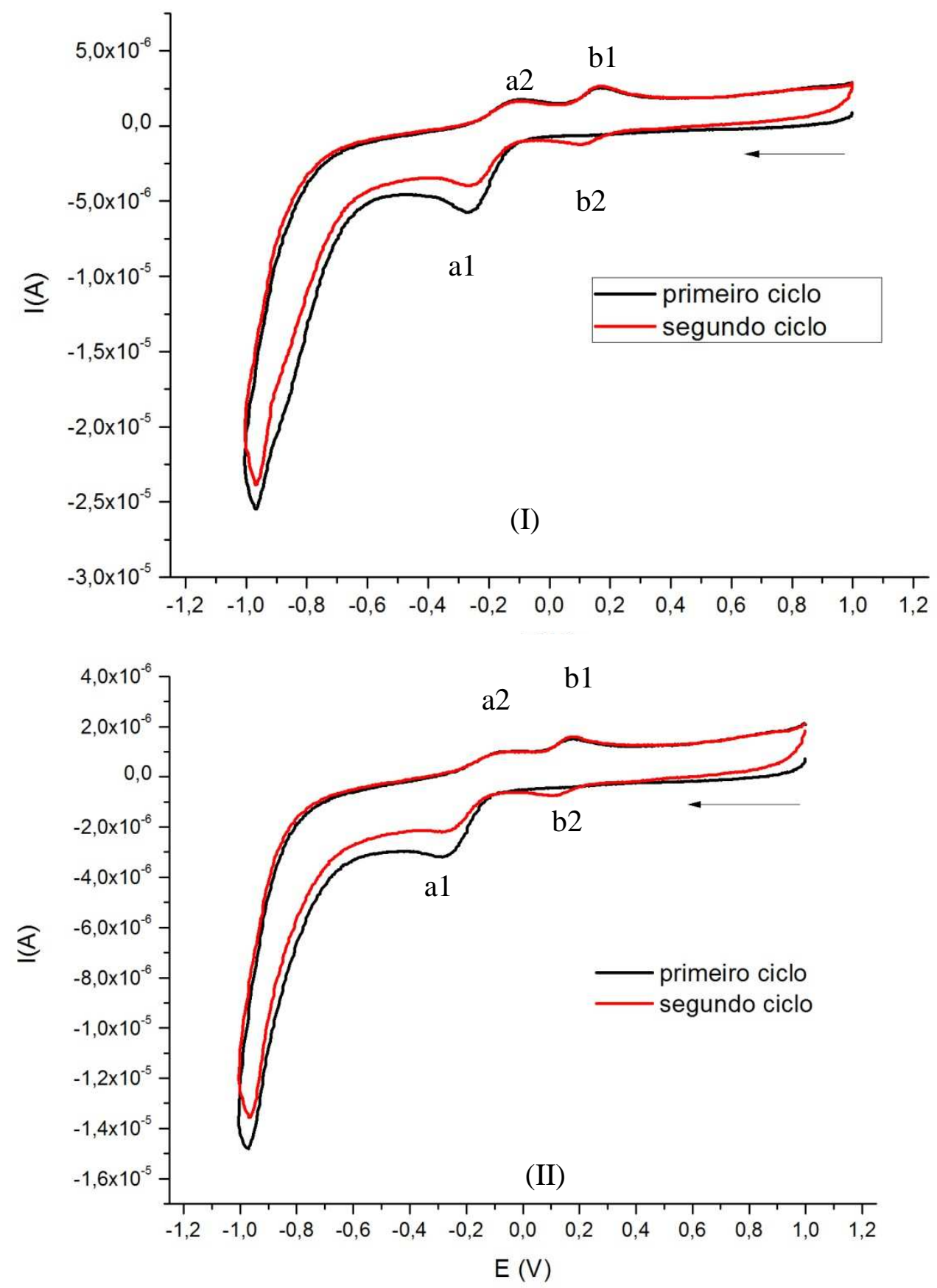

Figura 36 - Voltamograma cíclico dos compostos (I) G0/RuNO e (II) G2/RuNO em solução aquosa, $\mathrm{pH} 2,0$ e $\mu=0,10 \mathrm{~mol} \mathrm{~L}{ }^{-1} \mathrm{CF}_{3} \mathrm{COOH} / \mathrm{CF}_{3} \mathrm{COONa}$, temperatura de $25^{\circ} \mathrm{C}, \mathrm{v}=100$ $\mathrm{mVs}^{-1}$. 
Tabela 9 - Valores de $\left(\mathrm{E}_{1 / 2}\right)$ obtidos por voltametria cíclica para soluções contendo os nitrosilo complexos livre e ancorado ao dendrímero G0 (Solução aquosa, pH 2,0 e $\mu=0,10$ $\mathrm{mol} \mathrm{L}{ }^{-1}\left(\mathrm{CF}_{3} \mathrm{COOH} / \mathrm{CF}_{3} \mathrm{COONa}\right)$, temperatura de $\left.25^{\circ} \mathrm{C}, \mathrm{v}=100 \mathrm{mV} \mathrm{s}^{-1}\right)$

\begin{tabular}{|c|c|c|}
\hline Composto & $\left(\mathrm{E}_{1 / 2}\right)\left(\mathrm{NO}^{+} / \mathrm{NO}^{0}\right) *$ & $\left(\mathrm{E}_{1 / 2}\right) \mathbf{R u}(\mathrm{III})-\mathbf{R u}(\mathrm{II}) * *$ \\
\hline trans- $\left[\mathrm{Ru}^{\mathrm{II}}\left(\mathrm{NO}^{+}\right)\left(\mathrm{NH}_{3}\right)_{4}\right.$ ina $]\left(\mathrm{BF}_{4}\right)_{3}$ & $-0,175 \mathrm{~V}$ & $0,155 \mathrm{~V}$ \\
\hline G0/RuNO & $-0,173 \mathrm{~V}$ & $0,150 \mathrm{~V}$ \\
\hline G2/RuNO & $-0,178 \mathrm{~V}$ & $0,150 \mathrm{~V}$ \\
\hline
\end{tabular}

* representado na Figura 36 pelo par a1/a2; ** representado na Figura 36 pelo par b1/b2

A concordância entre os valores de $\left(\mathrm{E}_{1 / 2}\right)$ do complexo livre e ligados ao PAMAM G0 e G2 sugere que o ancoramento do complexo no dendrímero não alterou, dentro do erro experimental, as características eletroquímicas do complexo original trans-[Ru ${ }^{\mathrm{II}}\left(\mathrm{NO}^{+}\right)\left(\mathrm{NH}_{3}\right)_{4}$ ina $]\left(\mathrm{BF}_{4}\right)_{3}$. Esta observação é coerente com resultados descritos na literatura, nos quais complexos de rutênio foram imobilizados[89] em xerogéis[95], na superfície de sílica gel[92,94] e em dendrímeros[96].

\subsection{4 - Espectroscopia Vibracional}

Na Figura 37 são apresentados os espectros de infravermelho dos complexos G0/RuNO, trans-[Ru ${ }^{\text {II }}\left(\mathrm{NO}^{+}\right)\left(\mathrm{NH}_{3}\right)_{4}$ ina $]\left(\mathrm{BF}_{4}\right)_{3}$ e PAMAM G0 e na Figura 38 os espectros de infravermelho dos complexos G2/RuNO, trans- $\left[\mathrm{Ru}^{\mathrm{II}}\left(\mathrm{NO}^{+}\right)\left(\mathrm{NH}_{3}\right)_{4}\right.$ ina $]\left(\mathrm{BF}_{4}\right)_{3}$ e PAMAM G2. Nessas figuras é possível observar a similaridade entre os espectros de infravermelho dos nitrosilo complexos livre e ancorados ao G0 e G2. 

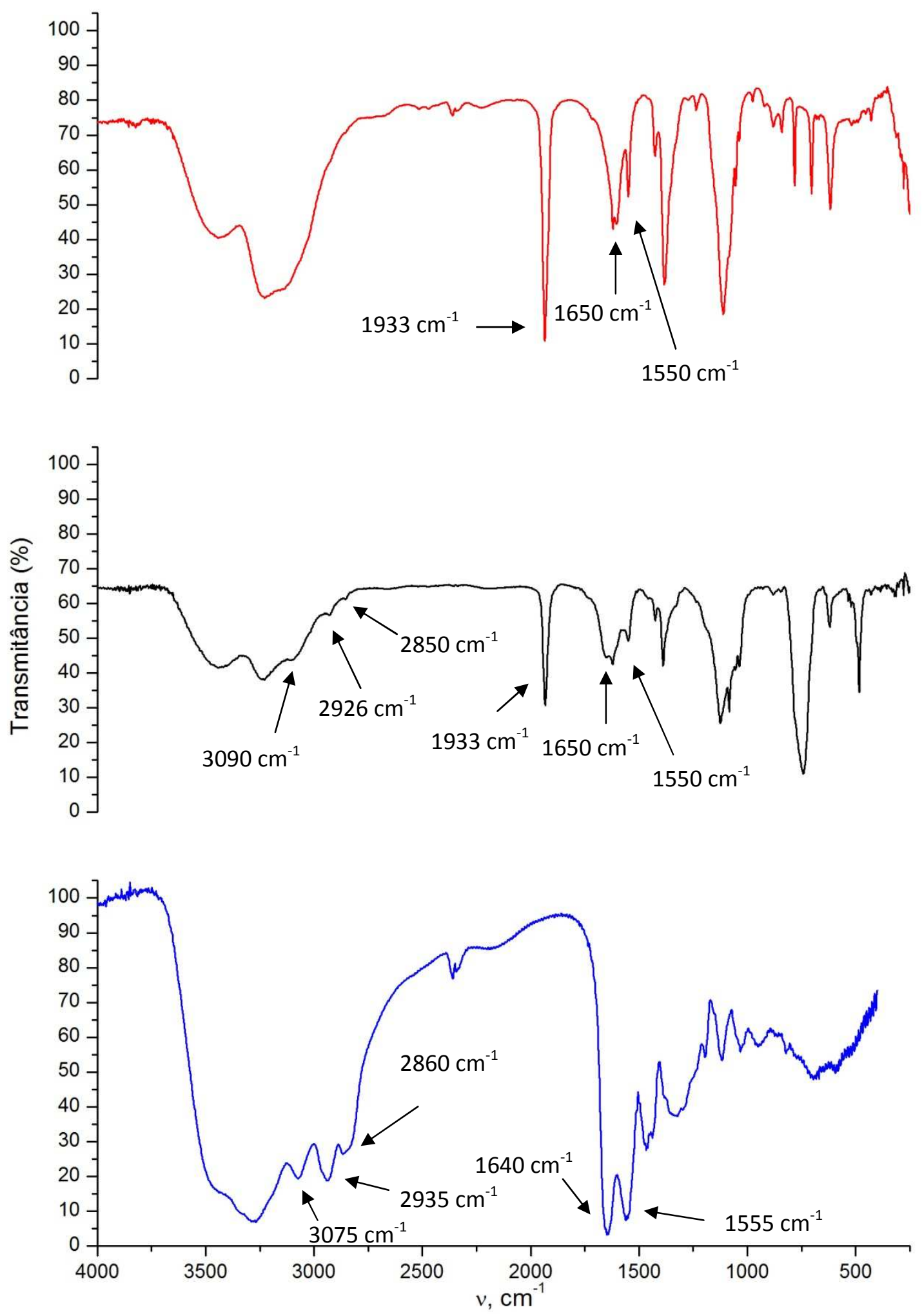

Figura 37 - Espectro de infravermelho dos complexos trans- $\left[\mathrm{Ru}^{\mathrm{II}}\left(\mathrm{NO}^{+}\right)\left(\mathrm{NH}_{3}\right)_{4}\right.$ ina $]\left(\mathrm{BF}_{4}\right)_{3}(-)$, G0/RuNO (-) e PAMAM G0 (-) em pastilha de KBr. 

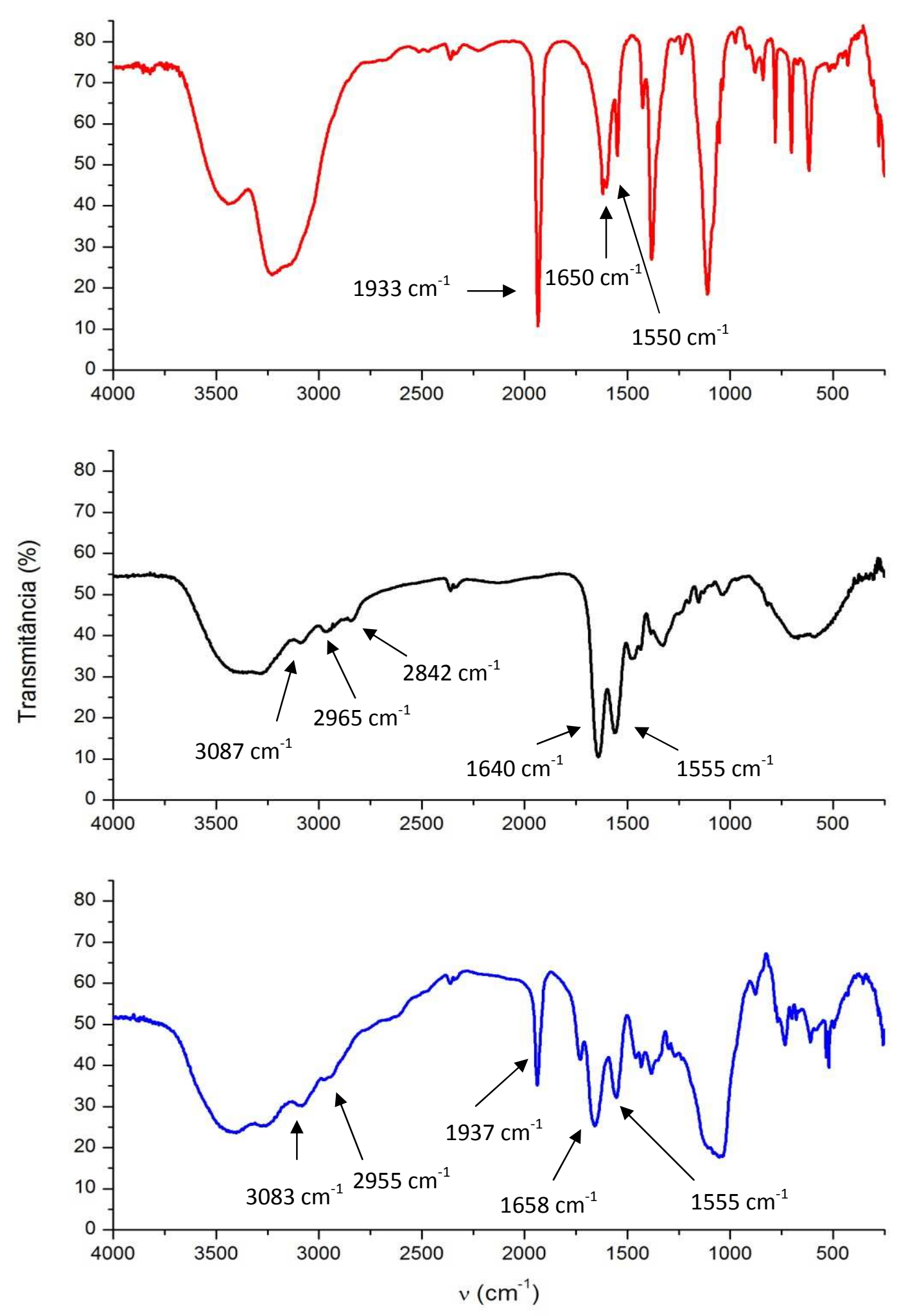

Figura 38 - Espectros de infravermelho dos complexos trans-[Ru ${ }^{\mathrm{II}}\left(\mathrm{NO}^{+}\right)\left(\mathrm{NH}_{3}\right)_{4}$ ina $]\left(\mathrm{BF}_{4}\right)_{3}(-)$, G2/RuNO (-) e PAMAM G2 (-) em pastilha de KBr. 
As bandas referentes a $v\left(\mathrm{NO}^{+}\right)$para os composto $\mathrm{G} 0 / \mathrm{RuNO}$ e trans-[Ru ${ }^{\mathrm{II}}\left(\mathrm{NO}^{+}\right)\left(\mathrm{NH}_{3}\right)_{4}$ ina $]\left(\mathrm{BF}_{4}\right)_{3}$ estão presentes na mesma região do espectro, em 1933 $\mathrm{cm}^{-1}$, e para G2/RuNO está presente em $1937 \mathrm{~cm}^{-1}$. Esses valores são compatíveis com resultados reportados na literatura para outras tetraaminas de rutênio com $\mathrm{NO}^{+}$na esfera de coordenação[55].

Ao comparar as intensidades relativas das bandas próximas a 1650 e $1550 \mathrm{~cm}^{-1}$ do complexo livre e ancorado ao dendrímero G0, observou-se o alargamento da banda em 1650 $\mathrm{cm}^{-1}$ para G0/RuNO. Alterações similares foram observadas por Benini e colaboradores [96] ao ancorar o composto $\left[\mathrm{Ru}^{\mathrm{III}}(\mathrm{edta})(\mathrm{H} 2 \mathrm{O})\right]^{-}$em dendrímeros PAMAM de geração 0,2 e 3. As bandas em 1650 e $1550 \mathrm{~cm}^{-1}$ foram atribuídas, respectivamente às vibrações amida $\mathrm{I} v(\mathrm{CO}) \mathrm{e}$ amida II $\left(\delta_{\mathrm{N}-\mathrm{H}}\right)$ e também estão presentes no dendrímero G0. A explicação para a alteração nessas bandas pode ser atribuída, tentativamente, à sobreposição das bandas do dendrímero PAMAM com as do complexo de rutênio, além do que foi discutido anteriormente no item 4.3.2 para os espectros de infravermelho dos produtos G0/RuSO4 e G2/RuSO4.

A alteração das bandas próximas a 1650 e $1550 \mathrm{~cm}^{-1}$ não ocorreu de forma tão intensa para o complexo G2/RuNO como foi observado para o G0/RuNO. Isto pode ter acontecido devido ao fato dos complexos de rutênio não terem sido ancorados em todas as 16 aminas superficiais do G2, fazendo com que a modificação nessas bandas não fosse tão intensa como observado no ancoramento em G0 (conforme discutido anteriormente no item 4.3.2)

Outra modificação observada no espectro do complexo G0/RuNO em relação ao complexo livre, foi o aparecimento das bandas em $3090[v(\mathrm{NH})], 2926[v(\mathrm{NH})$ e $v(\mathrm{CH})]$ e $2850[v(\mathrm{CH})] \mathrm{cm}^{-1}$ (Figura 37), as quais também estão presentes no G0. Alterações similares foram observadas para o complexo G2/RuNO (Figura 38), com o aparecimento de bandas em $3083[v(\mathrm{NH})]$ e $2955 \mathrm{~cm}^{-1}[v(\mathrm{NH})$ e $v(\mathrm{CH})]$. 


\subsection{5 - Ressonância Magnética Nuclear de ${ }^{1} \mathrm{H}$ e ${ }^{13} \mathrm{C}$}

Na Figura 39 é apresentada a fórmula estrutural do dendrímero PAMAM G0 e o respectivo espectro de RMN ${ }^{1} \mathrm{H}$. A Figura 40 ilustra o espectro de RMN ${ }^{1} \mathrm{H}$ do PAMAM G2. As atribuições dos sinais de RMN ${ }^{1} \mathrm{H}$ para o $\mathrm{G} 0$ foram feitas de acordo com dados reportados na literatura[123].
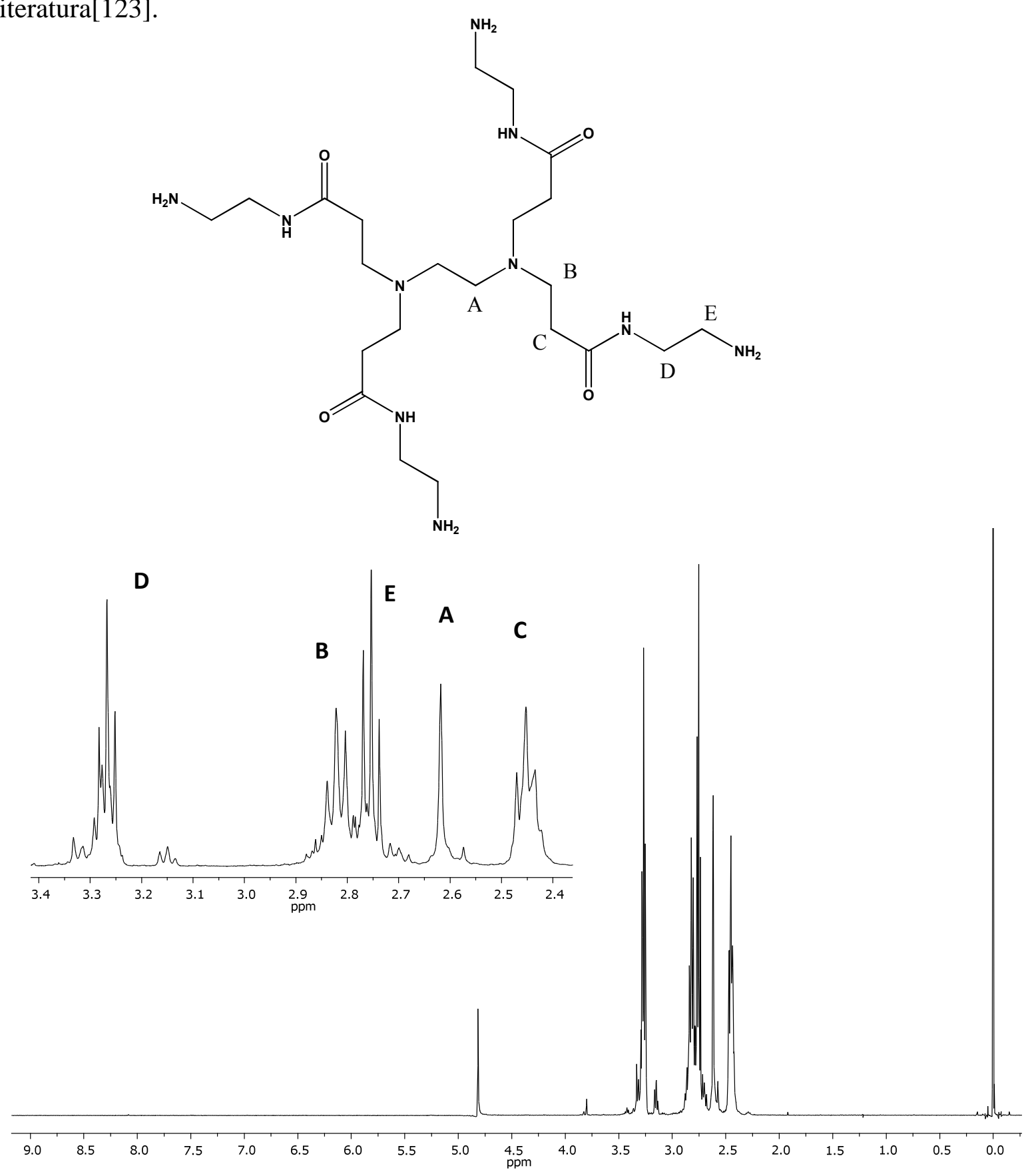

Figura 39 - Estrutura e ${ }^{1} \mathrm{H}$ RMN do dendrímero PAMAM de geração 0 em $\mathrm{D}_{2} \mathrm{O}$. O espectro menor é uma ampliação na região entre 2,4 2 3,4 ppm. As letras A, B, C, D e E correspondem ao tipo de hidrogênio na estrutura do G0 e o respectivo sinal no espectro de RMN. 


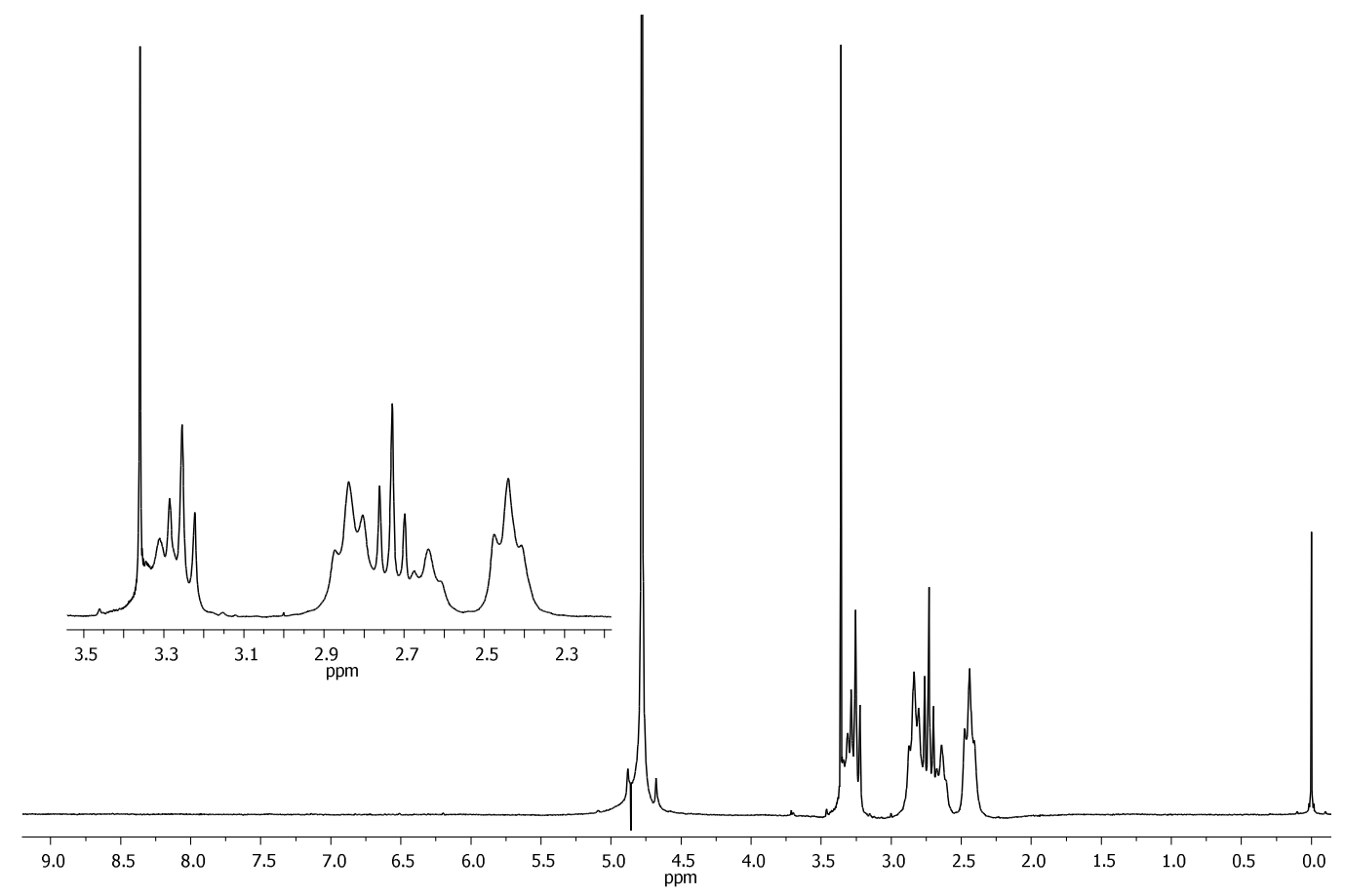

Figura 40 - Espectro de RMN ${ }^{1} \mathrm{H}$ do dendrímero PAMAM de geração 2 em $\mathrm{D}_{2} \mathrm{O}$. O espectro menor é uma ampliação na região entre 2,3 a 3,5 ppm.

Nas Figuras 41 e 42 são apresentados, respectivamente, os espectro de $\mathrm{RMN}{ }^{1} \mathrm{H}$ do complexo G0/RuNO e G2/RuNO. 


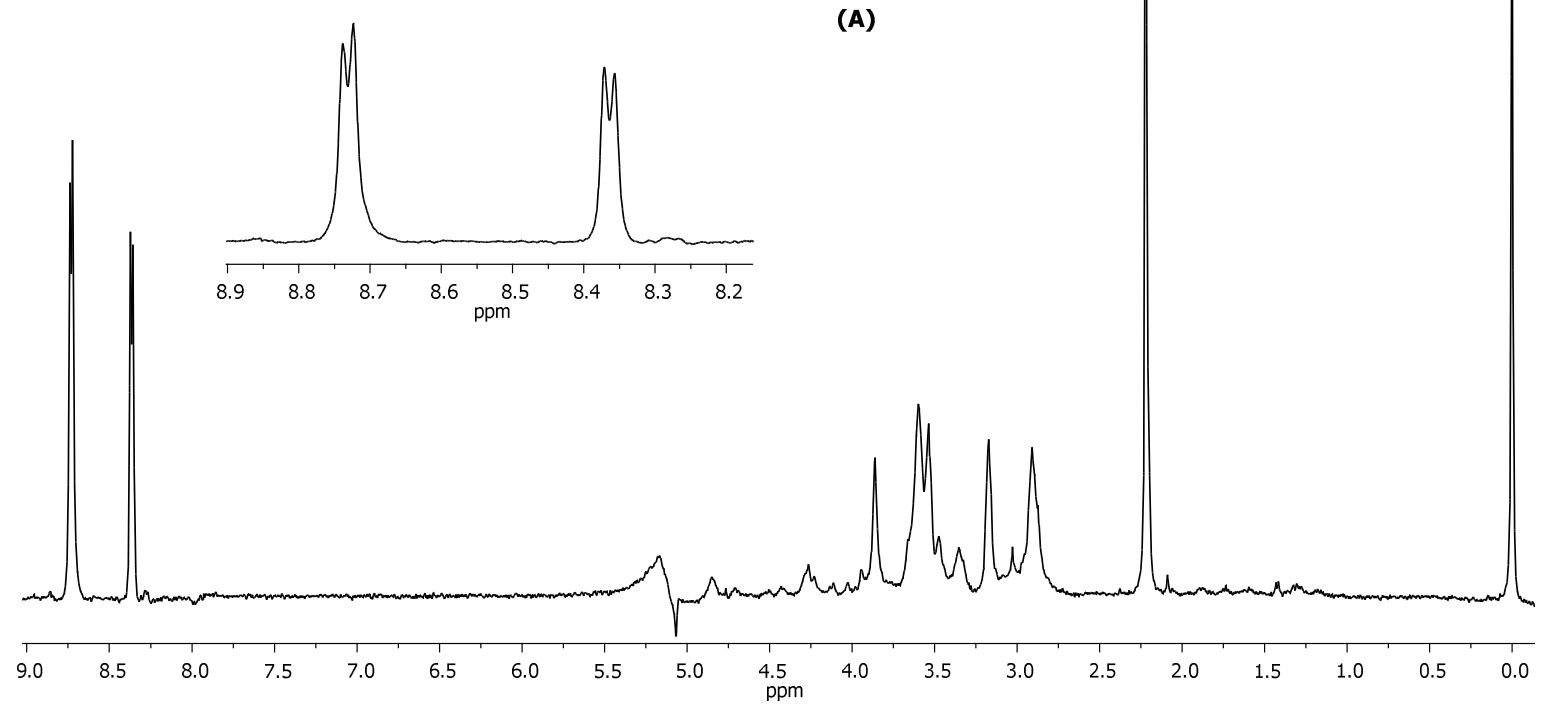

(B)

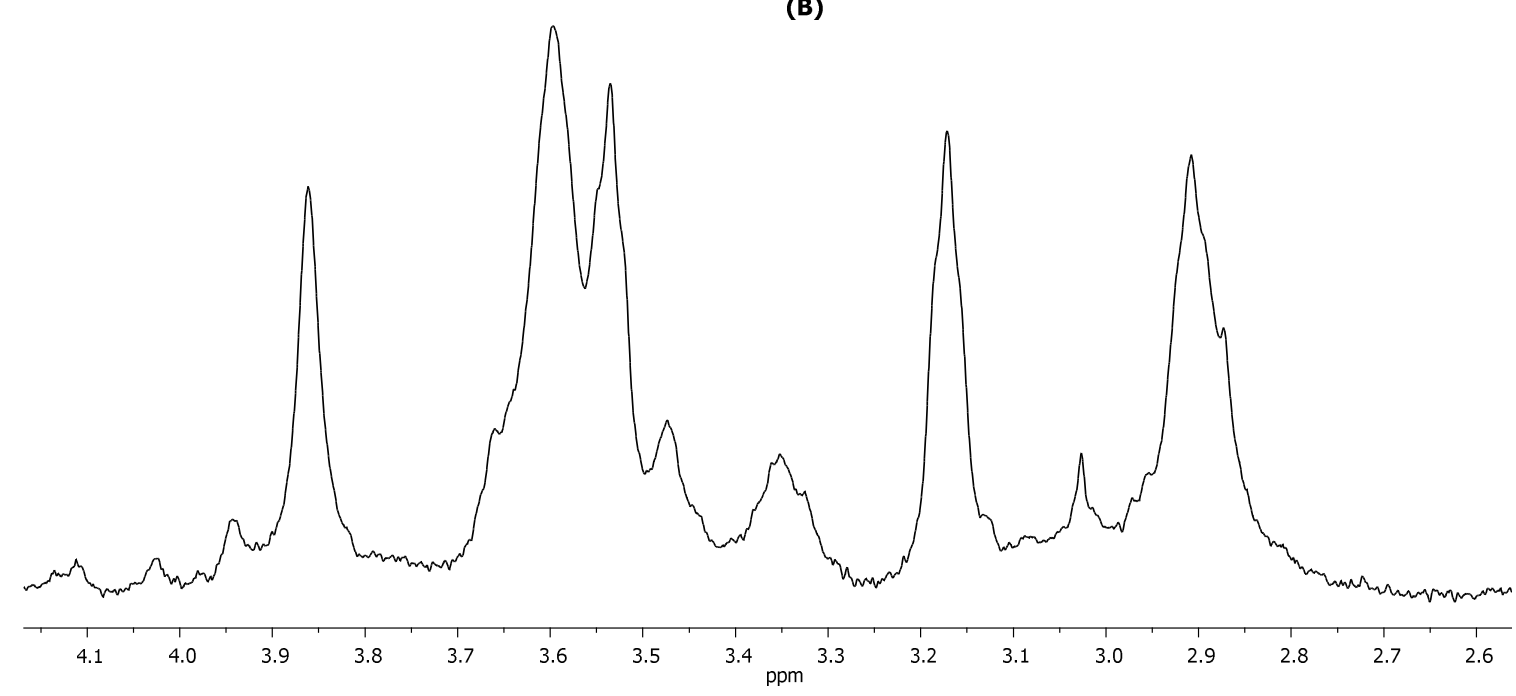

Figura 41 - Espectro de $\mathrm{RMN}^{1} \mathrm{H}$ do complexo (A) G0/RuNO em $\mathrm{D}_{2} \mathrm{O}$ (1M CF $3 \mathrm{COOD}_{3}$. $\mathrm{O}$ espectro (B) é uma ampliação do espectro (A) na faixa de 2,6 a 4,1 ppm. 

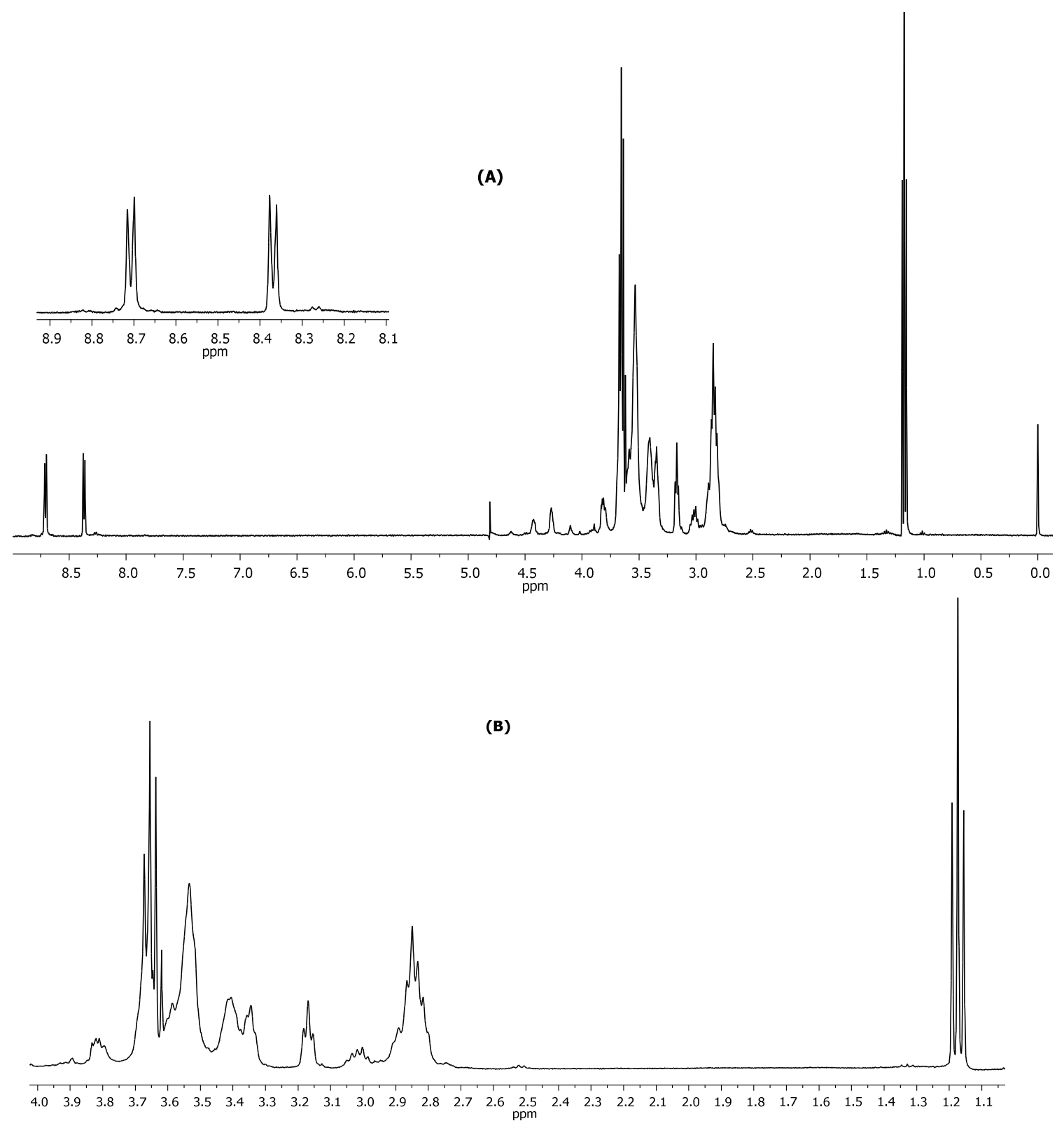

Figura 42 - Espectro de $\mathrm{RMN}^{1} \mathrm{H}$ do complexo (A) G2/RuNO em $\mathrm{D}_{2} \mathrm{O}$ (1M CF $3 \mathrm{COOD}_{3}$. $\mathrm{O}$ espectro (B) é uma ampliação do espectro (A) na faixa de 1,1 a 4,0 ppm.

Os dois dubletos com $\delta$ centrados em 8,73 e 8,36 ppm nas Figuras 41 e 42 referem-se respectivamente aos hidrogênios aromáticos nas posições orto e meta do ligante ina nos complexos G0/RuNO e G2/RuNO. Conforme ilustrado nesses espectros de RMN, os sinais referentes aos hidrogênios dos dendrímeros ligados ao complexo são largos e pouco definidos. Esses sinais foram observados no intervalo de 2,7 a 4,0 ppm para ambos os compostos, G0/RuNO e G2/RuNO. Na Figura 41 verifica-se o sinal referente à acetona em 
2,21 ppm e na Figura 42 o sinal de etanol com um tripleto centrado em 1,16 ppm e um quarteto centrado em 3,65 ppm. Storrier et al. [120] relataram resultados similares nos espectros de ${ }^{1} \mathrm{H}$ RMN em complexos polipiridínicos de Ru(II) ligados a PAMAM, em que mencionam sinais largos dos hidrogênios referentes ao dendrímero. Dessa forma, em seu trabalho, esses autores apenas apresentam os sinais referentes aos hidrogênios aromáticos dos ligantes.

$\mathrm{O}$ alargamento dos sinais em $\mathrm{RMN}$ de ${ }^{1} \mathrm{H}$ são geralmente observados para complexos de Ru(III), que é paramagnético. Esse não é o caso dos nitrosilo complexos, em que têm-se $\mathrm{Ru}(\mathrm{II})$. Com o intuito de verificar se os sinais largos observados no $\mathrm{RMN}$ de ${ }^{1} \mathrm{H}$ de G0/RuNO e G2/RuNO são provenientes da presença de eventuais centros de $\mathrm{Ru}(\mathrm{III})$ presentes na amostra, foi obtido um espectro de RPE para esses produtos. Nenhum sinal de paramagnetismo foi observado, e dessa forma é bastante provável a presença de apenas $\mathrm{Ru}(\mathrm{II})$ nesses complexos.

$\mathrm{Na}$ Figura 43 está ilustrado o espectro de $\mathrm{RMN}$ de ${ }^{13} \mathrm{C}$ do dendrímero G0 e dos complexos trans-[Ru ${ }^{\mathrm{II}}\left(\mathrm{NO}^{+}\right)\left(\mathrm{NH}_{3}\right)_{4}$ ina $]\left(\mathrm{BF}_{4}\right)_{3}$ e G0/RuNO. A tentativa de atribuição dos deslocamentos químicos observados foi efetuada por comparação, considerando-se os espectros dos precursores e os dados disponíveis na literatura [96,99]. O PAMAM G0 apresentou seis sinais de carbono (Figura 43), os quais estão de acordo com dados reportados na literatura [99]. Conforme apresentado na Figura 43 o espectro do composto trans- $\left[\mathrm{Ru}^{\mathrm{II}}\left(\mathrm{NO}^{+}\right)\left(\mathrm{NH}_{3}\right)_{4} \mathrm{ina}\right]\left(\mathrm{BF}_{4}\right)_{3}$ tem quatro sinais de carbono, cujas atribuições foram apresentadas no item 4.2.4, Figura 27 deste trabalho. O espectro do complexo G0/RuNO apresentou 10 sinais de carbono em regiões similares às observadas para seus precursores, o que é um forte indício do ancoramento (Figura 43). Os quartetos observados em deslocamentos químicos entre 110 e 128 ppm e entre 163 e 167 ppm são referentes ao ácido trifluoroacético deuterado $\left(\mathrm{CF}_{3} \mathrm{COOD}\right)$ utilizado para ajustar o $\mathrm{pH}$ da solução. 


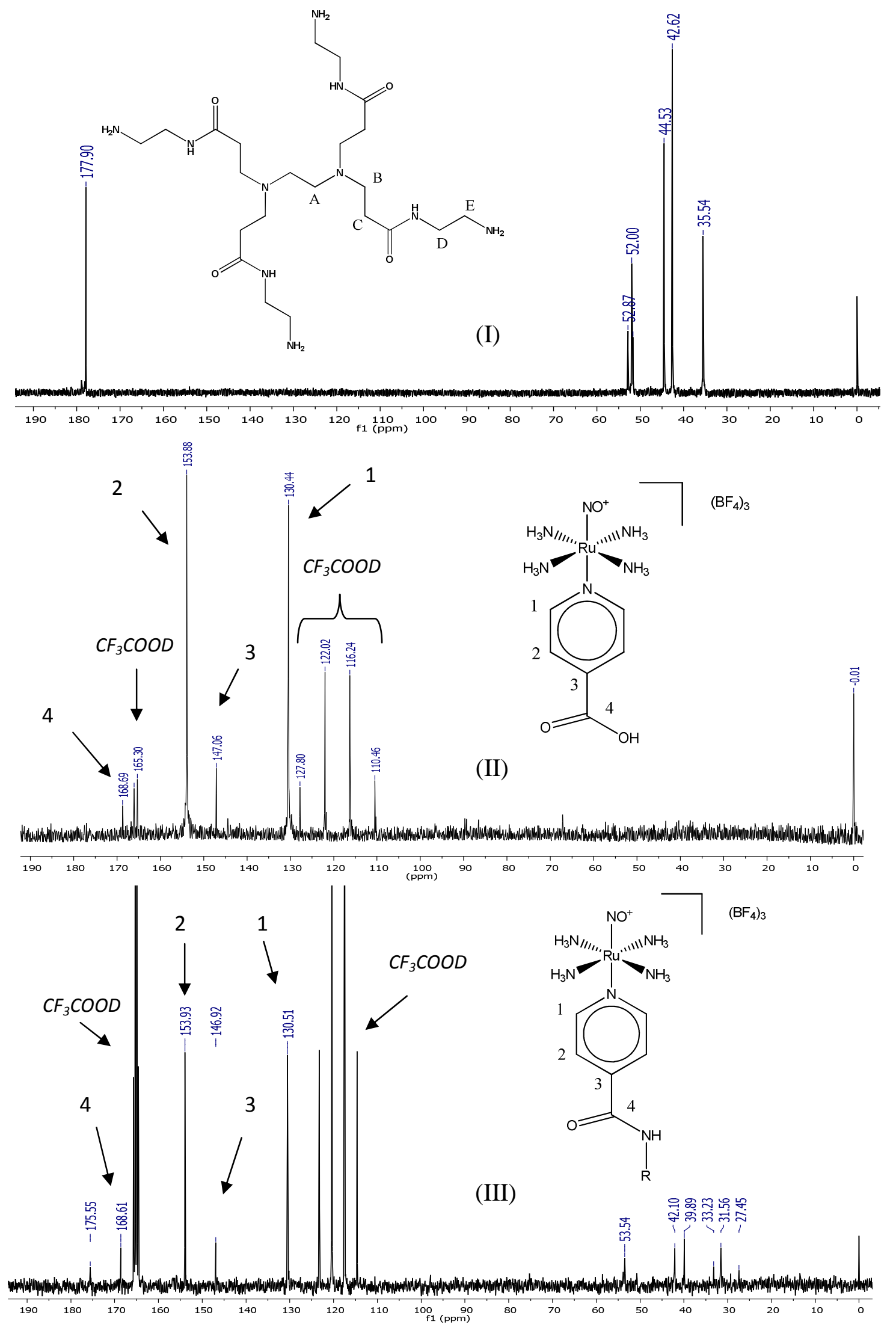

Figura 43 - Espectro de RMN ${ }^{13} \mathrm{C}$ : (I) G0, (II) trans-[Ru ${ }^{\mathrm{II}}\left(\mathrm{NO}^{+}\right)\left(\mathrm{NH}_{3}\right)_{4}$ ina $]\left(\mathrm{BF}_{4}\right)_{3}$ e (III) G0/RuNO. Em (III), a letra R representa a estrutura do dendrímero. 
Na Figura 44 está ilustrado o espectro de RMN de ${ }^{13} \mathrm{C}$ do dendrímero G2 e dos complexos trans-[Ru ${ }^{\mathrm{II}}\left(\mathrm{NO}^{+}\right)\left(\mathrm{NH}_{3}\right)_{4}$ ina $]\left(\mathrm{BF}_{4}\right)_{3}$ e G2/RuNO. A tentativa de atribuição dos deslocamentos químicos observados foi efetuada por comparação. O PAMAM G2 apresentou oito sinais de carbono (Figura 44) e o composto trans- $\left[\mathrm{Ru}^{\mathrm{II}}\left(\mathrm{NO}^{+}\right)\left(\mathrm{NH}_{3}\right)_{4}\right.$ ina $]\left(\mathrm{BF}_{4}\right)_{3}$ tem quatro sinais de carbono, os quais foram atribuídos anteriormente no item 4.2.4, Figura 27 deste trabalho. O espectro do complexo G2/RuNO apresentou 12 sinais de carbono em regiões similares às observadas para seus precursores, o que também é um forte indício do ancoramento. Os quartetos observados em deslocamentos químicos entre 110 e 128 ppm e entre 163 e 167 ppm são referentes ao ácido trifluoroacético deuterado $\left(\mathrm{CF}_{3} \mathrm{COOD}\right)$ utilizado para ajustar o pH da solução. 

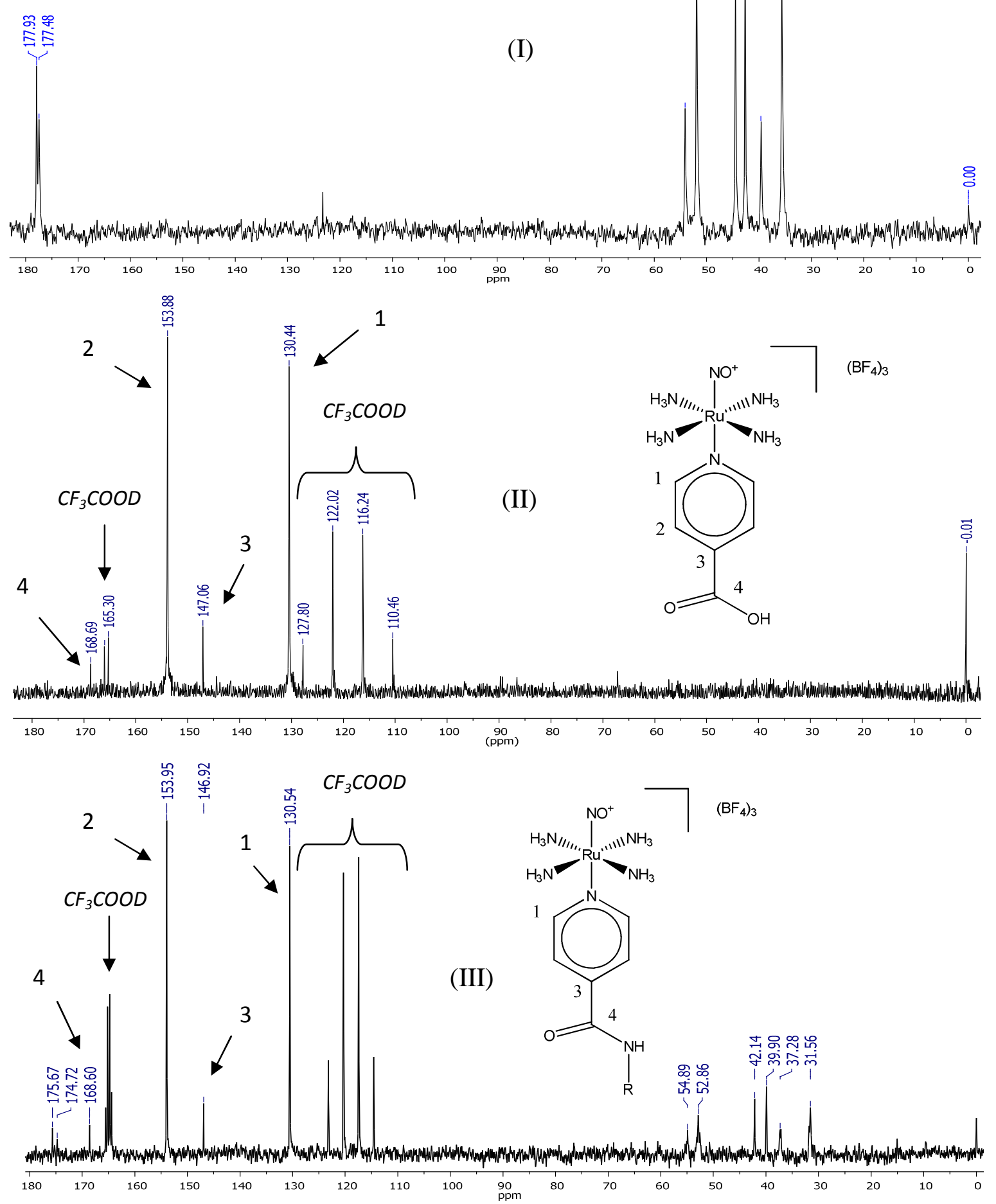

Figura 44 - Espectro de RMN de ${ }^{13} \mathrm{C}$ : (I) G2, (II) trans-[Ru ${ }^{\mathrm{II}}\left(\mathrm{NO}^{+}\right)\left(\mathrm{NH}_{3}\right)_{4}$ ina $]\left(\mathrm{BF}_{4}\right)_{3}$ (solução $1 \mathrm{M} \mathrm{CF} \mathrm{CFOD}_{3} \mathrm{COO}$ ) e (III) $\mathrm{G} 2 / \mathrm{RuNO}$ (solução $1 \mathrm{M} \mathrm{CF} \mathrm{CFOOD}_{3} \mathrm{COO}$ ). Em (III), a letra R representa a estrutura do dendrímero. 
Ao realizar a ligação entre o ácido isonicotínico (coordenado ao metal) e os dendrímeros, aventou-se a possibilidade de que o sinal referente ao carbono 4 desse ligante (168 ppm Figura 43 e 44) estaria deslocado. Isso porque no composto trans-[Ru ${ }^{\mathrm{II}}\left(\mathrm{NO}^{+}\right)\left(\mathrm{NH}_{3}\right)_{4}$ ina $]\left(\mathrm{BF}_{4}\right)_{3}$ esse carbono está ligado ao oxigênio e à hidroxila $(\mathrm{HO}-\mathrm{C}=\mathrm{O})$ e ao reagir com o dendrímero, forma-se uma ligação amida $(\mathrm{R}-\mathrm{HN}-\mathrm{C}=\mathrm{O})$, conforme representado na Figura 45. Para efeito de comparação, realizou-se a síntese do complexo trans- $\left[\mathrm{Ru}^{\mathrm{II}}\left(\mathrm{NO}^{+}\right)\left(\mathrm{NH}_{3}\right)_{4}\right.$ isn $]\left(\mathrm{BF}_{4}\right)_{3}(\mathrm{em}$ que isn = isonicotinamida) e obteve-se o espectros de $\mathrm{RMN}{ }^{13} \mathrm{C}$ para esse composto. A escolha desse complexo foi devido à semelhança estrutural com os produtos G0/RuNO e G2/RuNO, conforme ilustrado na Figura 46.

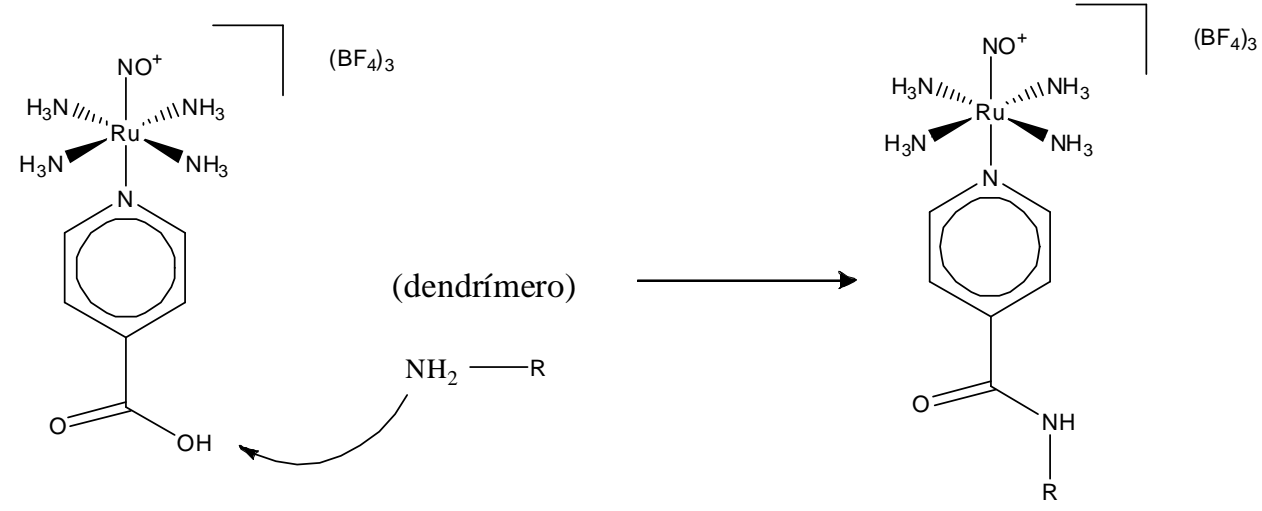

Figura 45 - Representação da ligação entre o complexo de rutênio e o dendrímero

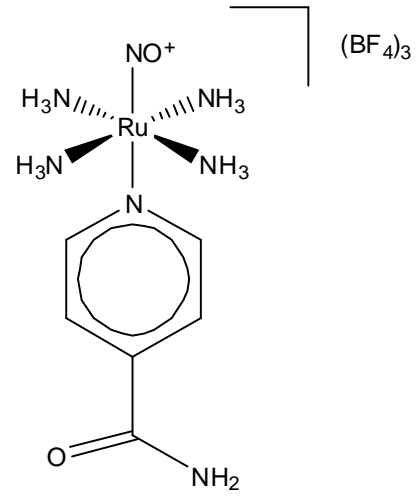

a

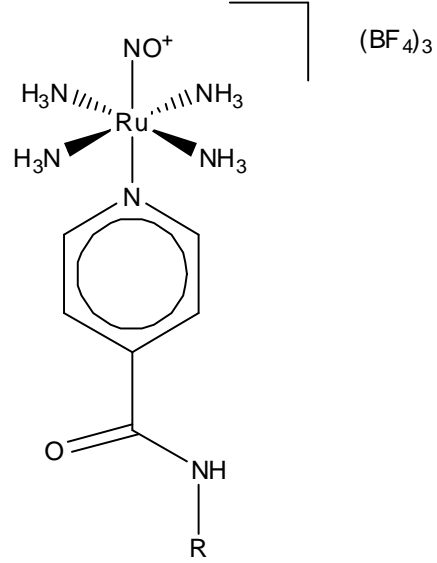

b

Figura 46 - Estrutura dos compostos (a) trans- $\left[\mathrm{Ru}^{\mathrm{II}}\left(\mathrm{NO}^{+}\right)\left(\mathrm{NH}_{3}\right)_{4}\right.$ isn $]\left(\mathrm{BF}_{4}\right)_{3}$ e (b) GX/RuNO (em que $\mathrm{X}=0$ e 2 ) e que $\mathrm{R}$ representa a estrutura do dendrímero. 
$\mathrm{Na}$ Figura 47 é apresentado o espectro de $\mathrm{RMN}$ de ${ }^{13} \mathrm{C}$ do complexo trans- $\left[\mathrm{Ru}^{\mathrm{II}}\left(\mathrm{NO}^{+}\right)\left(\mathrm{NH}_{3}\right)_{4}\right.$ isn $]\left(\mathrm{BF}_{4}\right)_{3}$ onde é possível observar o sinal referente ao carbono $4 \mathrm{em}$ deslocamento químico semelhante ao observado para o compostos trans-[Ru $\left.{ }^{\mathrm{II}}\left(\mathrm{NO}^{+}\right)\left(\mathrm{NH}_{3}\right)_{4} \mathrm{ina}\right]\left(\mathrm{BF}_{4}\right)_{3}, \mathrm{G} 0 / \mathrm{RuNO}$ e G2/RuNO em 169 ppm (Figuras 43 e 44).

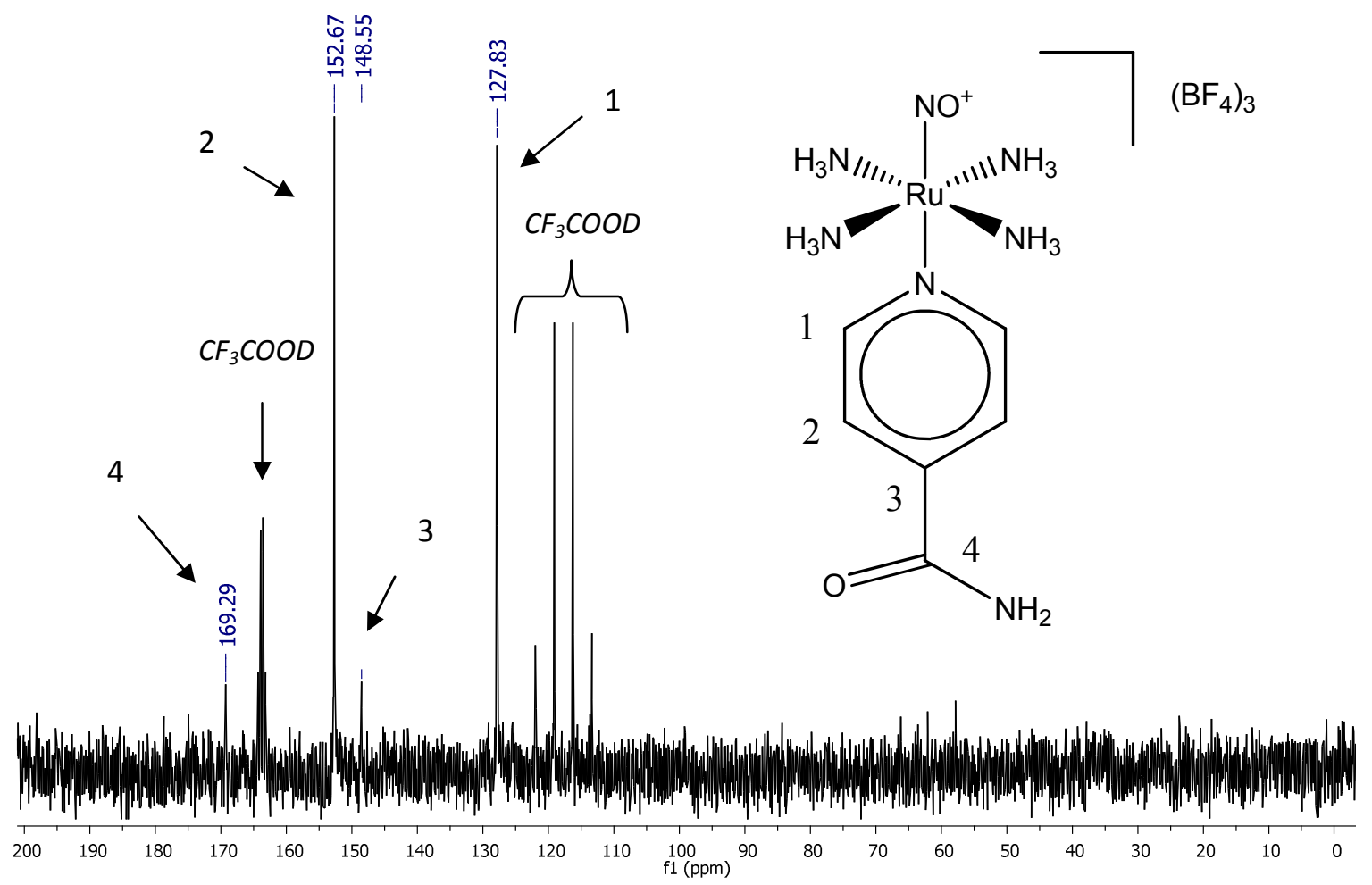

Figura $47-\mathrm{RMN}$ de ${ }^{13} \mathrm{C}$ do complexo trans- $\left[\mathrm{Ru}^{\mathrm{II}}\left(\mathrm{NO}^{+}\right)\left(\mathrm{NH}_{3}\right)_{4}\right.$ ina $]\left(\mathrm{BF}_{4}\right)_{3}$ (solução $1 \mathrm{M}$ $\left.\mathrm{CF}_{3} \mathrm{COOD}\right)$

Portanto, de acordo com os dados apresentados até o momento é possível afirmar que o ancoramento do complexo de rutênio nos dendrímeros G0 e G2 ocorreu de forma satisfatória e que as propriedades desses produtos não foram alteradas em relação ao complexo nãoancorado. 


\section{5 - ENSAIOS BIOLÓGICOS}

\subsection{1 - Citotoxicidade}

Os ensaios de citotoxicidade foram efetuados com a finalidade de verificar se os compostos de rutênio, livres ou ligados aos dendrímeros, têm efeito tóxico sobre células saudáveis (células do hospedeiro). Os experimentos foram conduzidos utilizando-se células do baço de camundongo e os resultados estão representados na Figura 48.

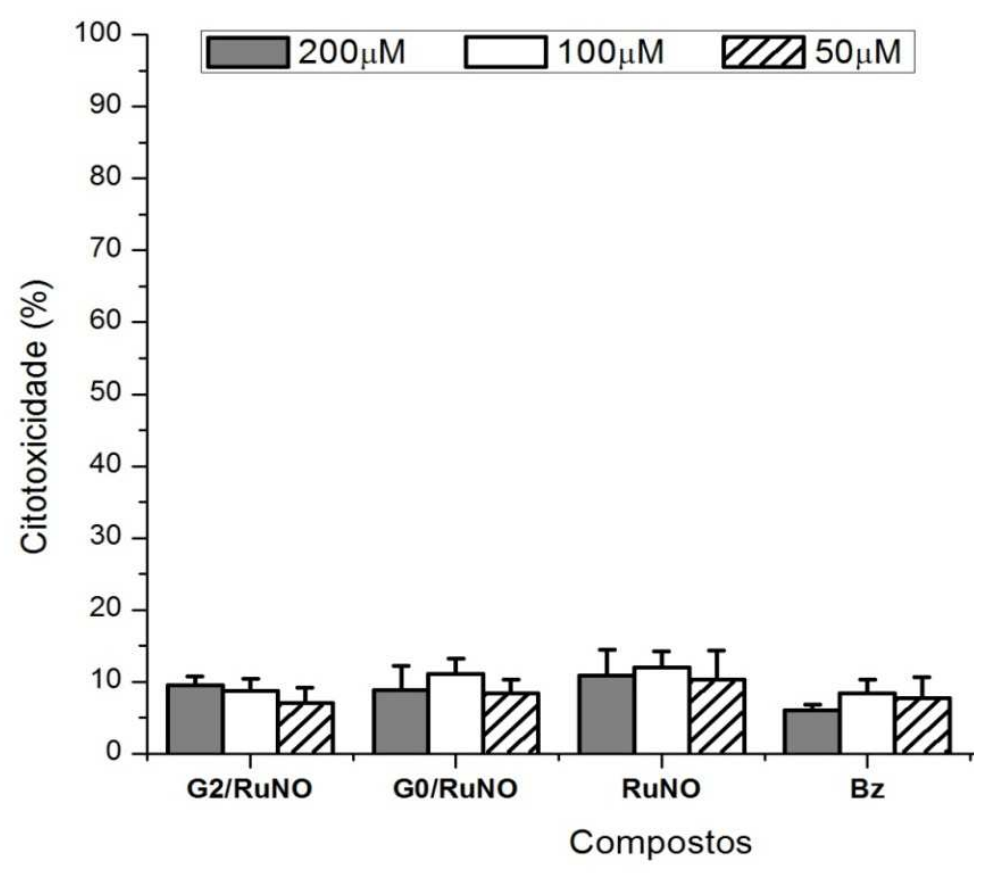

Figura 48 - Citotoxicidade dos compostos de rutênio sobre células saudáveis. Bz (referência)

A partir dos resultados obtidos é possível inferir que todos os nitrosilos de rutênio em estudo, bem como o Bz, apresentaram baixo efeito tóxico às células saudáveis $(<15 \%)$, nas concentrações utilizadas neste trabalho. Esses resultados corroboram com dados reportados na literatura nos quais se avaliou a citotoxicidade in vitro e in vivo de nitrosilo complexos de rutênio[11,124]. 
Estudos indicam que a toxicidade (ou biocompatibilidade) dos dendrímeros, em geral, está relacionada com a sua geração (a toxicidade aumenta com o aumento da geração)[125] [126] e com a estrutura, principalmente na superfície da molécula[127], e que a citotoxicidade deve ser avaliada para cada caso específico[127]. Esse fato corrobora com os dados obtidos neste trabalho em relação ao efeito tóxico dos compostos em estudo, uma vez que G0/RuNO e G2/RuNO, os quais têm complexos de rutênio ligados na superfície do dendrímero, apresentaram citotoxicidade similar à observada para o complexo livre (RuNO). Dessa forma, pode-se inferir que a citotoxicidade verificada para os compostos G0/RuNO e G2/RuNO possivelmente está relacionada ao complexo de rutênio que está ligado à superfície desses dendrímeros.

\subsection{2 - Resultados preliminares da atividade tripanocida in vitro sobre as formas}

\section{tripomastigotas do $T$. cruzi}

A Figura 49 reúne os resultados preliminares da atividade tripanocida in vitro para os compostos de rutênio livre e ancorado aos dendrímeros PAMAM de geração 0 e 2, e do benznidazol (controle positivo). 


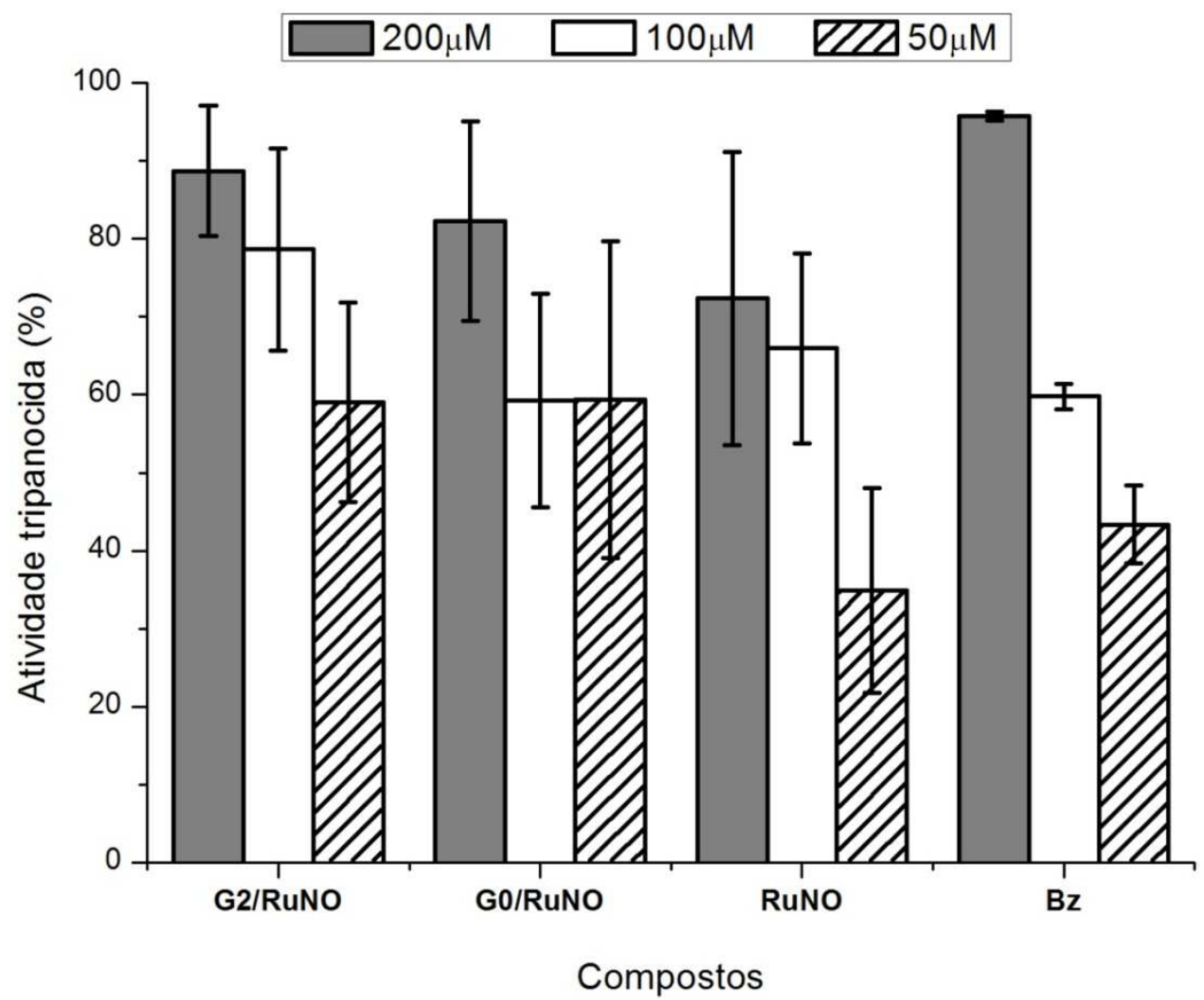

Figura 49 - Atividade tripanocida para os nitrosilo complexos de rutênio e para Bz (controle positivo) sobre as formas tripomastigotas do $T$. cruzi após $24 \mathrm{~h}$ de incubação. As concentrações dos nitrosilo complexos utilizadas nos testes foram normalizadas em relação à quantidade de rutênio.

É possível observar que houve uma grande dispersão nos resultados de atividade tripanocida (AT) para praticamente todos os compostos utilizados nos testes, com exceção do Bz, em que verifica-se pequenos desvios em relação à média. Essa dispersão pode ser atribuída ao reduzido número de experimentos realizados para a atividade tripanocida, constituindo-se até o momento de duas repetições independentes, em duplicata. Apesar dos desvios serem significativos, foi possível verificar que para a concentração de $200 \mu \mathrm{M}$, os valores médios da AT foram aproximadamente $88 \%$ para G2/RuNO, $82 \%$ para G0/RuNO e $72 \%$ para RuNO, enquanto que para o Bz, a média da atividade tripanocida foi de $96 \%$. Já para a concentração de $100 \mu \mathrm{M}$, apenas a atividade tripanocida do composto G2/RuNO foi ligeiramente superior à do $\mathrm{Bz}$ e na concentração de $50 \mu \mathrm{M}$, os compostos $\mathrm{G} 2 / \mathrm{RuNO}$ e 
G0/RuNO apresentaram resultados similares aos obtidos para Bz. Baseando-se em estudos realizados para outros nitrosilo complexos de rutênio, a atividade tripanocida observada para os compostos RuNO, G0/RuNO e G2/RuNO possivelmente está relacionada à liberação de NO [49].

Apesar dos resultados obtidos até o momento não serem conclusivos em relação à ação tripanocida dos compostos em estudo neste trabalho, os dados demonstram que é possível utilizar nitrosilo compostos de rutênio ligados a dendrímeros como sistemas carregadores/liberadores de NO. Também é importante ressaltar a necessidade de se realizar mais ensaios de atividade tripanocida com o objetivo de tentar reduzir os desvios observados nos testes preliminares, tornando os resultados mais concretos.

Em adição, com base nos resultados preliminares, pretende-se realizar novos testes de atividade tripanocida empregando-se concentrações dos complexos de rutênio superiores às utilizadas neste trabalho, pois a baixa citotoxicidade verificada para esses compostos (item 4.5.1) possibilita essa alternativa. Essa estratégia pode resultar em um aumento na atividade tripanocida dos nitrosilo complexos de rutênio livre e ancorados aos dendrímeros.

\subsection{3 - Resultados preliminares de atividade leishmanicida in vitro sobre as formas} promastigotas de L. major

A Figura 50 ilustra os resultados obtidos para a atividade leishmanicida in vitro dos compostos de rutênio contra a forma promastigota do parasito L. major. 


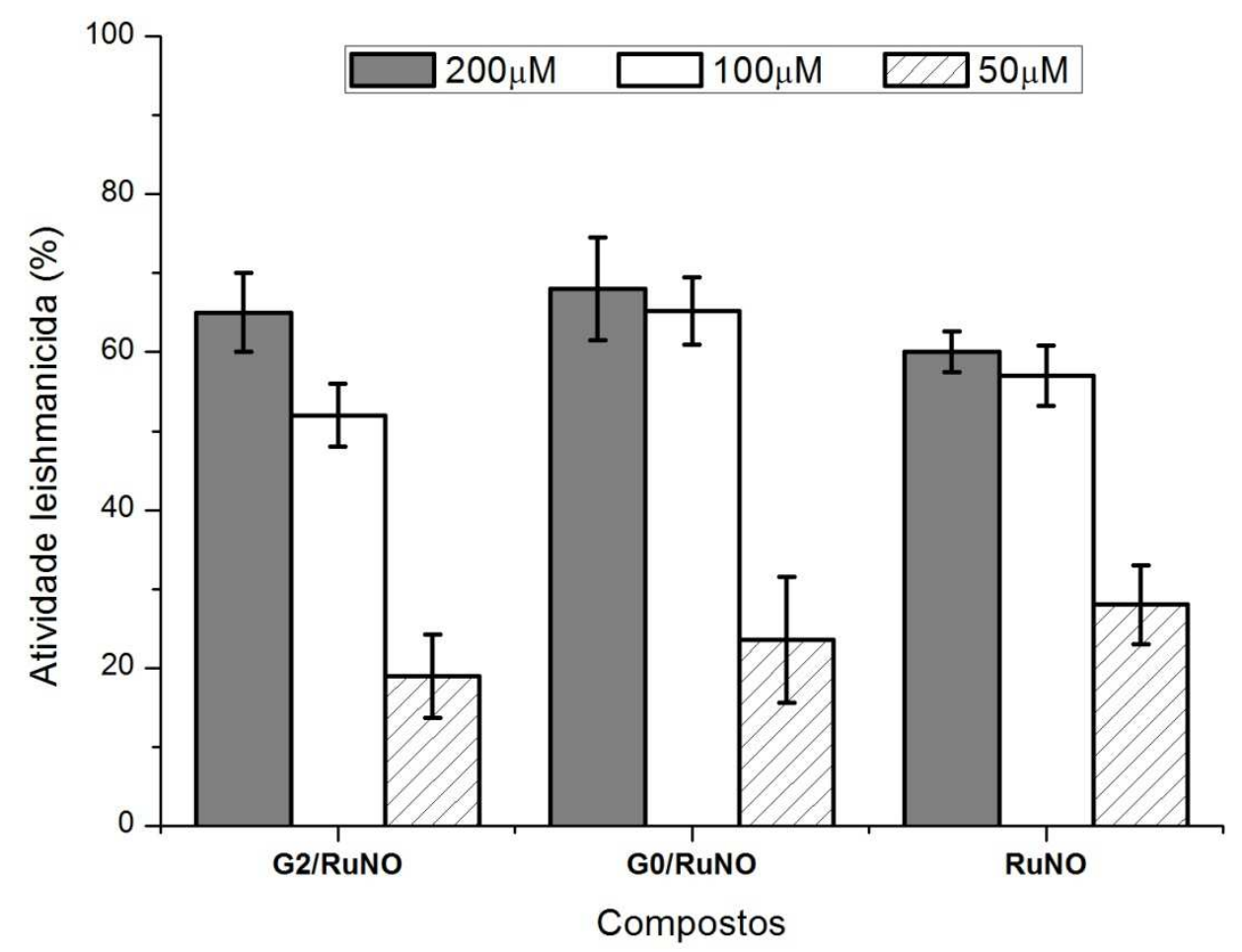

Figura 50 - Atividade leishmanicida para os nitrosilo complexos de rutênio sobre as formas promastigotas de L. major após $24 \mathrm{~h}$ de incubação. As concentrações dos nitrosilo complexos utilizadas nos testes foram normalizadas em relação à quantidade de rutênio.

Os melhores resultados de atividade leishmanicida foram obtidos na concentração de $200 \mu \mathrm{M}$ para os três compostos em estudo, os quais apresentaram atividade entre 60 a $70 \%$ (65\% para G2RuNO, 69\% para G0/RuNO e 60\% para RuNO). Resultados similares foram obtidos por Pereira e colaboradores[48] para alguns nitrosilo complexos de rutênio, dentre os quais trans- $\left[\mathrm{Ru}^{\mathrm{II}}\left(\mathrm{NO}^{+}\right)\left(\mathrm{NH}_{3}\right)_{4}\right.$ isn $]\left(\mathrm{BF}_{4}\right)_{3}$, que apresentou $\mathrm{IC}_{50}=280 \mu \mathrm{M}$. O parâmetro $\mathrm{IC}_{50}$ pode ser utilizado para comparar o potencial leishmanicida de diferentes compostos, no entanto, para os complexos em estudo neste trabalho não foi possível calcular esse parâmetro até o momento, devido ao limitado número de experimentos realizados (duas repetições em duplicada).

Da mesma forma que para a atividade tripanocida, atribui-se a atividade leishmanicida dos complexos G0/RuNO, G2/RuNO e RuNO à liberação da molécula de óxido nítrico. Também devem-se realizar novos ensaios para atividade tripanocida dos compostos de rutênio 
em estudo utilizando-se concentrações superiores às utilizadas neste trabalho, o que poderia aumentar a eficiência desses compostos contra o parasito L. major.

Em trabalhos futuros pretende-se realizar ensaios in vivo contra os parasitos L. major e T. cruzi utilizando-se os complexos livre e ancorados aos dendrímeros. Além dos testes de atividade tripanocida e leishmanicida, estudos de biodistribuição, análogos aos realizados por Zanichelli e colaboradores[87], permitirão avaliar se os compostos ligados aos dendrímeros permanecem por mais tempo no organismo dos animais utilizados nos testes que o respectivo composto livre (não ligados ao dendrímero). Conforme discutido anteriormente (item 1.6), o aumento no tempo de permanência dos nitrosilo complexos de rutênio na circulação dos animais pode, eventualmente, propiciar a regeneração desses complexos dentro do organismo. Isso permitiria que o número de doses utilizadas no tratamento contra parasitos fosse reduzido, uma vez que a atuação dos complexos em cada dose seria prolongada. 


\section{V - CONSIDERAÇÕES FINAIS}

O ancoramento do ntirosilo complexo de rutênio em dendrímeros PAMAM de geração 0 e 2 foi efetuado com sucesso por meio da formação de ligação peptídica. Os resultados de espectroscopia eletrônica e eletroquímica indicaram que os compostos ancorados aos dendrímeros apresentam características similares às observadas para o complexo livre (nãoligado ao dendrímero).

Os ensaios de citotoxicidade in vitro indicaram que os nitrosilo complexos RuNO, G0/RuNO e G2/RuNO têm baixo efeito tóxico ( $<15 \%$ para $\mathrm{C}_{\mathrm{Ru}}=200,100$ e $\left.50 \mu \mathrm{M}\right)$ às células do baço de camundongos (células saudáveis) e que portanto podem ser utilizados como sistemas liberadores de NO em testes contra os parasitos T. cruzi e L. major. Pretende-se realizar novos ensaios de atividade tripanocida e leishmanicida in vitro utilizando-se concentrações dos complexos superiores às deste trabalho, bem como testes de biodistribuição, citotoxicidade e atividade tripanocida e leishmanicida in vivo. 


\section{VI - REFERÊNCIAS BIBLIOGRÁFICAS}

1. NWAKA, S.; RIDLEY, R. G. Virtual drug discovery and development for neglected diseases through public-private partnerships. Nature Reviews Drug Discovery, v. 2, n. 11, p. 919-928, 2003.

2. KETTLER, H. E.; MARJANOVIC, S. Engaging biotechnology companies in the development of innovative solutions for diseases of poverty. Nature Reviews Drug Discovery, v. 3, n. 2, p. 171-176, 2004.

3. WORLD HEALTH ORGANIZATION, W. H. O. A turning point: report of the global partners' meeting on neglected tropical diseases. Geneva: World Health Organization, 2007. 77 p.

4. WORLD HEALTH ORGANIZATION, W. H. O. The world health report 2002: reducing risk, promoting healthy life. Geneva: World Health Organization, 2002. 248 p.

5. KOLA, I. The state of innovation in drug development. Clinical Pharmacology \& Therapeutics, v. 83, n. 2, p. 227-230, 2008.

6. DIAS, L. C.; DESSOY, M. A.; SILVA, J. J. N.; THIEMANN, O. H.; OLIVA, G.; ANDRICOPULO, A. D. Quimioterapia da doença de chagas: estado da arte e perspectivas no desenvolvimento de novos fármacos. Quimica Nova, v. 32, n. 9, p. 2444-2457, 2009.

7. IGREJA, R. P. Chagas disease 100 years after its discovery. Lancet, v. 373, n. 9672, p. 1340-1340, 2009.

8. HOTEZ, P. J.; MOLYNEUX, D. H.; FENWICK, A.; KUMARESAN, J.; SACHS, S. E.; SACHS, J. D.; SAVIOLI, L. Current concepts - control of neglected tropical diseases. New England Journal of Medicine, v. 357, n. 10, p. 1018-1027, 2007.

9. RASSI JUNIOR, A.; RASSI, A.; MARIN-NETO, J. A. Chagas disease. Lancet, v. 375, n. 9723, p. 1388-1402, 2010.

10. CLAYTON, J. Chagas disease 101. Nature, v. 465, n. 7301, p. S4-S5, 2010.

11. SILVA, J. J.; PAVANELLI, W. R.; PEREIRA, J. C.; SILVA, J. S.; FRANCO, D. W. Experimental chemotherapy against Trypanosoma cruzi infection using ruthenium NOdonors. Antimicrobial Agents and Chemotherapy, v. 53, n. 10, p. 4414-4421, 2009.

12. RASSI JR, A.; RASSI, A.; MARIN-NETO, J. A. Chagas disease. Lancet, v. 375, n. 9723 , p. 1388-1402, 2010.

13. UMEZAWA, E. S.; STOLF, A. M.; CORBETT, C. E.; SHIKANAI-YASUDA, M. A. Chagas' disease. Lancet, v. 357, n. 9258, p. 797-799, 2001.

14. ANDRADE, A. L.; ZICKER, F.; DE OLIVEIRA, R. M.; ALMEIDA SILVA, S.; LUQUETTI, A.; TRAVASSOS, L. R.; ALMEIDA, I. C.; DE ANDRADE, S. S.; DE 
ANDRADE, J. G.; MARTELLI, C. M. Randomised trial of efficacy of benznidazole in treatment of early Trypanosoma cruzi infection. Lancet, v. 348, n. 9039, p. 1407-1413, 1996.

15. FAUNDEZ, M.; PINO, L.; LETELIER, P.; ORTIZ, C.; LOPEZ, R.; SEGUEL, C.; FERREIRA, J.; PAVANI, M.; MORELLO, A.; MAYA, J. D. Buthionine sulfoximine increases the toxicity of nifurtimox and benznidazole to Trypanosoma cruzi. Antimicrobial Agents and Chemotherapy, v. 49, n. 1, p. 126-130, 2005.

16. SILVA, J. J. N.; PAVANELLI, W. R.; GUTIERREZ, F. R. S.; LIMA, F. C. A.; DA SILVA, A. B. F.; SILVA, J. S.; FRANCO, D. W. Complexation of the antiTrypanosoma cruzi drug benznidazole improves solubility and efficacy. Journal of Medicinal Chemistry, v. 51, n. 14, p. 4104-4114, 2008.

17. VIOTTI, R.; VIGLIANO, C.; LOCOCO, B.; BERTOCCHI, G.; PETTI, M.; ALVAREZ, M. G.; POSTAN, M.; ARMENTI, A. Long-term cardiac outcomes of treating chronic Chagas disease with benznidazole versus no treatment: a nonrandomized trial. Annals of Internal Medicine, v. 144, n. 10, p. 724-734, 2006.

18. JACKSON, Y.; ALIROL, E.; GETAZ, L.; WOLFF, H.; COMBESCURE, C.; CHAPPUIS, F. Tolerance and safety of nifurtimox in patients with chronic chagas disease. Clinical Infectious Diseases, v. 51, n. 10, p. E69-E75, 2010.

19. MAYA, J. D.; CASSELS, B. K.; ITURRIAGA-VASQUEZ, P.; FERREIRA, J.; FAUNDEZ, M.; GALANTI, N.; FERREIRA, A.; MORELLO, A. Mode of action of natural and synthetic drugs against Trypanosoma cruzi and their interaction with the mammalian host. Comparative Biochemistry and Physiology a-Molecular \& Integrative Physiology, v. 146, n. 4, p. 601-620, 2007.

20. OLIVEIRA, M. F.; NAGAO-DIAS, A. T.; PONTES, V. M. O.; SOUZA JR, A. S. S.; COELHO, H. L. L.; COELHO, I. C. B. Tratamento etiológico da doença de Chagas no Brasil. Revista de Patologia Tropical, v. 37, n. 3, p. 209-228, 2008.

21. CASTRO, J. A.; DE MECCA, M. M.; BARTEL, L. C. Toxic side effects of drugs used to treat Chagas' disease (American trypanosomiasis). Human \& Experimental Toxicology, v. 25, n. 8, p. 471-479, 2006.

22. HERWALDT, B. L. Leishmaniasis. Lancet, v. 354, n. 9185, p. 1191-1199, 1999.

23. SANTOS, D. O.; COUTINHO, C. E. R.; MADEIRA, M. F.; BOTTINO, C. G.; VIEIRA, R. T.; NASCIMENTO, S. B.; BERNARDINO, A.; BOURGUIGNON, S. C.; CORTEREAL, S.; PINHO, R. T.; RODRIGUES, C. R.; CASTRO, H. C. Leishmaniasis treatment - a challenge that remains: a review. Parasitology Research, v. 103, n. 1, p. $1-10,2008$.

24. GOTO, H.; LINDOSO, J. A. L. Immunity and immunosuppression in experimental visceral leishmaniasis. Brazilian Journal of Medical and Biological Research, v. 37, n. 4, p. 615-623, 2004. 
25. PETERSON, A. T.; SHAW, J. Lutzomyia vectors for cutaneous leishmaniasis in Southern Brazil: ecological niche models, predicted geographic distributions, and climate change effects. International Journal for Parasitology, v. 33, n. 9, p. 919-931, 2003.

26. REITHINGER, R.; DUJARDIN, J. C.; LOUZIR, H.; PIRMEZ, C.; ALEXANDER, B.; BROOKER, S. Cutaneous leishmaniasis. Lancet Infectious Diseases, v. 7, n. 9, p. 581596, 2007.

27. ROCHA, L. G.; ALMEIDA, J. R. G. S.; MACEDO, R. O.; BARBOSA-FILHO, J. M. A review of natural products with antileishmanial activity. Phytomedicine, v. 12, n. 6-7, p. 514-535, 2005.

28. HERWALDT, B. L. Laboratory-acquired parasitic infections from accidental exposures. Clinical Microbiology Reviews, v. 14, n. 4, p. 659-688, 2001.

29. MINODIER, P.; PAROLA, P. Cutaneous leishmaniasis treatment. Travel Medicine and Infectious Disease, v. 5, n. 3, p. 150-158, 2007.

30. FREZARD, F.; DEMICHELI, C.; RIBEIRO, R. R. Pentavalent antimonials: new perspectives for old drugs. Molecules, v. 14, n. 7, p. 2317-2336, 2009.

31. CROFT, S. L.; SUNDAR, S.; FAIRLAMB, A. H. Drug resistance in leishmaniasis. Clinical Microbiology Reviews, v. 19, n. 1, p. 111-+, 2006.

32. NAVARRO, M.; GABBIANI, C.; MESSORI, L.; GAMBINO, D. Metal-based drugs for malaria, trypanosomiasis and leishmaniasis: recent achievements and perspectives.

Drug Discovery Today, v. 15, n. 23-24, p. 1070-1078, 2010.

33. GONTIJO, B.; CARVALHO, M. L. R. Leishmaniose tegumentar americana. Revista Da Sociedade Brasileira De Medicina Tropical, v. 36, n. 1, p. 71-80, 2003.

34. BERMAN, J. D. Human leishmaniasis: Clinical, diagnostic, and chemotherapeutic developments in the last 10 years. Clinical Infectious Diseases, v. 24, n. 4, p. 684-703, 1997.

35. FRICKER, S. P.; MOSI, R. M.; CAMERON, B. R.; BAIRD, I.; ZHU, Y. B.; ANASTASSOV, V.; COX, J.; DOYLE, P. S.; HANSELL, E.; LAU, G.; LANGILLE, J.; OLSEN, M.; QIN, L.; SKERLJ, R.; WONG, R. S. Y.; SANTUCCI, Z.; MCKERROW, J. H. Metal compounds for the treatment of parasitic diseases. Journal of Inorganic Biochemistry, v. 102, n. 10, p. 1839-1845, 2008.

36. NAVARRO, M. Gold complexes as potential anti-parasitic agents. Coordination Chemistry Reviews, v. 253, n. 11-12, p. 1619-1626, 2009.

37. FARRELL, N. P.; WILLIAMSON, J.; MCLAREN, D. J. M. Trypanocidal and antitumour activity of platinum-metal and platinum-metal-drug dual-function complexes. Biochemical Pharmacology, v. 33, n. 7, p. 961-971, 1984.

38. SANCHEZ-DELGADO, R. A.; ANZELLOTTI, A.; SUAREZ, L. Metal complexes as chemotherapeutic agents against tropical diseases: Malaria, trypanosomiasis, and 
leishmaniasis. Metal Ions in Biological Systems, Vol 41: Metal Ions and Their

Complexes in Medication, v. 41, n. p. 379-419, 2004.

39. SANCHEZ-DELGADO, M. C.; NAVARRO, M.; LAZARDI, K.; ATENCIO, R.; CAPPARELLI, M.; VARGAS, F.; URBINA, J. A.; BOUILLEZ, A.; NOELS, A. F.; MASI, D. Toward a novel metal based chemotherapy against tropical diseases 4 . Synthesis and characterization of new metal-clotrimazole complexes and evaluation of their activity against Trypanosoma cruzi. Inorganica Chimica Acta, v. 276, n. p. 528540, 1998.

40. OTERO, L.; VIEITES, M.; BOIANI, L.; DENICOLA, A.; RIGOL, C.; OPAZO, L.; OLEA-AZAR, C.; MAYA, J. D.; MORELLO, A.; KRAUTH-SIEGEL, R. L.; PIRO, O. E.; CASTELLANO, E.; GONZALEZ, M.; GAMBINO, D.; CERECETTO, H. Novel antitrypanosomal agents based on palladium nitrofurylthiosemicarbazone complexes: DNA and redox metabolism as potential therapeutic targets. Journal of Medicinal Chemistry, v. 49, n. 11, p. 3322-3331, 2006.

41. PAGANO, M.; DEMORO, B.; TOLOZA, J.; BOIANI, L.; GONZALEZ, M.; CERECETTO, H.; OLEA-AZAR, C.; NORAMBUENA, E.; GAMBINO, D.; OTERO, L. Effect of ruthenium complexation on trypanocidal activity of 5-nitrofuryl containing thiosemicarbazones. European Journal of Medicinal Chemistry, v. 44, n. 12, p. 4937 4943, 2009.

42. DEMORO, B.; CARUSO, F.; ROSSI, M.; BENITEZ, D.; GONZALEZ, M.; CERECETTO, H.; PARAJON-COSTA, B.; CASTIGLIONI, J.; GALIZZI, M.; DOCAMPO, R.; OTERO, L.; GAMBINO, D. Risedronate metal complexes potentially active against Chagas disease. Journal of Inorganic Biochemistry, v. 104, n. 12, p. 1252-1258, 2010.

43. VIEITES, M.; OTERO, L.; SANTOS, D.; OLEA-AZAR, C.; NORAMBUENA, E.; AGUIRRE, G.; CERECETTO, H.; GONZALEZ, M.; KEMMERLING, U.; MORELLO, A.; MAYA, J. D.; GAMBINO, D. Platinum-based complexes of bioactive 3-(5-nitrofuryl)acroleine thiosemicarbazones showing anti-Trypanosoma cruzi activity. Journal of Inorganic Biochemistry, v. 103, n. 3, p. 411-418, 2009.

44. VIEITES, M.; OTERO, L.; SANTOS, D.; TOLOZA, J.; FIGUEROA, R.; NORAMBUENA, E.; OLEA-AZAR, C.; AGUIRRE, G.; CERECETTO, H.; GONZALEZ, M.; MORELLO, A.; MAYA, J. D.; GARAT, B.; GAMBINO, D. Platinum(II) metal complexes as potential anti-Trypanosoma cruzi agents. Journal of Inorganic Biochemistry, v. 102, n. 5-6, p. 1033-1043, 2008.

45. VIEITES, M.; SMIRCICH, P.; PARAJON-COSTA, B.; RODRIGUEZ, J.; GALAZ, V.; OLEA-AZAR, C.; OTERO, L.; AGUIRRE, G.; CERECETTO, H.; GONZALEZ, M.; GOMEZ-BARRIO, A.; GARAT, B.; GAMBINO, D. Potent in vitro anti-Trypanosoma cruzi activity of pyridine-2-thiol N-oxide metal complexes having an inhibitory effect on parasite-specific fumarate reductase. Journal of Biological Inorganic Chemistry, v. 13, n. 5, p. 723-735, 2008.

46. MAFFEI, R. D.; YOKOYAMA-YASUNAKA, J. K. U.; MIGUEL, D. C.; ULIANA, S. R. B.; ESPOSITO, B. P. Synthesis, characterization and evaluation of antileishmanial 
activity of copper(II) with fluorinated alpha-hydroxycarboxylate ligands. Biometals, v. 22, n. 6, p. 1095-1101, 2009.

47. GUEDES, P. M. M.; OLIVEIRA, F. S.; GUTIERREZ, F. R. S.; DA SILVA, G. K.; RODRIGUES, G. J.; BENDHACK, L. M.; FRANCO, D. W.; MATTA, M. A. D.; ZAMBONI, D. S.; DA SILVA, R. S.; SILVA, J. S. Nitric oxide donor trans$[\mathrm{RuCl}([15]$ aneN(4))NO]2+as a possible therapeutic approach for Chagas' disease. British Journal of Pharmacology, v. 160, n. 2, p. 270-282, 2010.

48. PEREIRA, J. C. M.; CARREGARO, V.; COSTA, D. L.; DA SILVA, J. S.; CUNHA, F. Q.; FRANCO, D. W. Antileishmanial activity of ruthenium(II)tetraammine nitrosyl complexes. European Journal of Medicinal Chemistry, v. 45, n. 9, p. 4180-4187, 2010 .

49. SILVA, J. J.; OSAKABE, A. L.; PAVANELLI, W. R.; SILVA, J. S.; FRANCO, D. W. In vitro and in vivo antiproliferative and trypanocidal activities of ruthenium NO donors. British Journal of Pharmacology, v. 152, n. 1, p. 112-121, 2007.

50. SILVA, J. J. N.; GUEDES, P. M. M.; ZOTTIS, A.; BALLIANO, T. L.; SILVA, F. O. N.; LOPES, L. G. F.; ELLENA, J.; OLIVA, G.; ANDRICOPULO, A. D.; FRANCO, D. W.; SILVA, J. S. Novel ruthenium complexes as potential drugs for Chagas's disease: enzyme inhibition and in vitro/in vivo trypanocidal activity. British Journal of Pharmacology, v. 160, n. 2, p. 260-269, 2010.

51. PAVANELLI, W. R.; SILVA, J. J. N. The role of nitric oxide in immune response against trypanosoma cruzi infection. The Open Nitric Oxide Journal, v. 2, n. p. 1-6, 2010.

52. BARROS, B. F.; TOLEDO, J. C.; FRANCO, D. W.; TFOUNI, E.; KRIEGER, M. H. A new inorganic vasodilator, trans-[Ru(NO)(NH3)(4)(POEt)(3)](PF6)(3): hypotensive effect of endothelium-dependent and -independent vasodilators in different hypertensive animals models. Nitric Oxide-Biology and Chemistry, v. 7, n. 1, p. 50-56, 2002.

53. CARMELI, E.; BEIKER, R.; MORAD, M. Nitric oxide and interlukin-6 levels in intellectual disability adults with epilepsy. Research in Developmental Disabilities, v. 30, n. 3, p. 567-571, 2009.

54. KONSTADT, S. Nitric oxide: Has it progressed from molecule of the year to wonder drug of the decade? Journal of Cardiothoracic and Vascular Anesthesia, v. 9, n. 6, p. 625626, 1995.

55. TFOUNI, E.; KRIEGER, M.; MCGARVEY, B. R.; FRANCO, D. W. Structure, chemical and photochemical reactivity and biological activity of some ruthenium amine nitrosyl complexes. Coordination Chemistry Reviews, v. 236, n. 1-2, p. 57-69, 2003.

56. MCCLEVERTY, J. A. Chemistry of nitric oxide relevant to biology. Chemical Reviews, v. 104, n. 2, p. 403-418, 2004.

57. PALMER, R. M.; ASHTON, D. S.; MONCADA, S. Vascular endothelial cells synthesize nitric oxide from L-arginine. Nature, v. 333, n. 6174, p. 664-666, 1988. 
58. ZWEIER, J. L.; WANG, P. H.; SAMOUILOV, A.; KUPPUSAMY, P. Enzymeindependent formation of nitric-oxide in biological tissues. Nature Medicine, v. 1, n. 8 , p. 804-809, 1995.

59. IGNARRO, L. J. Biosynthesis and metabolism of endothelium-derived nitric oxide. Annual Review of Pharmacology and Toxicology, v. 30, n. p. 535-560, 1990.

60. MCCLEVERTY, J. A. Chemistry of nitric oxide relevant to biology. Chemichal Reviews, v. 104, n. 2, p. 403-418, 2004.

61. LANCASTER, J. R., JR. Diffusion of free nitric oxide. Methods in Enzymology, v. 268, n. p. 31-50, 1996.

62. IGNARRO, L. J. Signal Transduction Mechanisms Involving Nitric-Oxide. Biochemical Pharmacology, v. 41, n. 4, p. 485-490, 1991.

63. PACHER, P.; BECKMAN, J. S.; LIAUDET, L. Nitric oxide and peroxynitrite in health and disease. Physiological Reviews, v. 87, n. 1, p. 315-424, 2007.

64. DE BARROS, B. F.; TOLEDO, J. C.; FRANCO, D. W.; TFOUNI, E.; KRIEGER, M. H. A new inorganic vasodilator, trans-[Ru(NO)(NH3)(4)(POEt)(3)](PF6)(3): hypotensive effect of endothelium-dependent and -independent vasodilators in different hypertensive animals models. Nitric Oxide-Biology and Chemistry, v. 7, n. 1, p. 50-56, 2002.

65. BARRETO, R. D. L.; CORREIA, C. R. D.; MUSCARÁ, M. N. Óxido nítrico: propriedades e potenciais usos terapêuticos. Quimica Nova, v. 28, n. 6, p. 1046-1054, 2005.

66. IGNARRO, L. J. Endothelium-derived nitric-oxide - actions and properties. Faseb Journal, v. 3, n. 1, p. 31-36, 1989.

67. KONSTADT, S. Nitric oxide: has it progressed from molecule of the year to wonder drug of the decade? Journal of Cardiothoracic and Vascular Anesthesia, v. 9, n. 6, p. 625626, 1995.

68. DIMMELER, S.; ZEIHER, A. M. Nitric oxide and apoptosis: Another paradigm for the double-edged role of nitric oxide. Nitric Oxide-Biology and Chemistry, v. 1, n. 4, p. 275-281, 1997.

69. GUTIERREZ, F. R. S.; MINEO, T. W. P.; PAVANELLI, W. R.; GUEDES, P. M. M.; SILVA, J. S. The effects of nitric oxide on the immune system during Trypanosoma cruzi infection. Memorias Do Instituto Oswaldo Cruz, v. 104, n. p. 236-245, 2009.

70. SALVATI, L.; MATTU, M.; COLASANTI, M.; SCALONE, A.; VENTURINI, G.; GRADONI, L.; ASCENZI, P. NO donors inhibit Leishmania infantum cysteine proteinase activity. Biochimica Et Biophysica Acta-Protein Structure and Molecular Enzymology, v. 1545, n. 1-2, p. 357-366, 2001.

71. GARNICA, M. R.; SILVA, J. S.; DE ANDRADE, H. F. Stromal cell-derived factor-1 production by spleen cells is affected by nitric oxide in protective immunity against 
blood-stage Plasmodium chabaudi CR in C57BL/6j mice. Immunology Letters, v. 89, n. 2-3, p. 133-142, 2003.

72. LUDER, C. G. K.; ALGNER, M.; LANG, C.; BLEICHER, N.; GROSS, U. Reduced expression of the inducible nitric oxide synthase after infection with Toxoplasma gondii facilitates parasite replication in activated murine macrophages. International Journal for Parasitology, v. 33, n. 8, p. 833-844, 2003.

73. VESPA, G. N. R.; CUNHA, F. Q.; SILVA, J. S. Nitric oxide is involved in control of Trypanosoma cruzi-induced parasitemia and directly kills the parasite in vitro. Infection and Immunity, v. 62, n. 11, p. 5177-5182, 1994.

74. COOPER, A. M.; ADAMS, L. B.; DALTON, D. K.; APPELBERG, R.; EHLERS, S. IFNgamma and NO in mycobacterial disease: new jobs for old hands. Trends in Microbiology, v. 10, n. 5, p. 221-226, 2002.

75. FUJII, S.; AKAIKE, T.; MAEDA, H. Role of nitric oxide in pathogenesis of herpes simplex virus encephalitis in rats. Virology, v. 256, n. 2, p. 203-212, 1999.

76. MAUEL, J.; RANSIJN, A. Leishmania spp.: Mechanisms of toxicity of nitrogen oxidation products. Experimental Parasitology, v. 87, n. 2, p. 98-111, 1997.

77. SILVA, J. S.; MACHADO, F. S.; MARTINS, G. A. The role of nitric oxide in the pathogenesis of Chagas disease. Frontiers in Bioscience, v. 8, n. p. s314-325, 2003.

78. GEA, S.; GUIÑAZU, N.; PELLEGRINI, A.; CARRERA SILVA, E. A.; GIORDANENGO, L.; CANO, R.; AOKI, M. P. Cruzipain, a major Trypanosoma cruzi cystein protease in the host-parasite interplay. Inmunología, v. 25, n. 4, p. 225-238, 2006.

79. VENTURINI, G.; SALVATI, L.; MUOLO, M.; COLASANTI, M.; GRADONI, L.; ASCENZI, P. Nitric oxide inhibits cruzipain, the major papain-like cysteine proteinase from Trypanosoma cruzi. Biochemical and Biophysical Research Communications, v. 270, n. 2, p. 437-441, 2000.

80. LUNDBERG, J. O.; GLADWIN, M. T.; AHLUWALIA, A.; BENJAMIN, N.; BRYAN, N. S.; BUTLER, A.; CABRALES, P.; FAGO, A.; FEELISCH, M.; FORD, P. C.; FREEMAN, B. A.; FRENNEAUX, M.; FRIEDMAN, J.; KELM, M.; KEVIL, C. G.; KIM-SHAPIRO, D. B.; KOZLOV, A. V.; LANCASTER, J. R.; LEFER, D. J.; MCCOLL, K.; MCCURRY, K.; PATEL, R. P.; PETERSSON, J.; RASSAF, T.; REUTOV, V. P.; RICHTER-ADDO, G. B.; SCHECHTER, A.; SHIVA, S.; TSUCHIYA, K.; VAN FAASSEN, E. E.; WEBB, A. J.; ZUCKERBRAUN, B. S.; ZWEIER, J. L.; WEITZBERG, E. Nitrate and nitrite in biology, nutrition and therapeutics. Nature Chemical Biology, v. 5, n. 12, p. 865-869, 2009.

81. FORD, P. C.; LORKOVIC, I. M. Mechanistic aspects of the reactions of nitric oxide with transition-metal complexes. Chemical Reviews, v. 102, n. 4, p. 993-1017, 2002. 
82. WANG, P. G.; XIAN, M.; TANG, X. P.; WU, X. J.; WEN, Z.; CAI, T. W.; JANCZUK, A. J. Nitric oxide donors: Chemical activities and biological applications. Chemical Reviews, v. 102, n. 4, p. 1091-1134, 2002.

83. TOLEDO, J. C.; SILVA, H. A. S.; SCARPELLINI, M.; MORI, V.; CAMARGO, A. J.; BERTOTTI, M.; FRANCO, D. W. Ruthenium tetraammines as a model of nitric oxide donor compounds. European Journal of Inorganic Chemistry, v. n. 9, p. 1879-1885, 2004.

84. CARAMORI, G. F.; FRENKING, G. The effects of n-heterocyclic ligands on the nature of the $\mathrm{Ru}-(\mathrm{NO})$ bond in ruthenium tetraammine nitrosyl complexes. Croatica Chemica Acta, v. 82, n. 1, p. 219-232, 2009.

85. MIRANDA, K. M. The chemistry of nitroxyl (HNO) and implications in biology. Coordination Chemistry Reviews, v. 249, n. 3-4, p. 433-455, 2005.

86. TOLEDO, J. C.; LOPES, L. G. D.; ALVES, A. A.; DA SILVA, L. P.; FRANCO, D. W. Release of NO by a nitrosyl complex upon activation by the mitochondrial reducing power. Journal of Inorganic Biochemistry, v. 89, n. 3-4, p. 267-271, 2002.

87. ZANICHELLI, P. G.; MIOTTO, A. M.; ESTRELA, H. F.; SOARES, F. R.; GRASSIKASSISSE, D. M.; SPADARI-BRATFISCH, R. C.; CASTELLANO, E. E.; RONCAROLI, F.; PARISE, A. R.; OLABE, J. A.; DE BRITO, A. R.; FRANCO, D. W. The $[\mathrm{Ru}(\mathrm{Hedta}) \mathrm{NO}]^{0,1-}$ system: structure, chemical reactivity and biological assays. Journal of Inorganic Biochemistry, v. 98, n. 11, p. 1921-1932, 2004.

88. MARGERUM, L. D.; CAMPION, B. K.; KOO, M.; SHARGILL, N.; LAI, J. J.; MARUMOTO, A.; SONTUM, P. C. Gadolinium(III) DO3A macrocycles and polyethylene glycol coupled to dendrimers - Effect of molecular weight on physical and biological properties of macromolecular magnetic resonance imaging contrast agents.

Journal of Alloys and Compounds, v. 249, n. 1-2, p. 185-190, 1997.

89. TFOUNI, E.; DORO, F. G.; GOMES, A. J.; DA SILVA, R. S.; METZKER, G.; BENINI, P. G. Z.; FRANCO, D. W. Immobilized ruthenium complexes and aspects of their reactivity. Coordination Chemistry Reviews, v. 254, n. 3-4, p. 355-371, 2010.

90. HIMENO, M.; ISHIBASHI, T.; NAKANO, S.; FURUYA, K.; YOSHIDA, J.; KIGOSHI, T.; UCHIDA, K.; NISHIO, M. Implication of steady state concentrations of nitrite and nitrate metabolites of nitric oxide in plasma and whole blood in healthy human subjects. Clinical and Experimental Pharmacology and Physiology, v. 31, n. 9, p. 591-596, 2004.

91. MASTRORILLI, P.; NOBILE, C. F. Supported catalysts from polymerizable transition metal complexes. Coordination Chemistry Reviews, v. 248, n. 3-4, p. 377-395, 2004.

92. DORO, F. G.; RODRIGUES, U. P.; TFOUNI, E. A regenerable ruthenium tetraammine nitrosyl complex immobilized on a modified silica gel surface: Preparation and studies of nitric oxide release and nitrite-to-NO conversion. Journal of Colloid and Interface Science, v. 307, n. 2, p. 405-417, 2007. 
93. STANDFEST-HAUSER, C. M.; LUMMERSTORFER, T.; SCHMID, R.; KIRCHNER, K.; HOFFMANN, H.; PUCHBERGER, M. Immobilization, characterization, and preliminary reactivity studies of halfsandwich ruthenium complexes on silica.

Monatshefte Fur Chemie, v. 134, n. 9, p. 1167-1175, 2003.

94. ZANICHELLI, P. G.; SERNAGLIA, R. L.; FRANCO, D. W. Immobilization of the [RuII(edta)NO+] ion on the surface of functionalized silica gel. Langmuir, v. 22, n. 1, p. 203-208, 2006.

95. FERREIRA, K. Q.; SCHNEIDER, J. F.; NASCENTE, P. A. P.; RODRIGUES, U. P.; TFOUNI, E. Design of an NO photoinduced releaser xerogel based on the controlled nitric oxide donor trans-[Ru(NO)Cl(cyclam)](PF6)(2) (cyclam=1,4,8, 11tetraazacyclotetradecane). Journal of Colloid and Interface Science, v. 300, n. 2, p. 543-552, 2006.

96. BENINI, P. G. Z.; MCGARVEY, B. R.; FRANCO, D. W. Functionalization of PAMAM dendrimers with [Ru-III(edta)(H2O)](-). Nitric Oxide-Biology and Chemistry, v. 19, n. 3, p. 245-251, 2008.

97. STASKO, N. A.; SCHOENFISCH, M. H. Dendrimers as a scaffold for nitric oxide release. Journal of the American Chemical Society, v. 128, n. 25, p. 8265-8271, 2006.

98. CHAUHAN, A. S.; JAIN, N. K.; DIWAN, P. V. Pre-clinical and behavioural toxicity profile of PAMAM dendrimers in mice. Proceedings of the Royal Society aMathematical Physical and Engineering Sciences, v. 466, n. 2117, p. 1535-1550, 2010 .

99. TOMALIA, D. A.; BAKER, H.; DEWALD, J.; HALL, M.; KALLOS, G.; MARTIN, S.; ROECK, J.; RYDER, J.; SMITH, P. A new class of polymers - starburst-dendritic macromolecules. Polymer Journal, v. 17, n. 1, p. 117-132, 1985.

100. MAITI, P. K.; CAGIN, T.; WANG, G. F.; GODDARD, W. A. Structure of PAMAM dendrimers: Generations 1 through 11. Macromolecules, v. 37, n. 16, p. 6236-6254, 2004.

101. TOMALIA, D. A.; FRECHET, J. M. J. Discovery of dendrimers and dendritic polymers: A brief historical perspective. Journal of Polymer Science Part a-Polymer Chemistry, v. 40, n. 16, p. 2719-2728, 2002.

102. TOMALIA, D. A.; HUANG, B.; SWANSON, D. R.; BROTHERS, H. M.; KLIMASH, J. W. Structure control within poly(amidoamine) dendrimers: size, shape and regiochemical mimicry of globular proteins. Tetrahedron, v. 59, n. 22, p. 3799-3813, 2003.

103. TOMALIA, D. A.; NAYLOR, A. M.; GODDARD, W. A. Starburst dendrimers molecular-level control of size, shape, surface-chemistry, topology, and flexibility from atoms to macroscopic matter. Angewandte Chemie-International Edition in English, v. 29 , n. 2 , p. $138-175,1990$. 
104. PETERSON, J.; ALLIKMAA, V.; SUBBI, J.; PEHK, T.; LOPP, M. Structural deviations in poly(amidoamine) dendrimers: a MALDI-TOF MS analysis. European Polymer Journal, v. 39, n. 1, p. 33-42, 2003.

105. ESFAND, R.; TOMALIA, D. A. Poly(amidoamine) (PAMAM) dendrimers: from biomimicry to drug delivery and biomedical applications. Drug Discovery Today, v. 6 , n. 8, p. 427-436, 2001.

106. SVENSON, S.; TOMALIA, D. A. Commentary - Dendrimers in biomedical applications - reflections on the field. Advanced Drug Delivery Reviews, v. 57, n. 15, p. 21062129, 2005.

107. PERRIN, D. D.; ARMAREGO, W., L.; PERRIN, D. P. Purification of laboratory chemicals. Oxford: Pergamon Press, 1983. 662 p.

108. CLARKE, M. J. Electrochemistry, synthesis, and spectra of pentaammineruthenium(III) complexes of cytidine, adenosine, and related ligands. Journal of the American Chemical Society, v. 100, n. 16, p. 5068-5075, 1978.

109. ALLEN, A. D.; BOTTOMLE.F; HARRIS, R. O.; REINSALU, V. P.; SENOFF, C. V. Ruthenium complexes containing molecular nitrogen. Journal of the American Chemical Society, v. 89, n. 22, p. 5595-5599, 1967.

110. VOGT, L. H.; KATZ, J. L.; WIBERLEY, S. E. Crystal and molecular structure of ruthenium-sulfur dioxide coordination compounds . I. Chlorotetraammine(sulfur dioxide)ruthenium(2)chloride. Inorganic Chemistry, v. 4, n. 8, p. 1157-1163, 1965.

111. BROWN, G. M.; SUTTON, J. E.; TAUBE, H. Binding of a tetraammineruthenium complex to imidazole and purine derivatives under equilibrium conditions. Journal of the American Chemical Society, v. 100, n. 9, p. 2767-2774, 1978.

112. SILVA, H. A. D.; MCGARVEY, B. R.; SANTOS, R. H. D.; BERTOTTI, M.; MORI, V.; FRANCO, D. W. Sulfate as a ligand in ruthenium(II) and (III) ammines. Canadian Journal of Chemistry-Revue Canadienne De Chimie, v. 79, n. 5, p. 679-687, 2001.

113. BORGES, S. S.; DAVANZO, C. U.; CASTELLANO, E. E.; J, Z. S.; SILVA, S. C.; FRANCO, D. W. Ruthenium Nitrosyl Complexes with N-Heterocyclic Ligands. Inorganic Chemistry, v. 37, n. 11, p. 2670-2677, 1998.

114. BODANSZKY, M. Principles of peptide synthesis Berlin, Heidelberg: SpringerVerlag, 1993. 329 p.

115. BRENER, Z. Observations on immunity to superinfections in mice experimentally inoculated with Trypanosoma cruzi and subjected to treatment. Revista do Instituto de Medicina Tropical de São Paulo, v. 4, n. . p. 119-123, 1962.

116. BORGES, S. D. S.; DAVANZO, C. U.; CASTELLANO, E. E.; Z-SCHPECTOR, J.; SILVA, S. C.; FRANCO, D. W. Ruthenium nitrosyl complexes with N-heterocyclic ligands. Inorganic Chemistry, v. 37, n. 11, p. 2670-2677, 1998. 
117. GOMES, M. G.; DAVANZO, C. U.; SILVA, S. C.; LOPES, L. G. F.; SANTOS, P. S.; FRANCO, D. W. Cis- and trans-nitrosyltetraammineruthenium(II). Spectral and electrochemical properties and reactivity. Journal of the Chemical Society-Dalton Transactions, v. n. 4, p. 601-607, 1998.

118. FRECHET, J. M. J. Functional polymers and dendrimers - reactivity, molecular architecture, and interfacial energy. Science, v. 263, n. 5154, p. 1710-1715, 1994.

119. ACHAR, S.; IMMOOS, C. E.; HILL, M. G.; CATALANO, V. J. Synthesis, characterization, and electrochemistry of heterometallic dendrimers. Inorganic Chemistry, v. 36, n. 11, p. 2314-2320, 1997.

120. STORRIER, G. D.; TAKADA, K.; ABRUNA, H. D. Synthesis, characterization, electrochemistry, and EQCM studies of polyamidoamine dendrimers surfacefunctionalized with polypyridyl metal complexes. Langmuir, v. 15, n. 3, p. 872-884, 1999.

121. TAKADA, K.; STORRIER, G. D.; GOLDSMITH, J. I.; ABRUNA, H. D. Electrochemical and adsorption properties of PAMAM dendrimers surfacefunctionalized with polypyridyl cobalt complexes. Journal of Physical Chemistry B, v. 105, n. 12, p. 2404-2411, 2001.

122. LANGE, P.; SCHIER, A.; SCHMIDBAUR, H. Dendrimer-based multinuclear gold(I) complexes. Inorganic Chemistry, v. 35, n. 3, p. 637-642, 1996.

123. DAVIS, A. P.; MA, G.; ALLEN, H. C. Surface vibrational sum frequency and Raman studies of PAMAM G0, G1 and acylated PAMAM G0 dendrimers. Analytica Chimica Acta, v. 496, n. 1-2, p. 117-131, 2003.

124. TORSONI, A. S.; DE BARROS, B. F.; TOLEDO, J. C.; HAUN, M.; KRIEGER, M. H.; TFOUNI, E.; FRANCO, D. W. Hypotensive properties and acute toxicity of trans$\left[\mathrm{Ru}\left(\mathrm{NH}_{3}\right)_{4} \mathrm{P}(\mathrm{OEt})_{3} \mathrm{NO}\right]\left(\mathrm{PF}_{6}\right)_{3}$, a new nitric oxide donor. Nitric Oxide-Biology and Chemistry, v. 6, n. 3, p. 247-254, 2002.

125. JEVPRASESPHANT, R.; PENNY, J.; JALAL, R.; ATTWOOD, D.; MCKEOWN, N. B.; D'EMANUELE, A. The influence of surface modification on the cytotoxicity of PAMAM dendrimers. International Journal of Pharmaceutics, v. 252, n. 1-2, p. 263 266, 2003.

126. EL-SAYED, M.; GINSKI, M.; RHODES, C.; GHANDEHARI, H. Transepithelial transport of poly(amidoamine) dendrimers across Caco-2 cell monolayers. Journal of Controlled Release, v. 81, n. 3, p. 355-365, 2002.

127. DUNCAN, R.; IZZO, L. Dendrimer biocompatibility and toxicity. Advanced Drug Delivery Reviews, v. 57, n. 15, p. 2215-2237, 2005. 